Portland State University

PDXScholar

Fall 12-8-2017

\title{
Structural Behavior of Lap Shear Connections with Thermally Insulating Filler Plates
}

Salih Qasim Mahmood

Portland State University

Follow this and additional works at: https://pdxscholar.library.pdx.edu/open_access_etds

Part of the Civil and Environmental Engineering Commons Let us know how access to this document benefits you.

\section{Recommended Citation}

Mahmood, Salih Qasim, "Structural Behavior of Lap Shear Connections with Thermally Insulating Filler Plates" (2017). Dissertations and Theses. Paper 4159.

https://doi.org/10.15760/etd.6047

This Thesis is brought to you for free and open access. It has been accepted for inclusion in Dissertations and Theses by an authorized administrator of PDXScholar. Please contact us if we can make this document more accessible: pdxscholar@pdx.edu. 
Behavior of Lap Shear Connections with Thermally Insulating Filler Plates

by

Salih Qasim Mahmood

A thesis submitted in partial fulfillment of the requirements for the degree of

Master of Science

in

Civil and Environmental Engineering

Thesis Committee:

Thomas Schumacher, Chair

Peter Dusicka

Hormoz Zarah

Portland State University

2017 
(C) 2017 Salih Qasim Mahmood 


\begin{abstract}
This research consists of experimental load tests and numerical simulations of structural steel connections with various filler materials to study the effect of non-steel fillers on the connection strength. Non-steel fillers are used in the steel connections to provide thermal insulation by reducing thermal bridging. Eight specimens having steel and polypropylene filler plates of various thicknesses were tested in the laboratory. The collected data were compared to a Finite Element Analysis (FEA) using ABAQUS to validate the numerical results. After validation, three parametric studies were conducted using ABAQUS to provide insight into general behavior of connections with a variety of fillers that could be used as thermal breaks. In addition, an extreme case of having air gaps instead of alternative fillers was also considered.
\end{abstract}

The Research Council on Structural Connections (RCSC 2014) suggests a reduction in the bolt shear strength when undeveloped fillers with a thickness of more than 0.25 inch are used while using any non-steel material is prohibited due the limited research available.

Most research studies have investigated the mechanical behavior of thermal breaks in either end-plate moment connections or slip-critical connections. No data is available for thermal breaks in bearing-type connections up to failure.

This research aims to study the effects of filler material properties such as modulus of elasticity and strength on bolt strength, as well as investigate whether the current equation in RCSC 2014 is applicable for alternative filler materials like polypropylene that has less than $0.5 \%$ of the steel modulus of elasticity and less than $10 \%$ of steel strength. 


\section{Acknowledgment}

This work would not have the spirit it has without the guidance and support provided by my academic advisor Dr. Thomas Schumacher. First and foremost, I would like to show my sincere gratitude to Dr. Schumacher for his expert advice, immense knowledge, encouragement, motivation and for funding the experimental test. Throughout the rough road to finish this thesis, Dr. Schumacher's support was not limited to the academic assistantship only, but also emotionally.

I would like to extend my gratitude to my thesis committee member Dr. Peter Dusicka for his ideas and feedback. I would also like to thank committee member Dr. Hormoz Zareh for his invaluable advice. The knowledge I gained from his classes along with his advice were of great help in numerous aspects of this research.

I would like to thank the Higher Committee of Education Development in Iraq (HCED) for giving me this scholarship and the opportunity to pursue my Master's degree. I would also like to thank Portland State University for their financial support.

I would like to further thank my friends and colleagues: Leah Goeres, Mohamed Saud, Ali Hafiz, Anas Yosefani, Mohammed Al-Saedi, Hayder Al-Khafaji, Wisam Abdulkader, Hosam Al Azzawi, Yasir Saeed, Jim Morud and Kevin Cady for their help and support through various stages of this research.

Lastly, special thanks to my family for their continuous love, encouragement, and support throughout my life and studies. Their enthusiasm and belief in me is the greatest gift anyone has ever given me. 


\section{Contents}

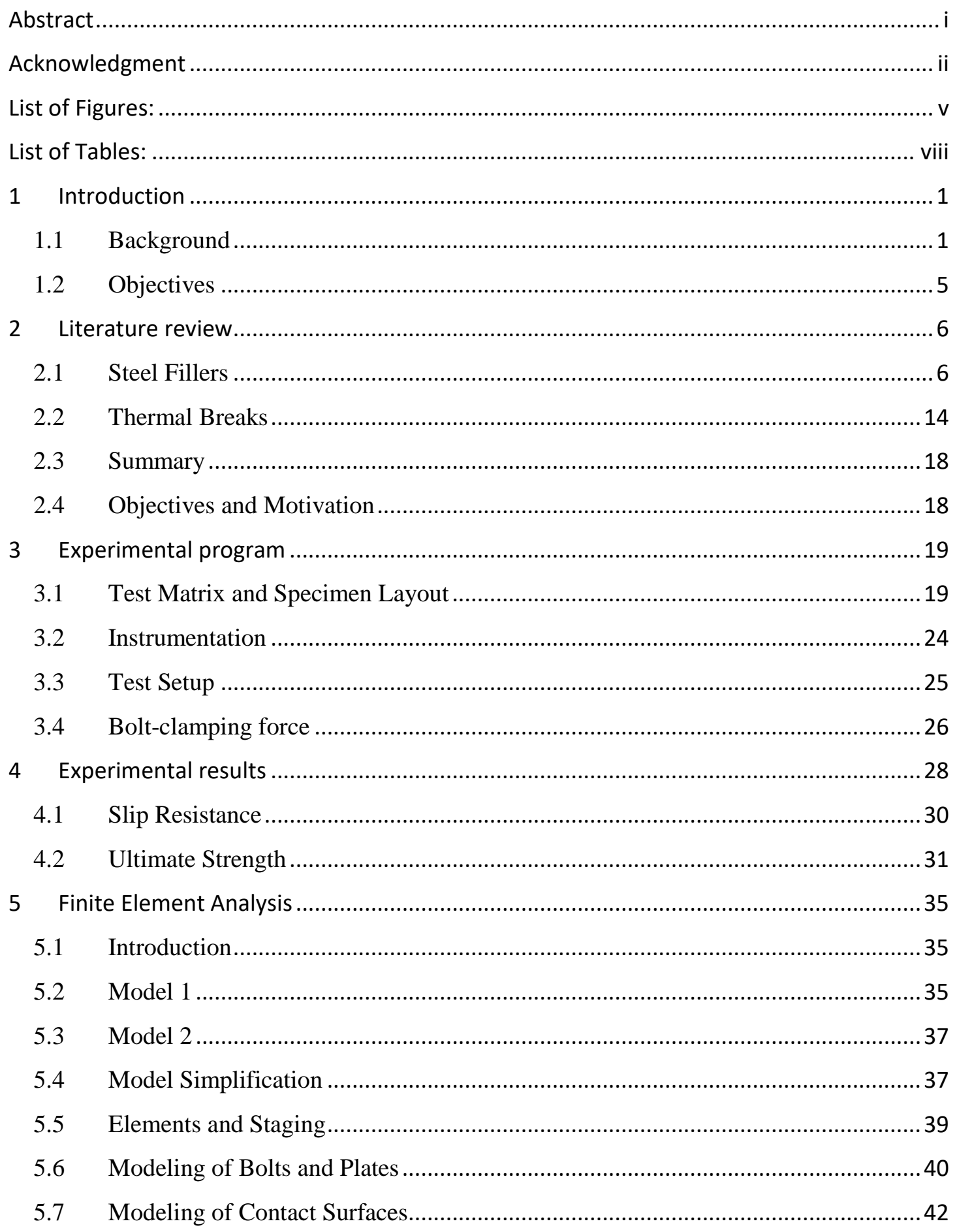




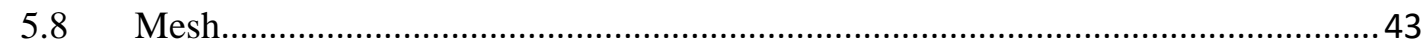

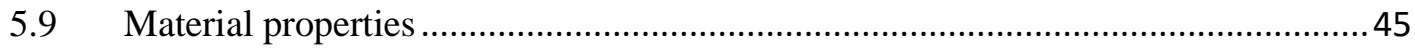

5.10 Load and Boundary Conditions ….................................................................. 49

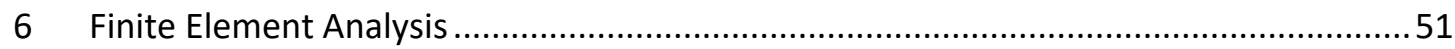

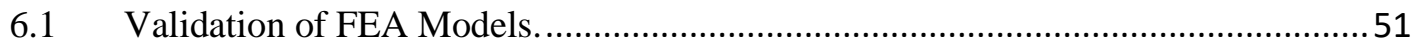

6.2 Validation of FEA Models for Steel Filler Plates ..................................................61

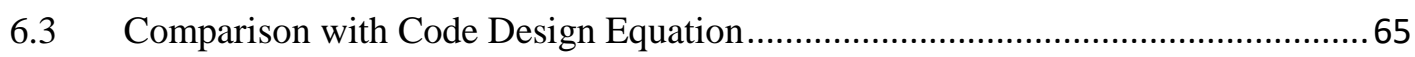

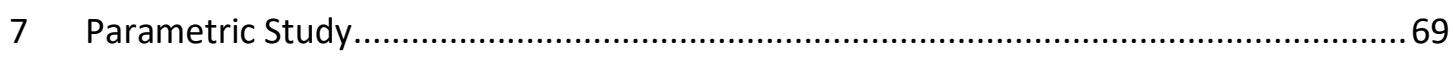

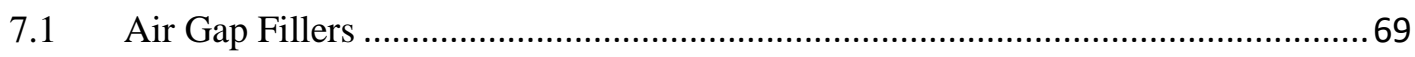

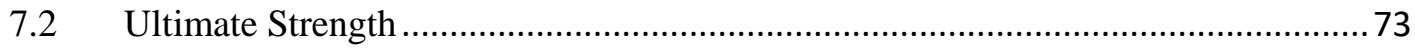

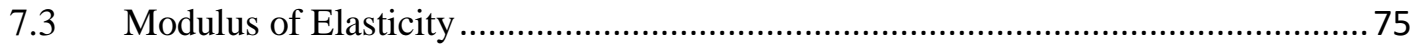

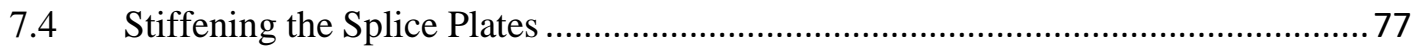

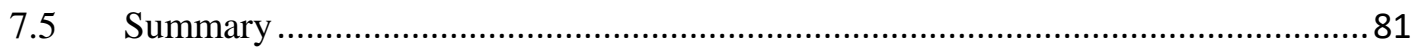

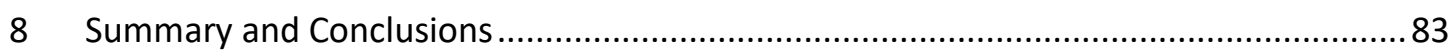

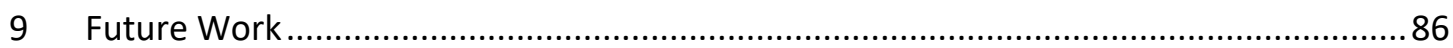

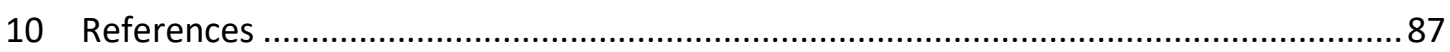

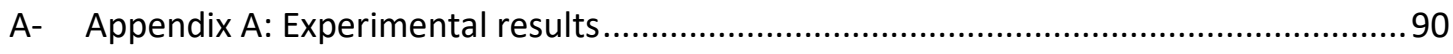

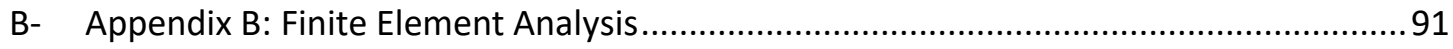




\section{List of Figures:}

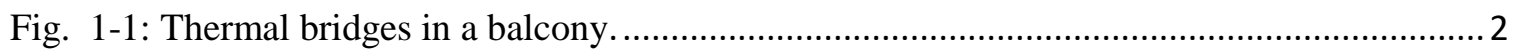

Fig. 1-2: Sketch showing a thermal break in the steel connection of a balcony. ............................ 3

Fig. 1-3: HSS - wide-flange beam connection. .................................................................. 4

Fig. 1-4: Hypothetical case of a steel connection with gaps. .................................................. 5

Fig. 2-1: Assembly layout used in Dusicka and Lewis (2010). .................................................. 9

Fig. 2-2: Load vs. deformation for different filler cases. From Dusicka and Lewis (2010).......... 9

Fig. 2-3: Ultimate load vs. fillers thickness. From Dusicka and Lewis (2010). .........................11

Fig. 2-4: Normalized load vs. filler thickness compared to the design equation in RCSC (2001).

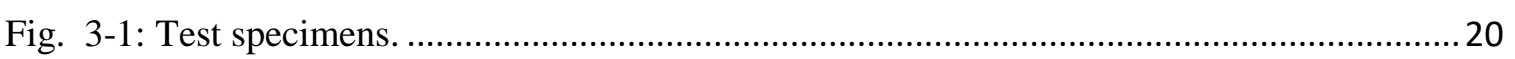

Fig. 3-2: Sketch showing the tested steel connection specimen with fillers...............................22

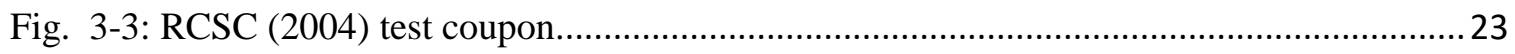

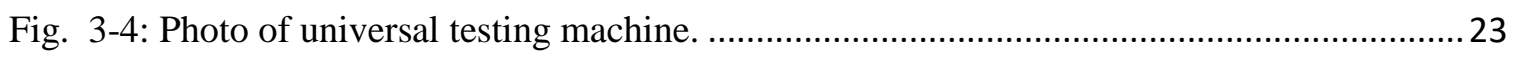

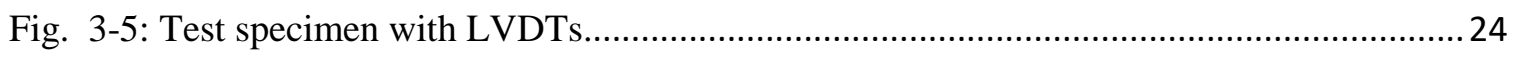

Fig. 3-6: Photo showing specimens with strain gauge locations. ............................................ 25

Fig. 3-7: Bolt clamping force test for a sandwich of Fig. 3-8: Direct tension indicators.

Fig. 3-9: Orange indicator appearing around the DTI washers when load reached 38 kips. ........27

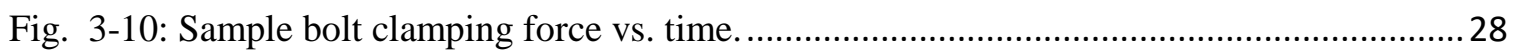

Fig. 4-1: Load vs. deformation curves for four select specimens from each test group. ..............29

Fig. 4-2: Bolts after testing connections to failure ................................................................ 29

Fig. 4-3: Ultimate load vs. filler thickness (all tests).............................................................. 31

Fig. 4-4: Normalized load at 0.25 inch deformation compared to the design equation (dashed

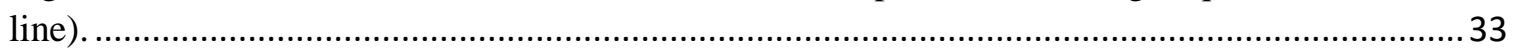

Fig. 4-5: Normalized ultimate load compared to the design equation (dashed line). ...................34

Fig. 4-6: Normalized load compared to Dusicka and Lewis' (2010) Eq. .................................... 34

Fig. 5-1: Example of one-bolt portion of steel connection with 1-inch PP fillers .........................36

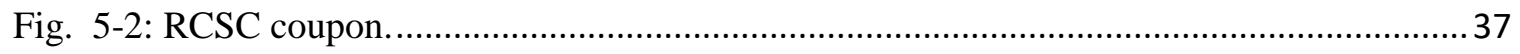

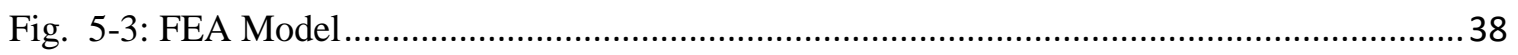

Fig. 5-4: C3D8R element used for all FEA. ……................................................................... 39

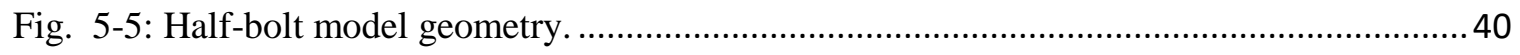

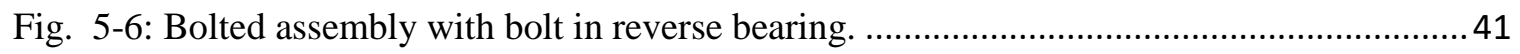

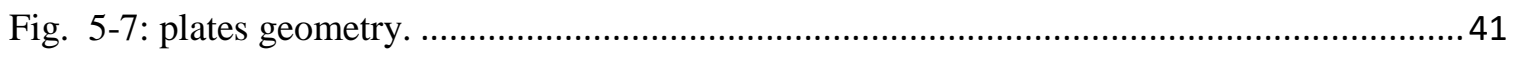

Fig. 5-8: Convergence study for a connection with no fillers................................................. 44

Fig. 5-9: Engineering stress-strain diagrams for used materials. ............................................... 46

Fig. 5-10: Mass sensitivity study for a bolted connection with no fillers. .................................. 49

Fig. 5-11: Boundary conditions of a bolted connection with $1 / 2$ steel filler plates. ........................50

Fig. 6-1: FEA and experimental results for load-deformation curves for no-filler specimen.......52

Fig. 6-2: FEA and experimental results for load-deformation curves for $1 / 2$ " steel filler plate

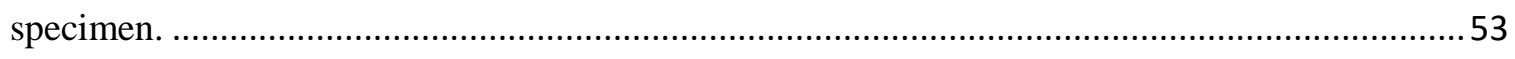


Fig. 6-3: FEA and experimental results for load-deformation curves for $1 \frac{1}{2}$ PP filler plate specimen.

Fig. 6-4: FEA and experimental results for load-deformation curves for 1" PP filler plate specimen.

Fig. 6-5: Comparison of ultimate connections strength for all test specimens. Both experimental and FEA results are shown for comparison. 55

Fig. 6-6: Comparison of force in connection at 0.25 inch deformation for all test specimens. Both experimental and FEA results are shown for comparison. .56 Fig. 6-7: Example of (a) test specimen and (b) corresponding FEA model at ultimate connection strength

Fig. 6-8: Example of (a) bolt and (b) corresponding FEA model at ultimate connection strength.

Fig. 6-9: Example of connection with $1 / 2$-inch steel fillers shows:

Fig. 6-10: Example of connections with $1 / 2$-inch fillers shows the deformation in the bolt hole of:

(a) PP fillers (b) Steel fillers. .60

Fig. 6-11:Catenary mechanism: (a) PP fillers (b) Steel fillers.................................................60

Fig. 6-12: load vs deformation for four assemblies with different filler thicknesses....................62

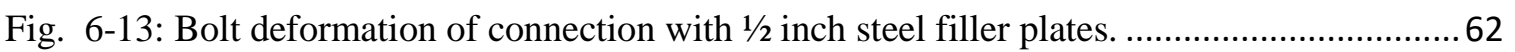

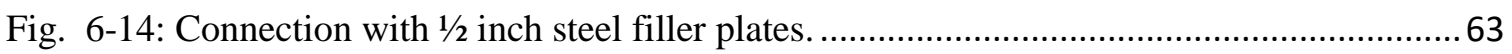

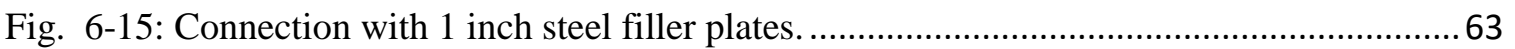

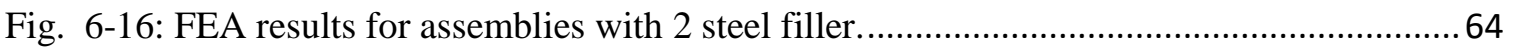

Fig. 6-17: Normalized ultimate strength and design equation (RCSC 2014), ..............................65

Fig. 6-18: Normalized ultimate strength and Dusicka and Lewis (2010) reduction equation......66

Fig. 6-19: Normalized ultimate strength at 0.25 in deformation and Frank and Yura's (1981) reduction equation. .66

Fig. 7-1: Ultimate strength vs. filler thickness for air gaps compared to steel and PP filler plates.

Fig. 7-2: Load at 0.25 in. deformation vs. filler thickness for air gaps compared to steel and PP filler plates.

Fig. 7-3: FEA models (deformed) of three types of connections when ultimate strength is reached. Colors in the bolts show the shear stress................................................................. 72

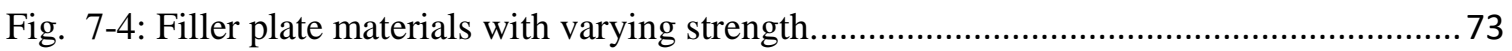

Fig. 7-5: FEA predicted ultimate strength vs. filler plate thickness for varying filler plate strengths.

Fig. 7-6: FEA predicted load at 0.25 inch deformation vs. filler plate thickness for varying filler

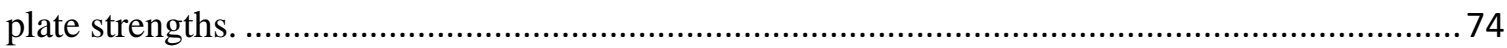

Fig. 7-7: ) Filler plate materials with varying modulus of elasticity......................................... 75

Fig. 7-8: FEA predicted ultimate strength vs. filler plate thickness for varying filler plate moduli of elasticity. 76

Fig. 7-9: FEA predicted load at 0.25 inch deformation vs. filler plate thickness for varying filler

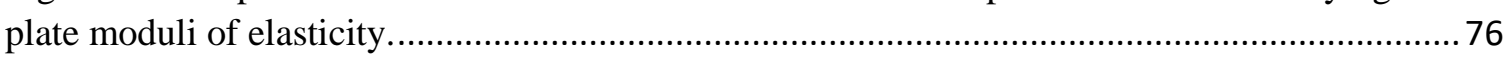

Fig. 7-10: three bolt connection with filler shows two different bolt groups...............................77

Fig. 7-11: Example of an FEA model with restraint of the splice plate along z-axis. ..................78 
Fig. 7-12 Example of (a) connection with stiffened splice plates and (b) connection with unstiffened splice plates for 1 inch PP filler.

Fig. 7-13: Load at 0.25 inch deformation vs. filler thickness for connections with PP fillers with and without stiffening.

Fig. 7-14: Ultimate load vs. filler thickness for connections with PP fillers with and without stiffening. .80

Fig. 7-15: FEA predicted ultimate strength vs. filler plate thickness compared with the code equation. .81

Fig. 7-16: FEA predicted ultimate strength vs. filler plate thickness compared with the Dusicka and Lewis (2010) equation.

Fig. 7-17: FEA predicted load at 0.25 inch deformation vs. filler plate thickness compared with the Frank and Yura's (1981) equation.

Fig. 7-18: Summary for the connections deformation with different filler thickness and material.

Fig. A-1: Experimental results of load vs. deformation for steel connection with different material. .90

Fig. B-1: FEA results of load vs. deformation for connection with steel fillers. ..........................91

Fig. B-2: FEA results of load vs. deformation for connection with Polypropylene fillers..........91

Fig. B-3: FEA results of load vs. deformation for connection with Air Gap.............................92

Fig. B-4: FEA results of load vs. deformation for connection with fillers that have $50 \%$ of steel

Strength

Fig. B-5: FEA results of load vs. deformation for connection with fillers that have $25 \%$ of steel Strength.

Fig. B-6: FEA results of load vs. deformation for connection with fillers that have $50 \%$ of steel modulus of elasticity

Fig. B-7: FEA results of load vs. deformation for connection with fillers that have $25 \%$ of steel modulus of elasticity .94

Fig. B-8: 1/2 inch PP fillers vs. connection with Stiffened splice plate.....................................94

Fig. B-9: 1 inch PP filler vs. connection with Stiffened splice plate. .........................................95

Fig. B-10: 2 inch PP vs. connection with Stiffened splice plate...............................................95 


\section{List of Tables:}

Table 2-1: Properties of thermal materials used by Cleary (2016)....................................... 16

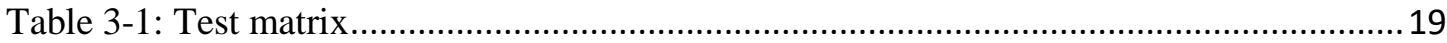

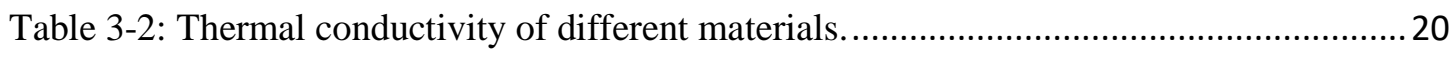

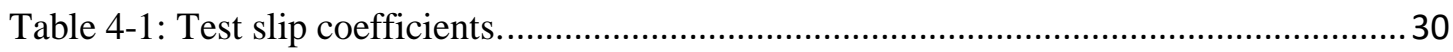

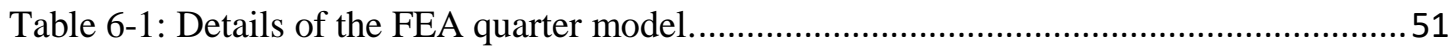

Table 6-2: Details of the FEA models used for model validation.............................................61

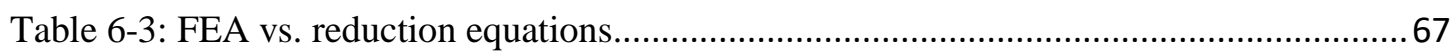




\section{Introduction}

\subsection{Background}

Global warming is one of the biggest issues threatening our planet. It is the result of an increasing percentage of greenhouse gases (GHG) in the atmosphere, which have the ability to absorb radiation, especially carbon dioxide. Since 1750 , the beginning of the first industrial revolution, humans have participated in increasing the percentage of carbon dioxide up to $40 \%$ according to the Earth Research System Laboratory. A study by Mora, C. (2013), shows that the earth's temperature will hit new historical records, if the rate of GHG emissions stays constant. One major contributor to global warming comes from the energy spent to compensate for heat loss, which elevates the percentage of GHG (greenhouse gases) in the atmosphere.

Heat loss is a common problem in most buildings. In addition to the environmental effects, it has economic effects. Reducing heat loss in buildings could be economically advantageous in the long run.

Heat loss can take place in buildings in many ways, through structural and nonstructural elements. One of the major contributors in buildings' heat loss is thermal bridging.

A study by Valério (2007), demonstrated that about $20 \%$ of the heat lost is caused by thermal bridging. Therefore, there are many projects in this field to mitigate the effect of thermal bridges. The term thermal bridge refers to a structure's element that has a 
higher heat transfer than any other elements or regions in the building, thereby reducing the efficiency of the thermal insulation of the building. Thermal Bridges occur in buildings in three forms: a gap or discontinuity in the building insulation envelope, a material that has higher thermal conductivity than the surrounding materials, and penetrations in the thermal envelope by thermally conductive elements as shown in Fig. 1-1. The last one is the focus of this study. In addition to heat loss caused by thermal bridges, condensation may occur when the inside of the building is colder than the outside leading to detrimental effects such as mold and corrosion of steel structural members.

To reduce thermal bridging, special thermal breaks are used to reduce heat transfer in those locations as shown in Fig. 1-2. Usually, thermal breaks have less strength and different behavior than structural steel, making them not compatible.

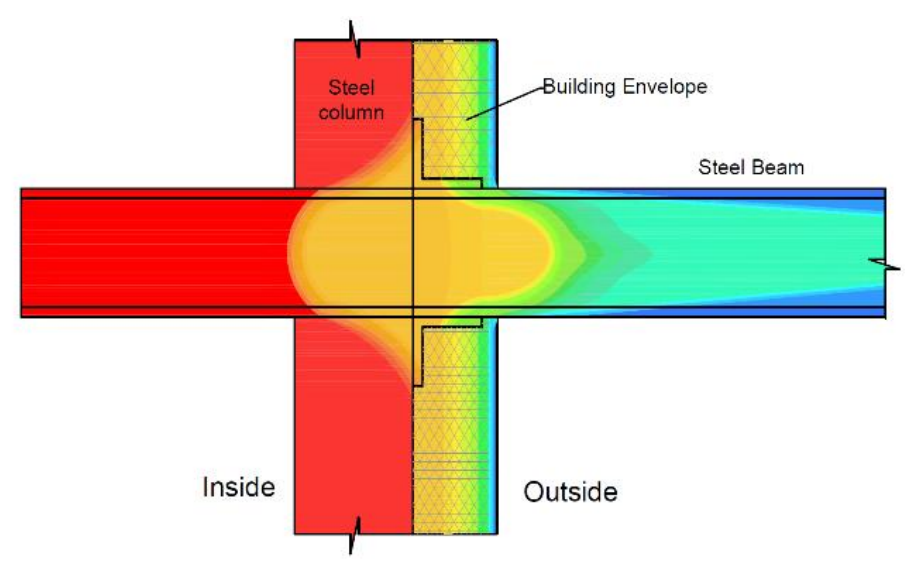

Fig. 1-1: Thermal bridges in a balcony. 


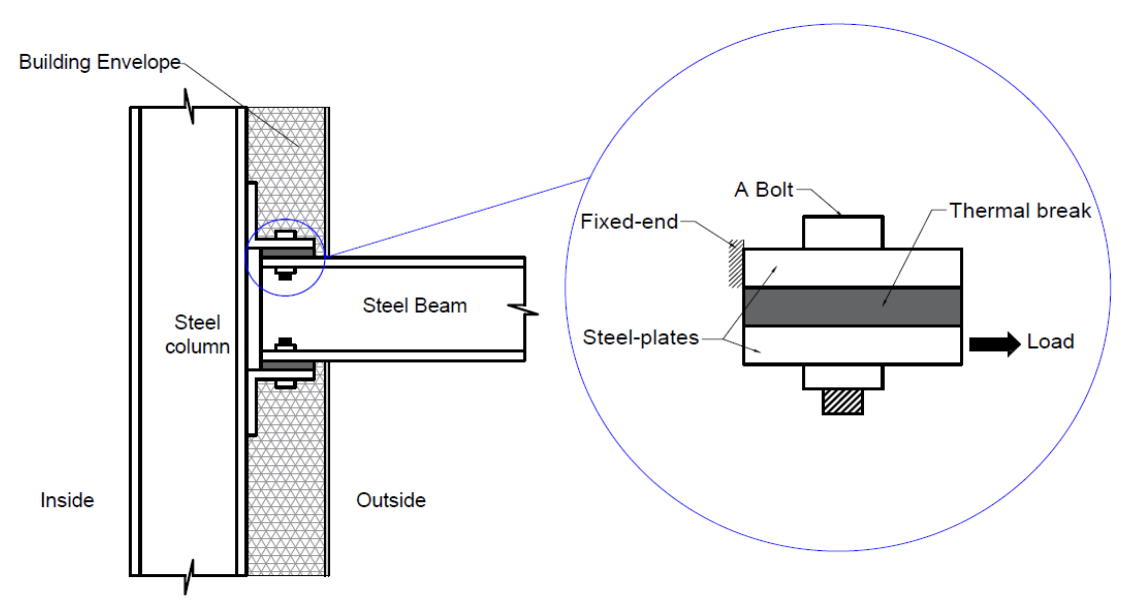

Fig. 1-2: Sketch showing a thermal break in the steel connection of a balcony.

The Research Council on Structural Connections (RCSC 2014) prohibits using compressible materials like gaskets within the grip of the bolt in structural steel connections. Therefore, more studies are required to fully understand the behavior of steel connections with thermal breaks and develop an analytical method that can take into account the effects of the thermal layer on steel connection strength. Currently, many companies such as Fabrica and Farrat are already producing structural thermal breaks but most of them are being used in the end plate connections as illustrated in Fig. 1-3. 


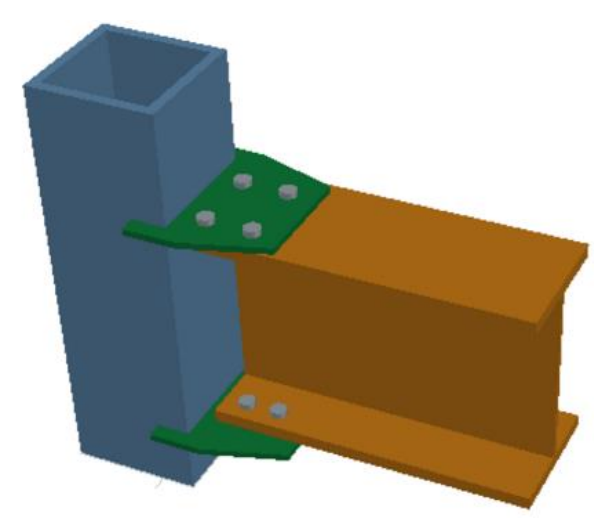

Fig. 1-3: HSS - wide-flange beam connection.

This research aims to study the mechanical behavior of steel and thermal fillers in steel moment connections where beams are being spliced. Using these kinds of connections gives more flexibility in the design and application of thermal breaks. An FEA model was created to simulate Dusicka's experimental work (Dusicka, 2010) of single-bolt high strength steel connections with undeveloped fillers. After verification, fillers of different thicknesses of polypropylene were used as thermal breaks. In addition, a hypothetical case of using air fillers or gaps between the bolted plates was further considered to simulate the worst-case scenario when the bolted plates are separated by a material with no stiffness (Fig. 1-4). This aims to outline the extreme boundaries of the behavior for this type of connection.

Generally, using undeveloped steel fillers in steel connections reduces the ultimate strength of a connection and increases the deformation at failure because fillers are relatively free to move giving the bolts more flexibility to deform, therefore, both codes 
AISC 2011 and European codes (CEN 2005) require reduction in the shear strength of bolts when steel fillers are used.

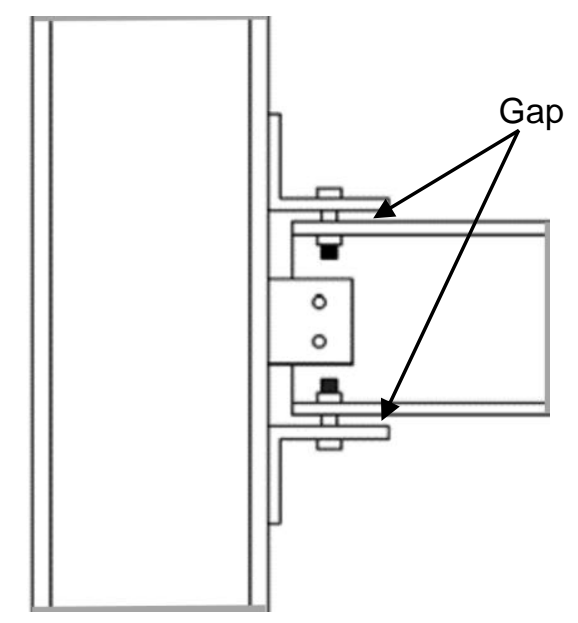

Fig. 1-4: Hypothetical case of a steel connection with gaps.

\subsection{Objectives}

This research consists of two major parts: experimental testing and finite element (FE) modeling. After validating the numerical model with the experimental test data, a parametric study was conducted on different types of fillers. Three parametric studies were conducted to study the behavior of the connection when the steel fillers are replaced by a gap and hypothetical materials. Using hypothetical materials was an attempt to study the effect of the modulus of elasticity and the material strength of the fillers on connection behavior and connection strength. 


\section{Literature review}

\subsection{Steel Fillers}

Fisher and Lee (1968), studied the effects of fillers on slip strength by using circular and rectangular washers and plates. Using washers was also an attempt to simulate the effect of out-of-flatness that might occur in the flat plates due to various reasons such as shearing, punching or welding during installation or fabrication. The main purpose of this study was to determine whether full contact is required over the entire faying surface. A series of thirty-six bolted connections were tested with circular and rectangular washers with fifteen joints that had clean mill scales on all their surfaces. All joints were fabricated from 1-inch A36 steel plate connected by 7/8-A325 bolts. For the case of clean mill scale, slip strength was found to drop by $12 \%$ to $32 \%$, when washers were used. For blast clean joints, the insertion of $3 \frac{1}{1} 2$-inch diameter washers between the faying surfaces of the blast cleaned joints and reduced the slip resistance from $56 \%$ to $72 \%$. Rectangular fillers had less of an effect, reducing the slip strength by $20 \%$.

Fank and Yura (1981) conducted two replicate tests of five different specimen assemblages to study the effects of undeveloped fillers of varying thicknesses and number of plies. Filler thicknesses ranged from 0 to 0.75 inch with single and multi-ply fillers. Undeveloped fillers have less strength than splice plates and pull plates. The bolted connection consisted of two 2-inch thick A514 pull plates and two 2-inch thick A514 splice plates. Both splice and pull plates were designed to induce failure in the bolt. 
The undeveloped fillers consisted of A36 steel with thicknesses of 0 in., 0.075 in., 0.25 inch, and 0.75 inch single-ply and three 0.25 inch to achieve 0.75 inch multi-ply filler. The bolts were A325 of 7/8 inch diameter with a standard hole of 15/16 inch. The upper part of the connection contained fully developed fillers by one bolt while the lower part of the connection contained the undeveloped fillers. The surface conditions were different for each plate. Full plates, splice plates, and 0.25-inch fillers had clean mill-scale finish. The 0.075 -inch fillers had a rust coating removed by wire brushing. The single-ply $0.75-$ inch filler had been sandblasted about eight months prior to testing with no observable surface corrosion. The bolt clamping force was achieved using the turn-of-nut method to one half turn past snug tight. It was found that the slip coefficient dropped by $16.7 \%$ when using 0.25 inch undeveloped fillers, which is consistent with Fish and Lee's findings. It was found that the use of multi-ply fillers had a greater detrimental effect on strength over single-ply fillers; the multi-ply fillers express less resistance to the bending of the bolt because they can move relative to each other. Moreover, it was observed that the ultimate load decreased with increasing thickness of the undeveloped fillers. The researchers suggested a reduction factor for connections with undeveloped fillers represented by the following equation:

$$
\mathrm{Rb}=1-0.4 \mathrm{t} \quad \text { Where } \mathrm{t}=\text { fillers thickness...... (Eq. } 2-1)
$$

Undeveloped fillers create an efficient separation in the loading pattern. This separation provides more space for the bolt to move and bend. Herein, any further increase in the filler thickness means increasing the load separation in which greater bending would occur. It was found that there is no significant difference in the ultimate load between $1 \mathrm{x}$ 
0.75-inch and $3 \times 0.25$ inch thickness because of the local bearing deformation that occurred in the solid plate of 0.75 -inch thickness. The difference might be greater if higher strength steel had been used, as it would decrease the bearing deformation.

Dusicka and Lewis (2010) studied the behavior of steel connections with fillers using high strength steel with standard holes and oversized holes of one-bolt and three-bolt assemblies. In an effort to consider different variables such as lower grade fillers, their study focused on strength issues and comprised only two repeated tests per configuration in order to achieve reliability. Most of the specimens had clean blast surfaces (SP-10 or NACE 2) and few fillers had clean mill scale. High strength steel A709HPS70W along with high strength bolts A490 were used, which was the focus of the research. Generally, assemblies consisted of two pull plates and two splice plates with single and multi-ply fillers in between. Pull plates and splice plates were HPS A709 Grade 70 of thickness 1.75 inch and 1.125 inch, respectively Fillers were A572 Grade 50 of 1/2-inch, 1-inch and 2-inch thicknesses for single plate fillers, while 0.25 -inch plates were used in the multiply fillers to achieve the required thickness. Plates were connected by $7 / 8$ inch diameter A490 bolts of various lengths and were placed in a reverse bearing to achieve larger movement. Bolt threads were excluded from the bearing area of the connection to account for the failure in the solid part of the bolt shank (Fig. 2-1) 


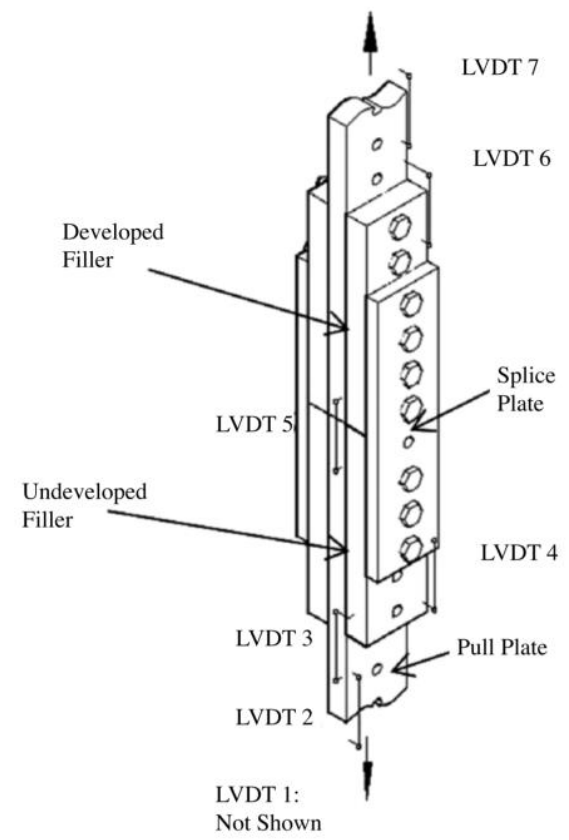

Fig. 2-1: Assembly layout used in Dusicka and Lewis (2010).
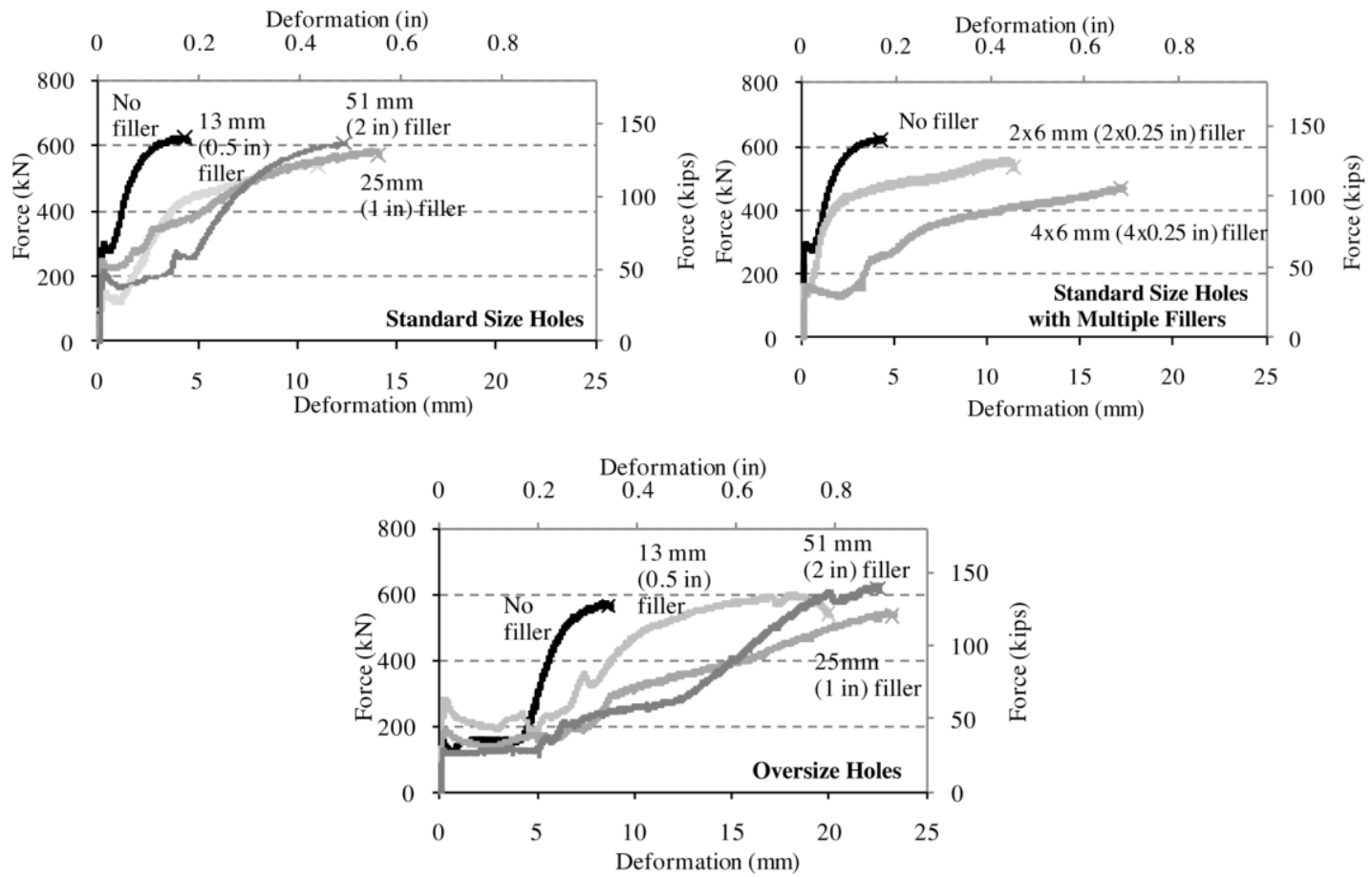

Fig. 2-2: Load vs. deformation for different filler cases. From Dusicka and Lewis (2010). 
The results expressed similar trends for one-bolt and three-bolt assemblies, but when comparing strength per bolt, the strength from one-bolt assembly is higher than that for the three-bolt assembly. Generally, the existence of fillers between pull plates and splice plates reduced the ultimate strength of the connection. The ultimate strength decreased with increasing filler thickness up to 1-inch, after which the shear strength recovered and expressed similar strength as when no fillers are used. Shear strength reduced by $5.5 \%$ and $6 \%$ for $1 / 2$-inch and 1 -inch fillers respectively (Fig. 2-3). The reason for the observed reduction in the connection strength for fillers up to 1-inch thickness is due to the increment of the deformation within the constraints of the holes. For 2-inch thick fillers, the flexural deformation decreased and the connection behavior was similar to the case without fillers. The detrimental effect was obvious for multi-ply fillers due to the minimum bolt restraints resulting from the-relative movement of the plies. 

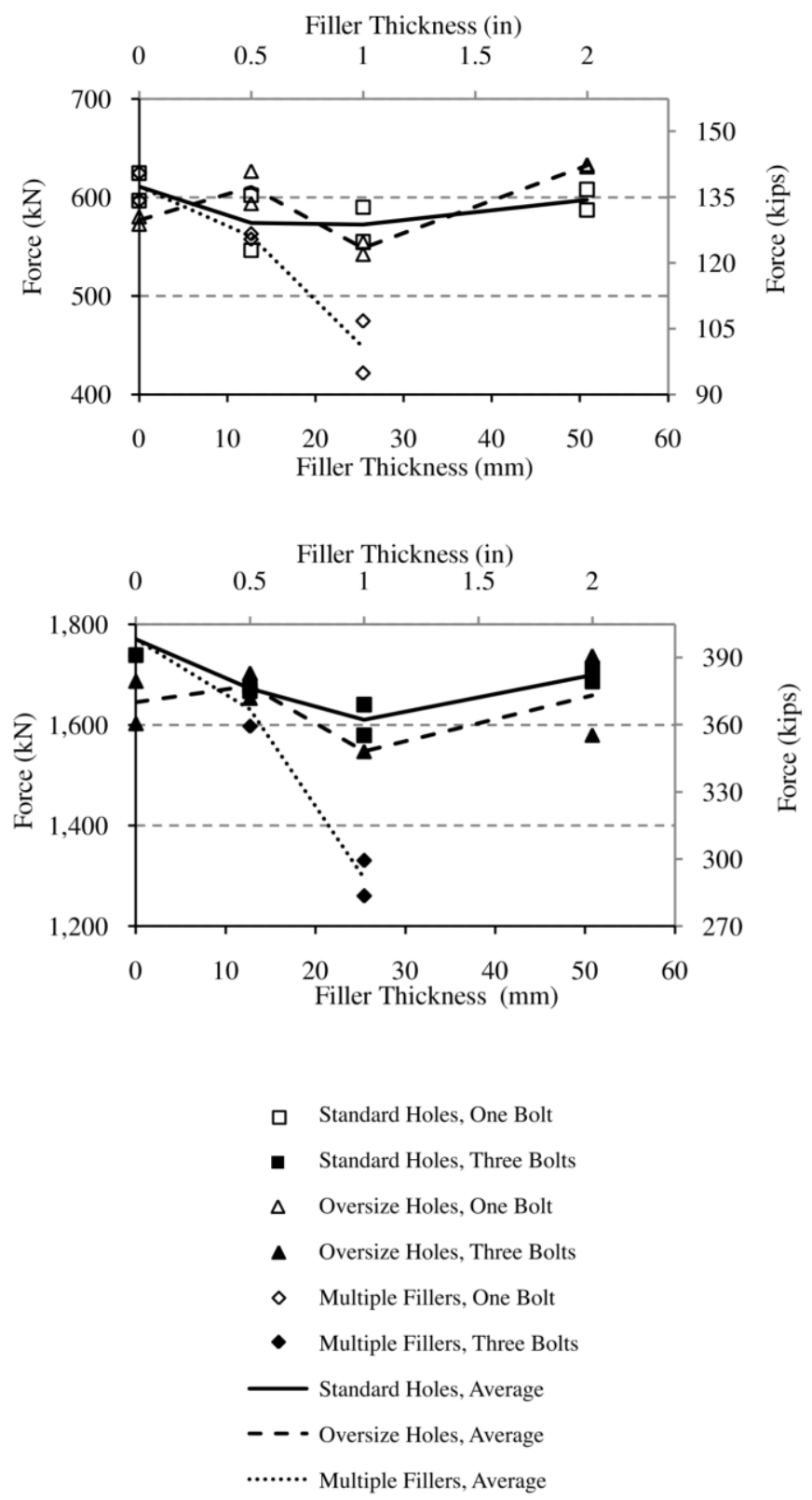

Fig. 2-3: Ultimate load vs. fillers thickness. From Dusicka and Lewis (2010).

In their research, Dusicka and Lewis compared the resistant load obtained at $1 / 4$ inch to those obtained from the design equation (RCSC, 2004). It was found that results correlated to the design equation up to 1-inch thick fillers; after that, the strength 
continued to decrease in a non-linear fashion (Fig. 2-4). This shows that the design equation is conservative for 2 -inch thick fillers and that is the reason the reduction factor is limited to 0.85 in the new design equation (RCSC, 2014).

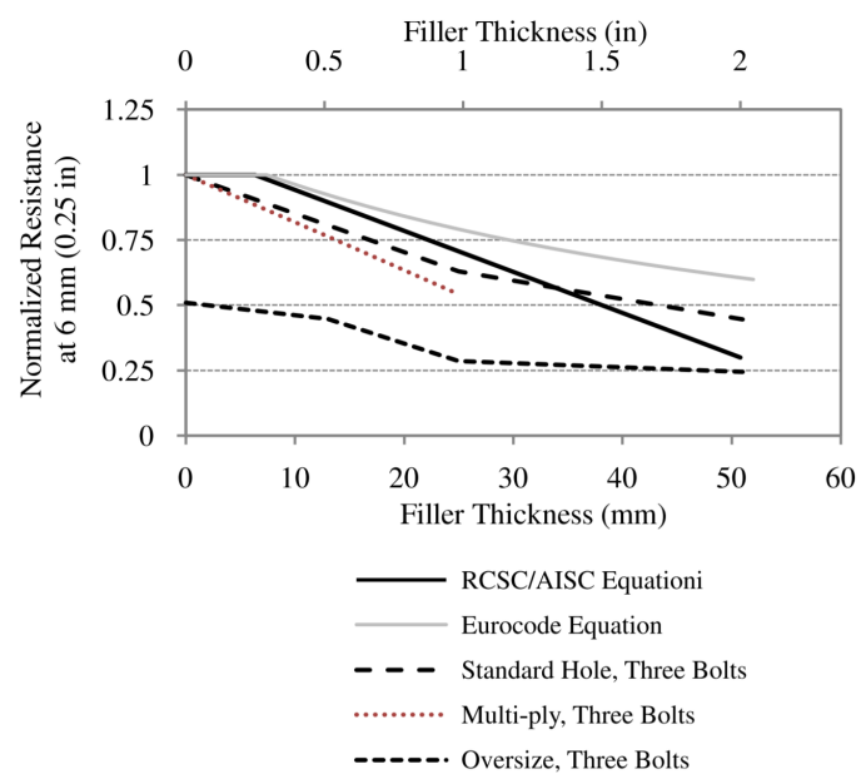

Fig. 2-4: Normalized load vs. filler thickness compared to the design equation in RCSC (2001).

Borello, et al. (2009) conducted sixteen experiments on slip-critical connections to study the behavior of oversized holes with fillers, the effect of thick fillers on slip and shear strength, and the effect of developing the filler plates. Fifteen specimens had oversized holes and one had standard sized holes for comparison. Three types of fillers were considered: undeveloped, partially developed and fully developed, with both single-ply and two-ply fillers. Unlike prior testing in the literature, the researcher tested the 
specimens in compression instead of tension. The specimens consisted of two wide flange columns connected by 2-inch thick splice plates. The bottom column for all specimens was a W14x730 section, while the top columns were W14x159, W14x455 and W14x730 sections, which required filler plates of 3 3/4-inch, $15 / 8$-inch, and 0 -inch thickness, respectively. All surfaces were Class B surfaces that meet the requirements of SSPC SP6. The bolts used in this study were A490X with diameters of 1 1/8 inch pretensioned either by the turn-of-nut or by tension-controlled bolts. During testing, it was observed that the behavior of the connection was linear before the slip. Similarly, to what was found in previous studies, increasing the number of plies resulted in reduced slip strength. However, it was found that developing the fillers can mitigate their detrimental effects significantly, depending on the added number of bolts. Additionally, extending the connection to accommodate all bolts required for the development can lessen the detrimental effects of additional slip surfaces depending on the required number of bolts. The counteracting mechanism of bolt bending and jamming within the bolt hole was also investigated. It was found that the shear strength decreased with increasing filler thickness. Multi-ply fillers had a detrimental effect in that they delayed the jamming of the bolt. The detrimental effect on shear strength can be mitigated significantly by extending the connection to accommodate the bolts used to develop the plate. 


\subsection{Thermal Breaks}

Most thermal breaks have low stiffness and strength compared to steel. Because of that, the behavior of the connection is different and a reduction in the connection strength is thus to be expected. Most research on connections with thermal breaks have considered the case of end plate moment connections. Thermal breaks used were mainly constructed from PVC and neoprene that have extremely low thermal conductivity $(0.025-0.05$ $\mathrm{W} / \mathrm{m} * \mathrm{~K})$.

A study by Sulcova, et al. (2010) investigated the compression strength of thermal break used in end plate moment connections. In their study, they tested Erthacetal H, a technical plastic that has thermal insulation characteristics in compression and used the resulting data for Erthacetal $\mathrm{H}$ in the design equation according to the Eurocode [EN 1993-1-8:2005] to predict the behavior of the connection under moment and shear loading. The end plate thicknesses were 12 and $20 \mathrm{~mm}$ ( 0.47 and $0.79 \mathrm{inch})$, while the Erthacetal $\mathrm{H}$ thermal insulation thicknesses were 8, 16, and $25 \mathrm{~mm}(0.32,0.63$, and 0.98 inch). It was found that when the thickness of the thermal breaks increases, there is a decrease in connection stiffness.

Nasdala, et al. (2006), conducted a Finite Element Analysis (FEA) study on an end-plate moment connection with elastomeric thermal breaks to develop analytical design rules for end-plate moment connections with thermal breaks. The FEA model considered geometric and material nonlinearities. The thermal breaks studied had a thermal 
conductivity of $0.2 \mathrm{~W} / \mathrm{mk}$ and found that creep has a negligible effect on the connection strength, while the length of the bolts, the bolt's preloading, and the friction between the steel and interference thermal layers have a direct effect on connection behavior.

Larbi, et al. (2017), studied the effect of using PVC and acoustic insulations with endplate moment connections for steel structures attached to a concrete support. A numerical simulation was used to study the thermal performance of the thermal breaks. It was found that using thermal barriers within the steel connection can reduce thermal bridging up to $65 \%$. It was also found that thermal performance depends on thermal configuration (whether additional thermal insulation is used to insulate the steel beam), the thickness of the thermal barriers, the material used in the fasteners (carbon or stainless steel) and the thickness of the thermal envelope.

Cleary, et al. (2016), conducted an experimental study on simple shear and moment connections using fiber reinforced resin (FRR) as thermal breaks $(0.3 \mathrm{~W} / \mathrm{mK}$ thermal conductivity) under service loading conditions. The study considered two FRR grades of standard weave and high weave in two thicknesses (1 and 2 inch). Two surface preparations were investigated: no surface preparation and roughened surfaces using ANSI (2012) to increase the friction coefficient. The bolts were $3 / 4$-inch diameter A563 with Grade C nuts with a clamping force of 32 kips with F436 washers. For shear tests, the researchers used a built-up steel angle of $1 / 2 \times 10 \times 6$ inch attached to steel leg 
through four bolts. The used fillers were $10 \times 6$ inch with different thicknesses as summarized in Table 2-1. A hydraulic jack was used to apply a force until the slip occurred or the load hit 45 kips. A load-displacement diagram was created to determine the slip load. It was found that friction between the FRR plates is less than that between steel plates. However, roughing the FRR surfaces increased the friction coefficient. For moment connections, it was found that the existence of thermal breaks within the connection increased connection rotation by $10 \%$ and $20 \%$ for 1 and 2 -inch plate thickness, respectively. The shear connection was not tested up to failure and further study is thus required to find the connection behavior in shear loading.

Table 2-1: Properties of thermal materials used by Cleary (2016).

\begin{tabular}{|c|c|c|c|}
\hline \multirow{2}{*}{ Property } & \multicolumn{2}{|c|}{ Value } \\
\cline { 2 - 4 } & Standard & High weave & Units \\
& weave & & ski \\
\hline Maximum Loading Stress & 36.5 & 41.9 & $\%$ \\
\hline Strain at maximum stress & 11 & 10 & ski \\
\hline Compressive modulus & 543 & 611 & \\
\hline
\end{tabular}

White (2016), studied end plate moment connections with neoprene fillers. The researchers investigated the thermal and mechanical behavior experimentally and numerically. In addition to the moment test, shear tests were conducted on steel plates with no fillers and with neoprene fillers of $0.5,1$ and 1.5-inch thickness. The steel plates were 0.5 inch thick A572 Grade 50 and four 0.5 inch A325 bolts were used in the 
connection as shown in It was found that shear stiffness decreases exponentially with an increase of the neoprene thickness. For connections without neoprene, slip occurred at a load of 5 kips, while in the case of neoprene fillers there was no clear transition between friction and bolt bearing. The shear stiffness between the cases of no filler and the 0.5 inch neoprene filler was close. The tests were not continued up to bolt failure, but the curvature of the bolts was significant. Double-curvature bending occurred in bolts because of the low shear resistance of the neoprene. 


\subsection{Summary}

Despite an anticipated trend towards using thermal break fillers within steel connections, no experimental studies have compared ultimate load and deformation of steel connections with fillers of different materials and thicknesses. Some thermal break studies were conducted on end plate connections. Very few studies were carried out on lap connections and no study has evaluated and compared the effect of steel and non-steel fillers on ultimate strength and ductility of the connection.

\subsection{Objectives and Motivation}

The main objective of this research was to collect enough physical data on the behavior of polypropylene (PP) fillers of different thicknesses with steel connections to determine the effect of non-steel fillers on connection capacity and slip resistance, and to compare them with a numerical model. The work was motivated by the growing interest in green buildings to enable the use of inexpensive non-steel fillers that have better thermal performance. 


\section{Experimental program}

\subsection{Test Matrix and Specimen Layout}

Eight single bolt connection assemblies were designed and tested to failure to determine the effect of non-steel fillers on connection strength (Table 3-1). Two thicknesses of propylene (PP) fillers were considered: 0.5 and 1 inch. Steel fillers are studied extensively in the literature; therefore, they are not the focus of this study. A 0.5 inch steel filler along with non-filler connections were considered for comparison purposes.

Two duplicate specimens were tested for each of the four configurations and are shown in Fig. 3-1.

Table 3-1: Test matrix

\begin{tabular}{|c|c|c|c|c|c|c|}
\hline \multirow{2}{*}{$\begin{array}{l}\text { Specimen } \\
\text { name }\end{array}$} & \multirow{2}{*}{$\begin{array}{c}\text { Filler } \\
\text { thickne } \\
\text { ss }\end{array}$} & \multirow{2}{*}{$\begin{array}{l}\text { Filler } \\
\text { material }\end{array}$} & \multirow{2}{*}{$\begin{array}{l}\text { Pull plate \& } \\
\text { Splice plate } \\
\text { materials }\end{array}$} & \multicolumn{2}{|c|}{ Bolts } & \multirow{2}{*}{$\begin{array}{c}\text { No. of } \\
\text { specimens }\end{array}$} \\
\hline & & & & Type & Length & \\
\hline No filler (N1) & \multirow[t]{2}{*}{ - } & \multirow[t]{2}{*}{-} & \multirow[t]{2}{*}{ A572 GR50 } & \multirow[t]{2}{*}{$7 / 8-A 325$} & \multirow[t]{2}{*}{$4 \frac{1}{2}{ }^{\prime \prime}$} & \multirow[t]{2}{*}{2} \\
\hline No filler (N2) & & & & & & \\
\hline $\begin{array}{c}\text { Steel Filler } \\
\text { (SF1) }\end{array}$ & \multirow[t]{2}{*}{$1 / 2 " 6$} & \multirow[t]{2}{*}{$\begin{array}{l}\text { A572 } \\
\text { GR50 }\end{array}$} & \multirow[t]{2}{*}{ A572 GR50 } & \multirow[t]{2}{*}{ 7/8-A325 } & \multirow[t]{2}{*}{$51 / 26$} & \multirow[t]{2}{*}{2} \\
\hline $\begin{array}{l}\text { Steel Filler } \\
\text { (SF2) }\end{array}$ & & & & & & \\
\hline $\begin{array}{l}\text { Polypropylene } \\
\text { Filler } \\
(\mathrm{PF} 1 / 2 \text { “ }-1)\end{array}$ & \multirow[t]{2}{*}{$1 / 26$} & \multirow[t]{2}{*}{$\begin{array}{c}\text { Polyprop } \\
\text { ylene }\end{array}$} & \multirow[t]{2}{*}{ A572 GR50 } & \multirow[t]{2}{*}{$7 / 8-A 325$} & \multirow[t]{2}{*}{$51 / 2 “$} & \multirow[t]{2}{*}{2} \\
\hline $\begin{array}{c}\text { Polypropylene } \\
\text { Filler } \\
\text { PF } 1 / 2 “-2 \\
\end{array}$ & & & & & & \\
\hline $\begin{array}{c}\text { Polypropylene } \\
\text { Filler } \\
\text { PF 1“ - 1 }\end{array}$ & \multirow[t]{2}{*}{$1 "$} & \multirow[t]{2}{*}{$\begin{array}{c}\text { Polyprop } \\
\text { ylene }\end{array}$} & \multirow[t]{2}{*}{ A572 GR50 } & \multirow[t]{2}{*}{ 7/8-A325 } & \multirow[t]{2}{*}{$61 / 2 ”$} & \multirow[t]{2}{*}{2} \\
\hline $\begin{array}{c}\text { Polypropylene } \\
\text { Filler } \\
\text { PF } 1 \text { “" }-2\end{array}$ & & & & & & \\
\hline
\end{tabular}




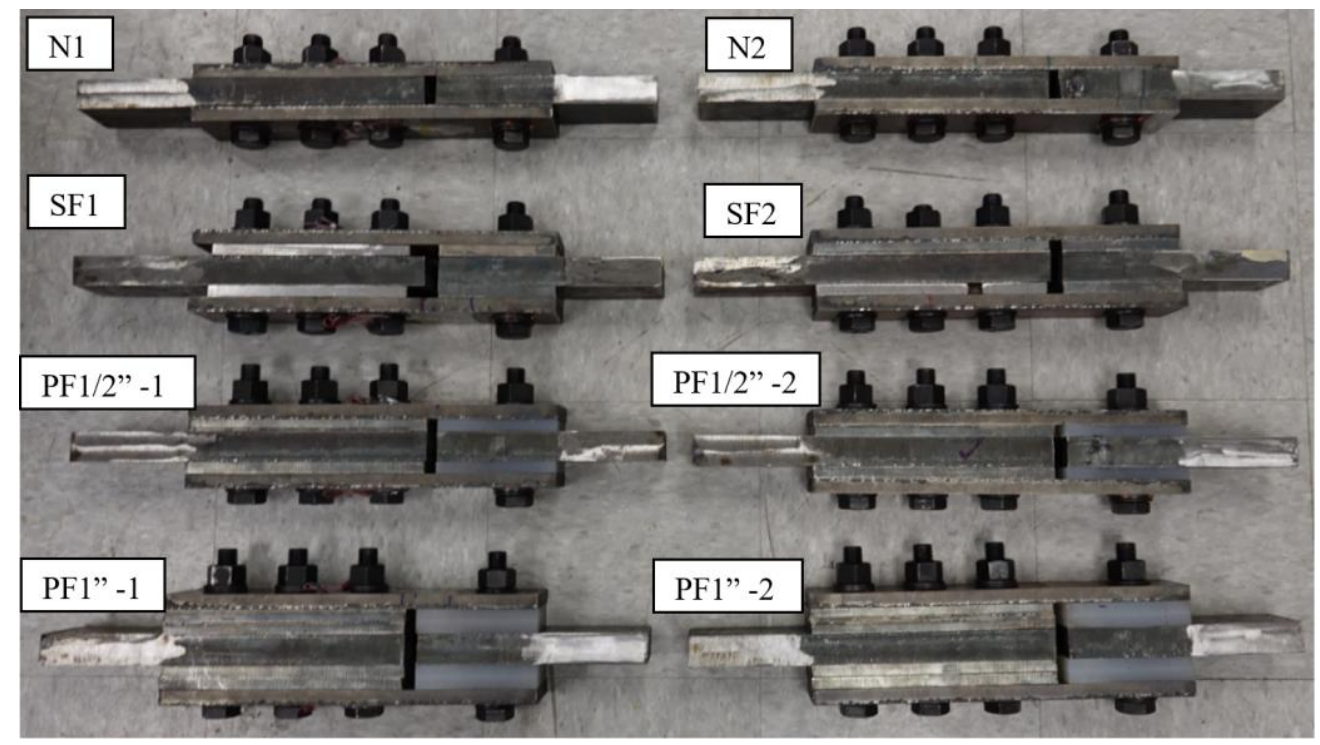

Fig. 3-1: Test specimens.

Fillers were added to both sides of the pull plate to cancel or at least reduce the effects of eccentricity. Thermal break fillers are made of propylene (PP) with a tensile strength of $4.8 \mathrm{ksi}$ and a thermal conductivity of $0.11 \mathrm{~W} / \mathrm{m} * \mathrm{k}$. Table 3.2 shows the thermal conductivity of select materials.

Table 3-2: Thermal conductivity of different materials.

\begin{tabular}{|c|c|}
\hline Material & Thermal conductivity $(\mathrm{W} / \mathrm{m} * \mathrm{k})$ \\
\hline Steel & 50.2 \\
\hline Propylene & 0.11 \\
\hline Air & $0.024-0.03$ \\
\hline
\end{tabular}

Generally, the pull plate, splice plate and steel filler plates were made of A572 Grade 50 steel with no surface preparation. The pull plates have a thickness of 1.25 inch while the splice plates have a thickness of 0.625 inch. Each specimen consisted of two parts: the upper part, which is a single bolt connection, and the lower part, which is a three-bolt 
connection (Fig. 3-2). The upper part is the area of consideration in this study. It has faying surfaces of 3 x 5 inch as specified in RCSC (2004) for slip critical tests (Fig. 3-3). The function of the lower part is to connect the splice plates to the lower pull plate and make sure no deformations occur in this part of the connection when ultimate load is reached in the single-bolt part. The connection was designed such that the failure occurs in the bolt while taking into consideration the threaded part of the bolt is excluded from the bearing area. The selected bolt is 7/8 inch diameter made of A325 steel and represents the most commonly used bolt in steel structures. The bolt hole is a standard sized hole (15/16 inch) located 2 inches from one end and 3 inches from the other end as shown in Fig. 3.2 (b). The specimens were tested using a 120-kip-capacity Tinius Olsen Super L testing machine owned by VGO, Inc. (Fig. 3.4). 


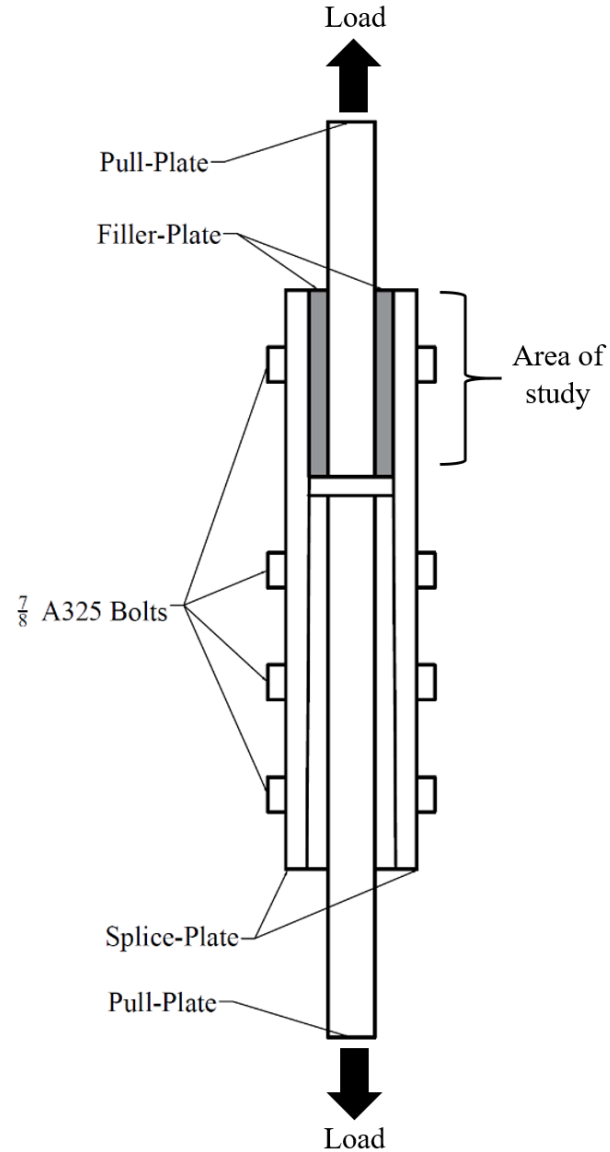

(a) Side view

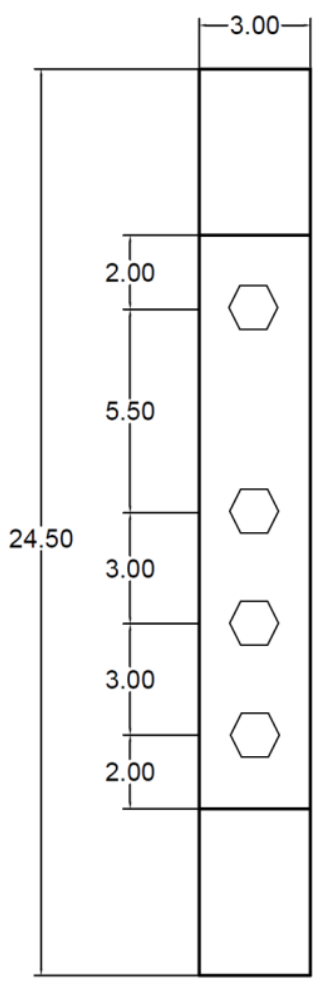

(b) Front view

Fig. 3-2: Sketch showing the tested steel connection specimen with fillers. 


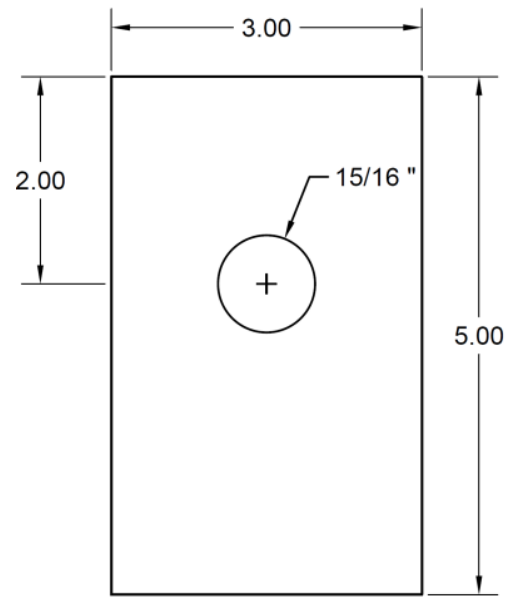

Fig. 3-3: RCSC (2004) test coupon.

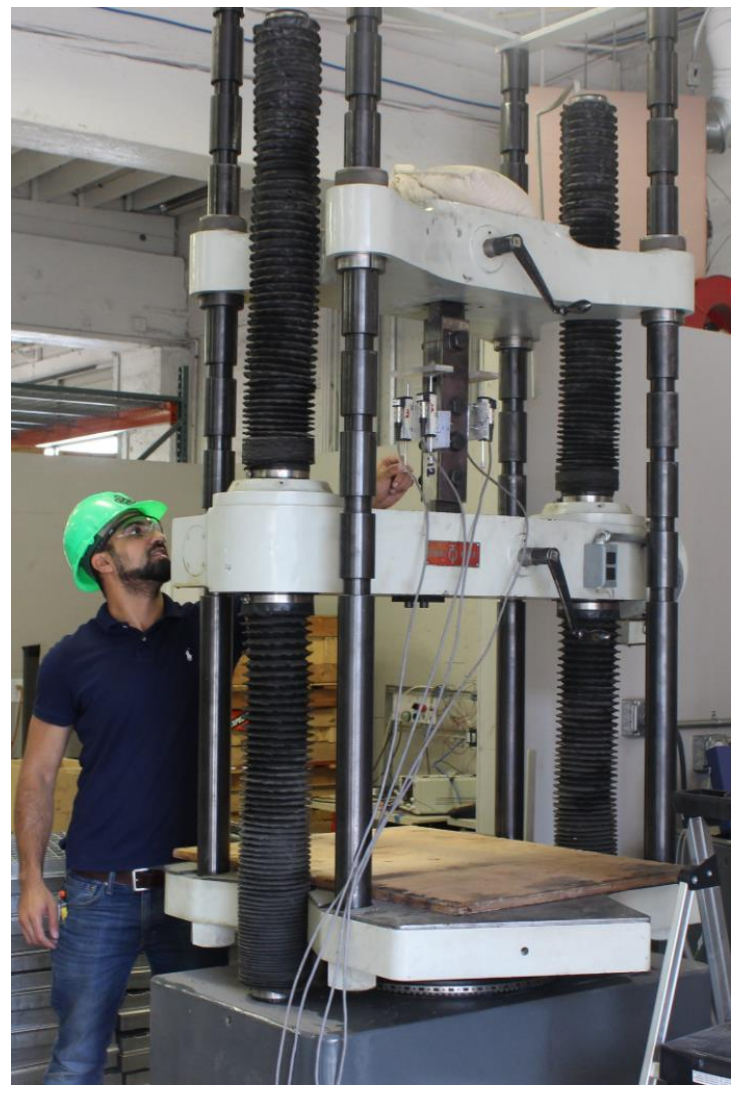

Fig. 3-4: Photo of universal testing machine. 


\subsection{Instrumentation}

In order to capture an accurate measure of the deformation between the pull plate and the splice plates, four LVDTs (one at each corner) were installed on each specimen as shown in Fig. 3.5. The LVDTs were attached to the sides of the splice plates to read the relative deformation between the splice plates and the near end of the pull plate.

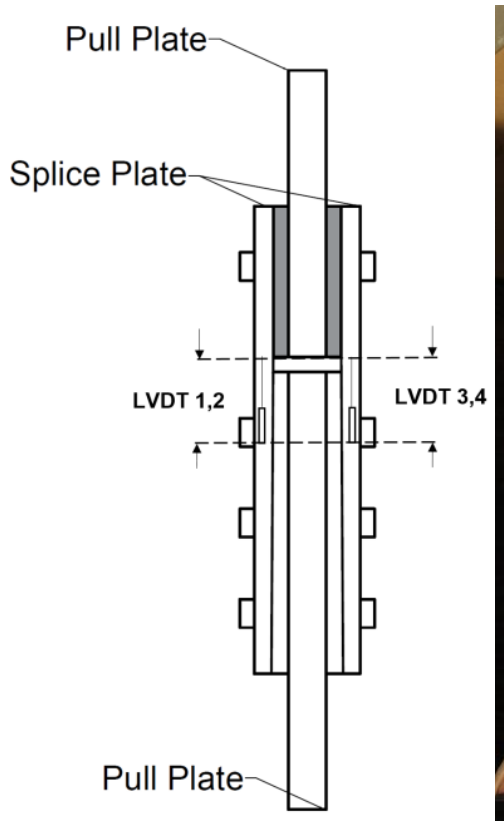

(a)

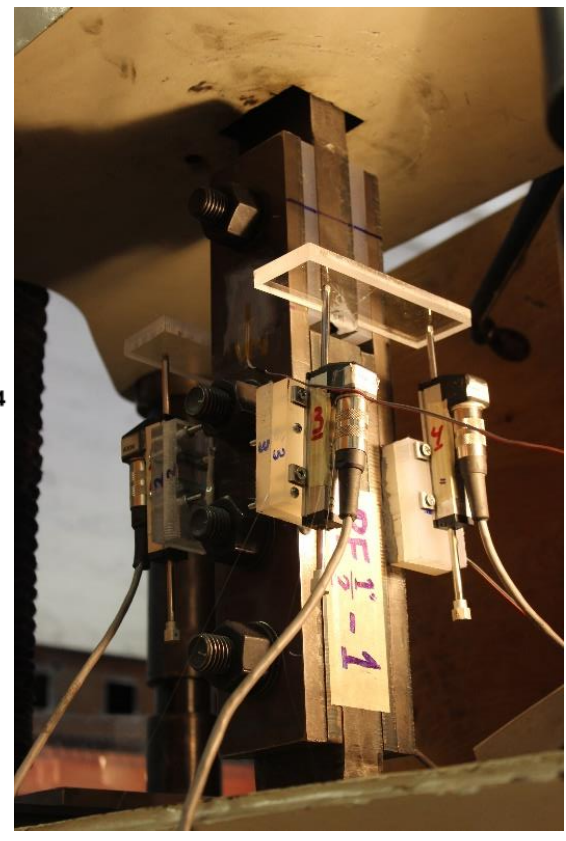

(b)

Fig. 3-5: Test specimen with LVDTs.

(a) Sketch showing the LVDTs locations. (b) Photo for tested specimen with LVDTs

Strain gauges were also used on four different specimens in the upper and lower splice plates as shown in Figure 3-6. 


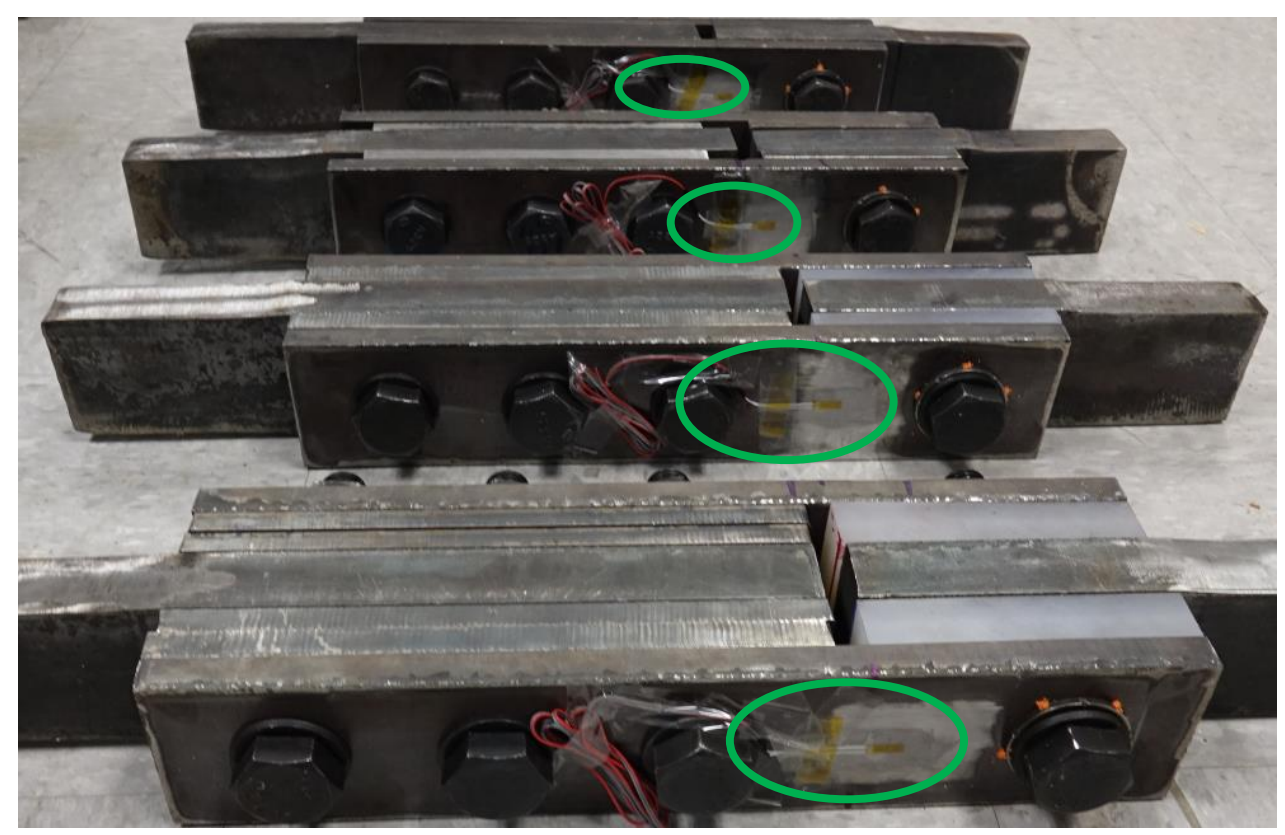

Fig. 3-6: Photo showing specimens with strain gauge locations.

\subsection{Test Setup}

The eight specimens were assembled prior to the test using a torque wrench to tighten the bolts to a snug-tight position. After that, the bolts were tightened to their targeted clamping force using a longer wrench arm. Three types of bolt lengths were used to achieve the required thickness and to ensure the non-threaded bolt-shank lies within the bearing area, as summarized in Table 3.1. After they were assembled, each specimen was installed in the testing machine by gripping the loose ends of the pull plates through which the load was applied. 


\subsection{Bolt-clamping force}

For slip-critical connections, it is important to measure the bolt clamping force precisely. The most widely used and preferred method for measuring bolt clamping force is the turn-of-nut method, as it is a direct and precise way to predict bolt clamping force.

However, this method is precise only when the bolted plates are made of steel. Since the thermal breaks used consist of a more compressible material (PP filler), the stiffness of the connection is not the same as when steel fillers are used. Using PP fillers reduces the stiffness of the connection, inducing some relaxation in the bolt and finally reducing the bolt clamping force. In order to understand how the bolt clamping force is affected by the PP fillers, a 7/8 inch A325 bolt was used with two steel plates of 0.625 -inch thickness and 1/2-inch PP filler plates in between (Fig. 3-7). RCSC (2014) specifies a minimum bolt pretension of 39 kips for slip-critical joints. The bolt was fastened up to 39 kips as it was measured by the connected load cell. In addition to the load cell, a direct tension indicator washer (DTI), as shown in Fig 3-8, was used to measure the clamping force and calibrate it with the load cell. At a load of 38 kips, the orange indicator started to emerge from around the DTI washer (Fig. 3-9) indicating that a load of 39 kips was reached. The bolt clamping force was recorded using a load cell for 24 hours (Fig. 3-7). It was found that the bolt load dropped by approximately $13 \%$ in the first hour and $18 \%$ after 24 hours, as shown in Fig. 3.10. 

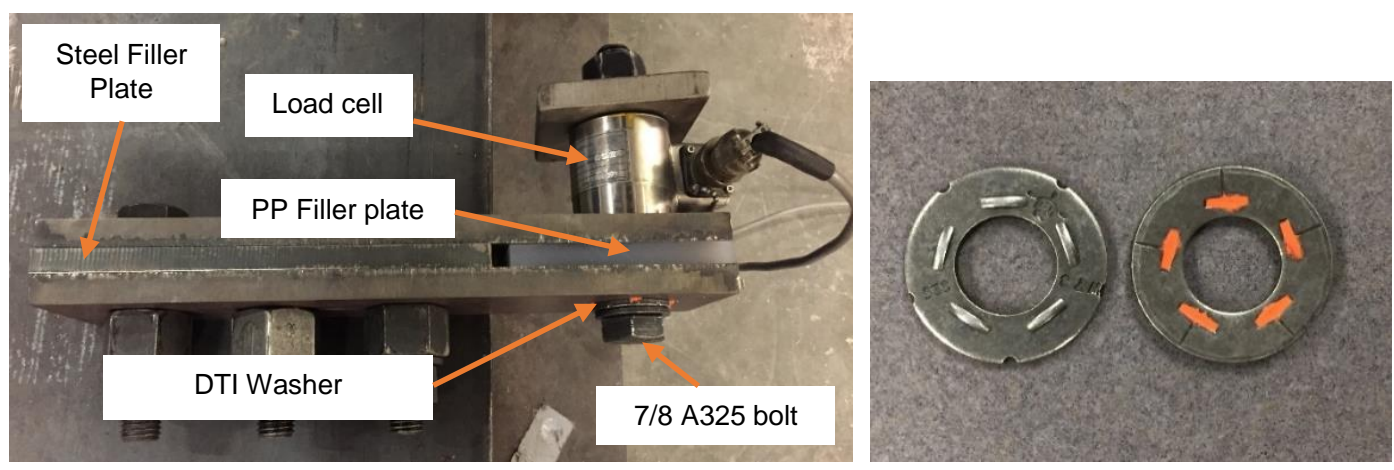

Fig. 3-7: Bolt clamping force test for a sandwich of two steel plates and a 1/2-inch PP filler plate.

Fig. 3-8: Direct tension indicators.

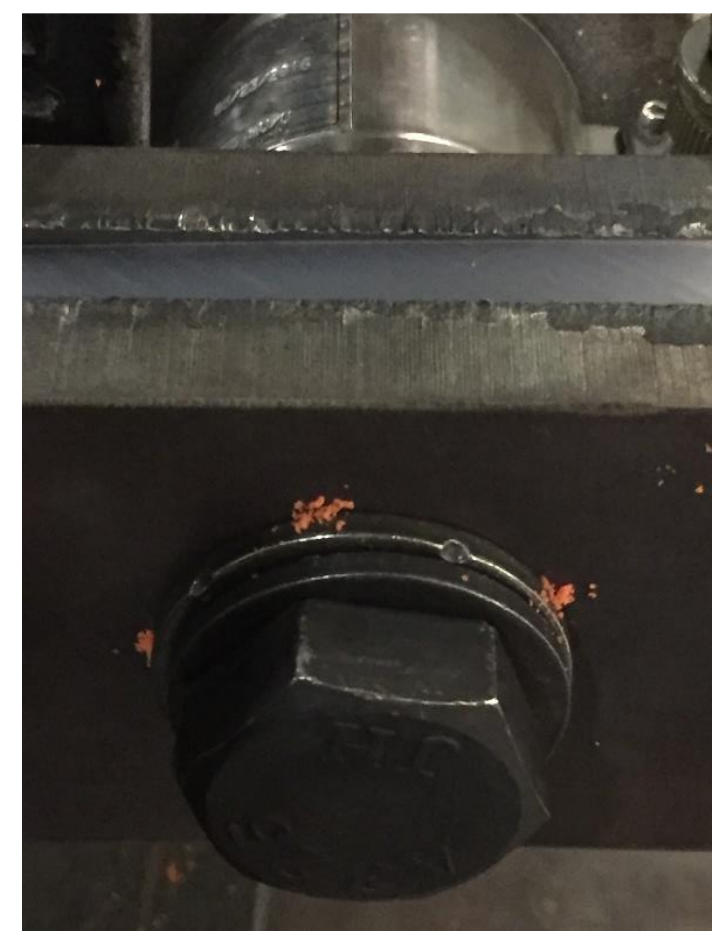

Fig. 3-9: Orange indicator appearing around the DTI washers when load reached 38 kips. 


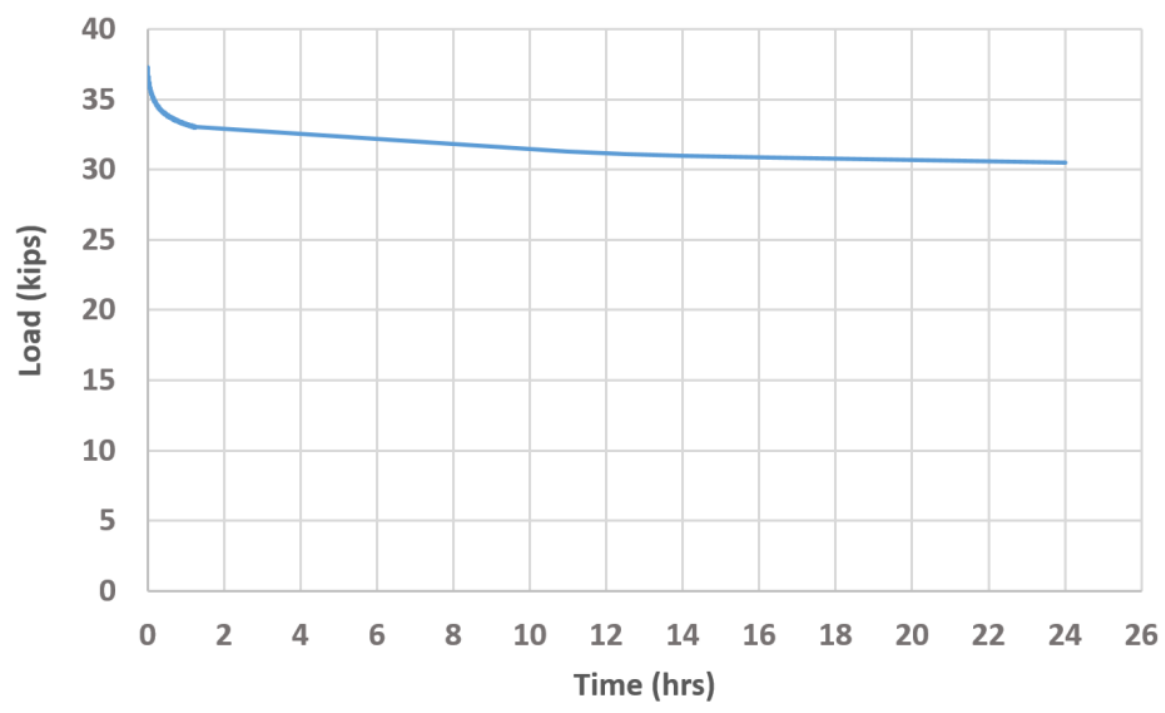

Fig. 3-10: Sample bolt clamping force vs. time.

\section{Experimental results}

The general behavior of the connection can be summarized as an initial slip followed by bearing, inelastic deformation, and finally bolt failure. The presence of steel and polypropylene fillers affected the slip strength and the ultimate strength of the connection. The presence of PP fillers made the splice plates more flexible because PP fillers have a lower stiffness than steel. This flexibility results in more deformation in the bolt and additional ductility (Fig. 4-1). Fig. 4-2 shows the bolts that were extracted from the specimens after testing to failure. It can be observed that the ultimate deformation is largest and smallest for the 2 inch PP and no filler plates, respectively, which is supported by the deformation curves shown in Fig. 4-1. The drops that can be seen in the load- 
deformation curves are assumed to be due to a slip in the grips when the load reached approximately 75 kips.

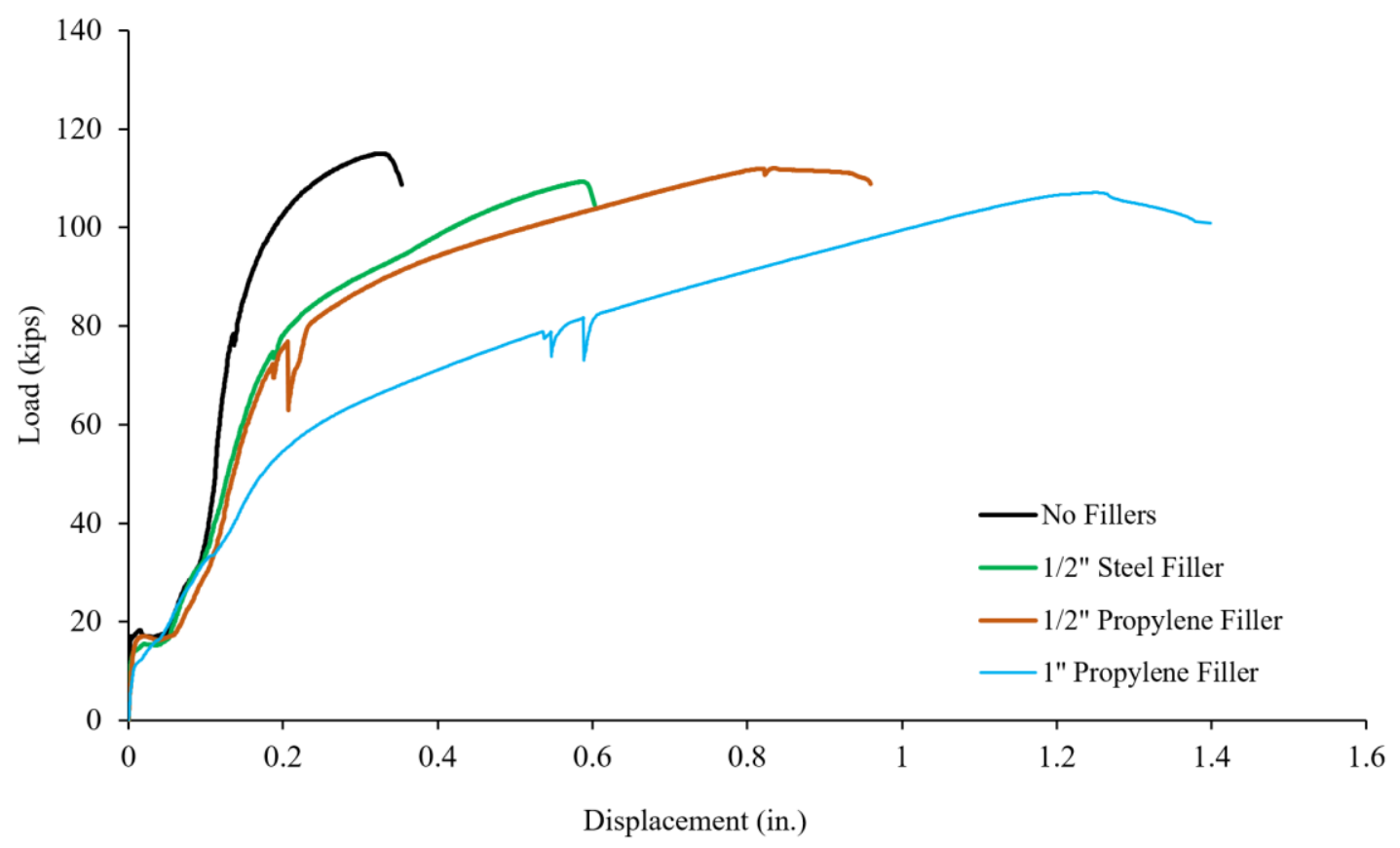

Fig. 4-1: Load vs. deformation curves for four select specimens from each test group.

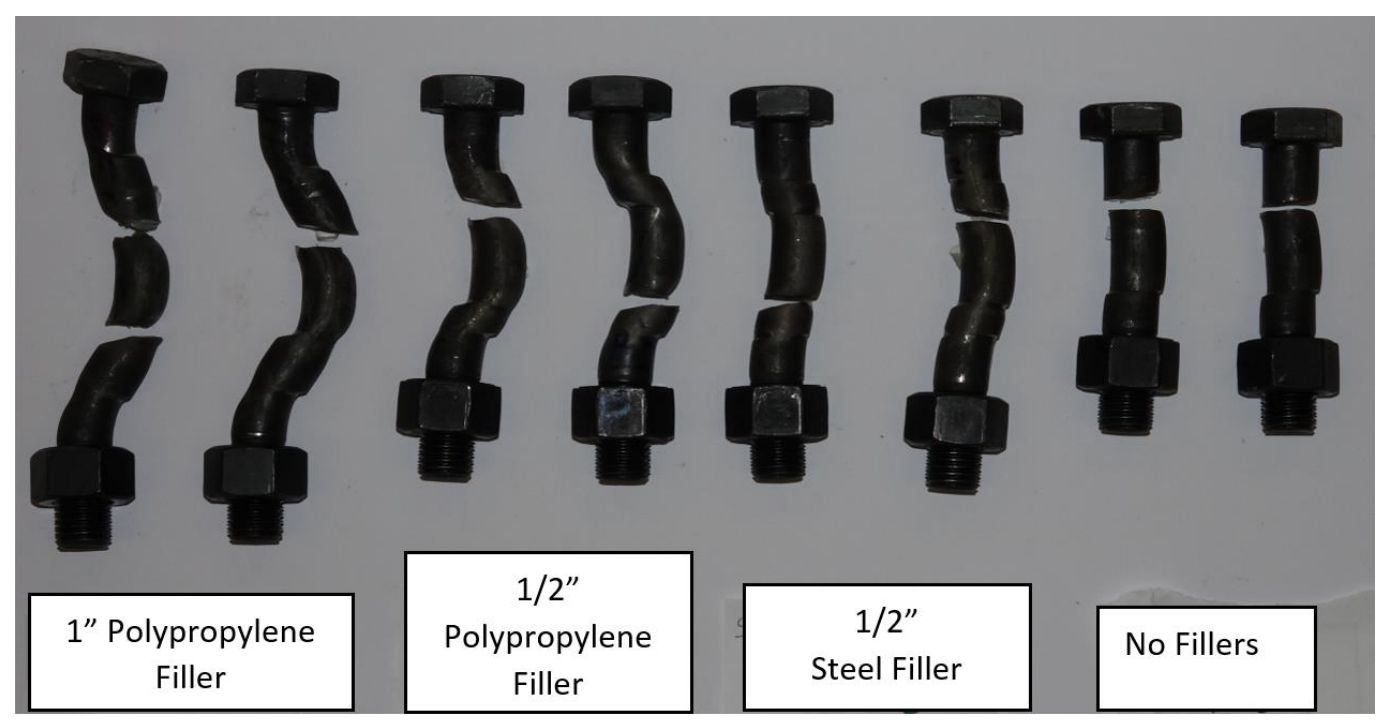

Fig. 4-2: Bolts after testing connections to failure. 


\subsection{Slip Resistance}

Although, the connections in this study were designed as bearing-type connections, it is important to report the slip coefficient of each test since one of the RCSC 2014 recommendations for connections with steel fillers are to be designed as slip critical connections. The slip load in Table 4-1 was extracted according to RCSC (2014) section A3.4. The slip coefficient $\left(\mathrm{k}_{\mathrm{s}}\right)$ from the test was calculated using equation (4.1):

$$
k_{s}=\frac{\text { slip Load }}{2 \times \text { Bolt Clamping Force }}
$$

Table 4-1 shows slip the coefficients observed from the eight specimens. It was found that using a $1 / 2$-steel filler reduced the slip coefficient by $21.6 \%$ while using the same thickness of polypropylene filler increased the slip coefficient by $54 \%$.

Table 4-1: Test slip coefficients.

\begin{tabular}{|c|c|c|c|}
\hline Specimen & $\begin{array}{c}\text { Average } \\
\text { Clamping Force } \\
\text { (kips) }\end{array}$ & $\begin{array}{c}\text { Slip Load } \\
\text { (kips) }\end{array}$ & $\begin{array}{c}\text { Slip Coefficient } \\
\left(\mathrm{k}_{\mathrm{s}}\right)\end{array}$ \\
\hline No Fillers & 39 & 20.1 & 0.26 \\
& 39 & 17.84 & 0.23 \\
\hline Steel Fillers & 39 & 15.87 & 0.20 \\
& 39 & 15.63 & 0.20 \\
\hline polypropylene Fillers & 30.5 & 18.39 & 0.42 \\
& 30.5 & 16.46 & 0.37 \\
\hline
\end{tabular}




\subsection{Ultimate Strength}

The ultimate strength versus filler thickness of the tested connections is plotted in Fig. 4.3. The presence of the steel and PP filler plates reduces the ultimate strength of the connection. It was observed that the connections with 1/2-inch PP fillers exhibited higher ultimate strengths than the connections with steel fillers of the same thickness. For $1 / 2-$ inch thick steel and PP fillers, the connection's ultimate strength was reduced by $5.25 \%$ and $2.48 \%$ respectively. The connection's ultimate strength was reduced by a $7.32 \%$ when 1-inch polypropylene was used.

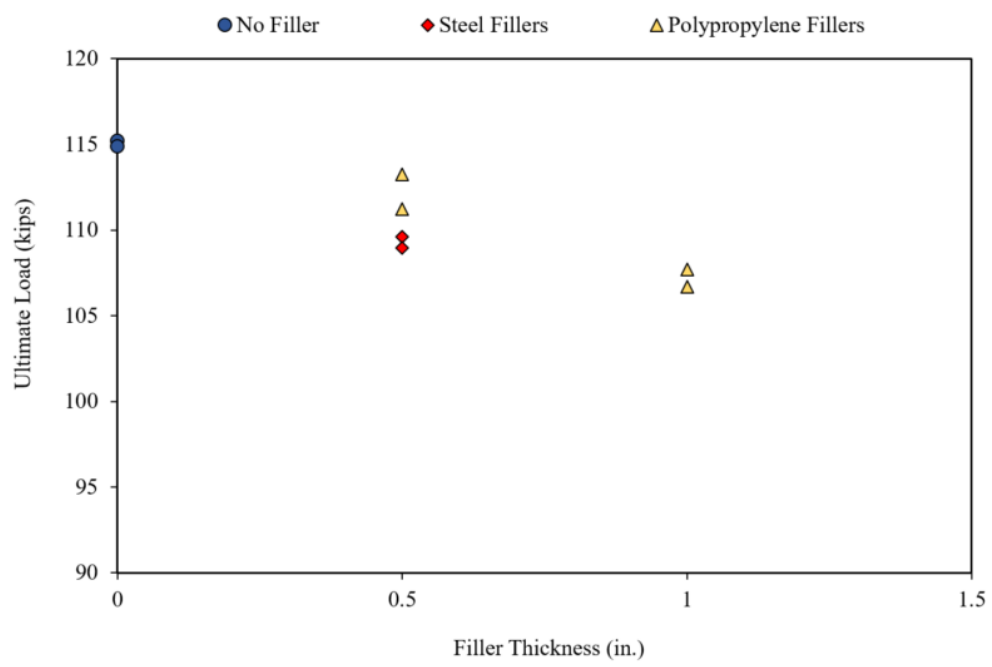

Fig. 4-3: Ultimate load vs. filler thickness (all tests).

For connections with fillers, the current design equation (RCSC 2014) recommends reducing the shear strength of the bolt on the ultimate nominal shear stress level through multiplying the nominal bolt shear stress by the following reduction factor (RCSC 2014):

$$
R_{b}=1-0.4(\mathrm{t}-0.25) \text { where } R_{b} \geq 0.85 \ldots \ldots \ldots \text { (Eq. 4.2) }
$$


The design equation from RCSC 2014 is conservative for connections with thick fillers, therefore, Dusicka and Lewis (2010) suggested a new adjustment factor. Their equation is based on the bolt diameter and filler thickness rather than the filler thickness only:

$f r=1+\left[\left(\frac{k f}{d b^{2}}\right)(0.75 t-d b)^{2}-k f\right] \ldots \ldots \ldots\left(\right.$ Eq.4.3) where $k_{f}=0.1$ for a standard size hole and $d_{b}$ is the bolt diameter.

Perry (1961) defined the useful load as the load at 0.25 inch deformation, after which the connection would experience excessive deformation and wouldn't be useful. Based on Perry's recommendation, Frank and Yura (1981) suggested a shear reduction factor for bolted connections with steel fillers at 0.25 inch deformation (equation 4.4 ):

$$
\mathrm{R}_{\mathrm{b}}=1-0.4 \mathrm{t} \ldots \ldots \ldots(\text { Eq. } 4.4)
$$

For reasons of comparison, the applied load extracted at 0.25 -inch deformation was normalized by the load at 0.25 -inch deformation for the specimen with no fillers and compared to the Frank and Yura's (1981) reduction factor (shown as dashed line) (Fig. 44). 1/2-inch steel fillers expressed a $2.98 \%$ lower strength than the design equation, while PP fillers showed a $3.96 \%$ and $5.9 \%$ lower strength for $1 / 2$-inch and 1 -inch fillers, respectively. 


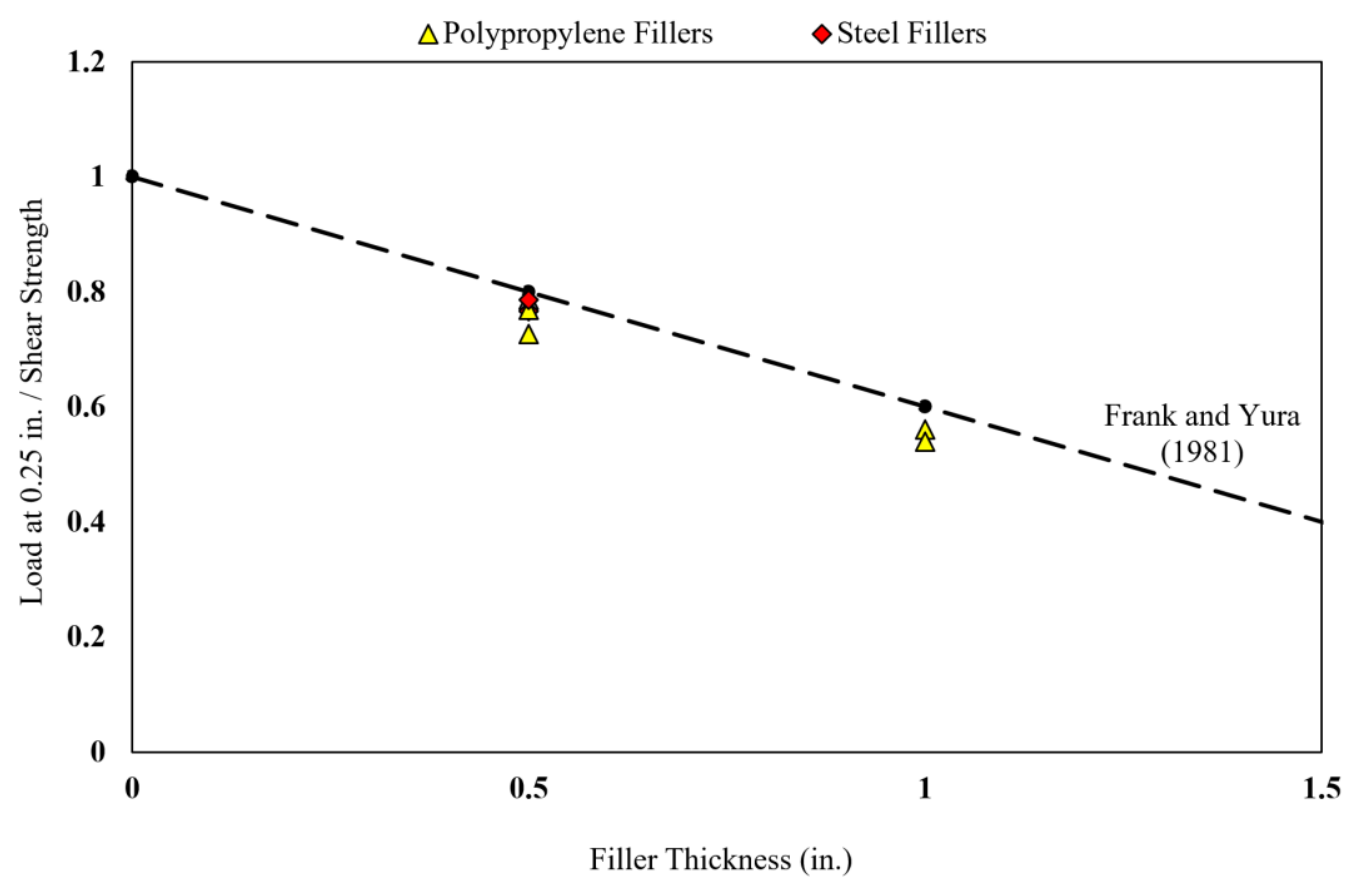

Fig. 4-4: Normalized load at 0.25 inch deformation compared to the design equation (dashed line).

The ultimate load on the other hand was also extracted and normalized to the ultimate load of specimen with no fillers and compared to the code design equation (RCSC 2014) in Fig. 4.5. 1/2-inch steel fillers expressed a 5.9\% higher strength than the design equation, while PP fillers showed a $8.4 \%$ and $9.6 \%$ higher strength for $1 / 2$-inch and 1 -inch fillers, respectively.

Ultimate load was also compared to Dusicka and Lewis' (2010) equation and it showed close results and matched better than the RCSC 2014 equation as shown in Fig. 4-6. 


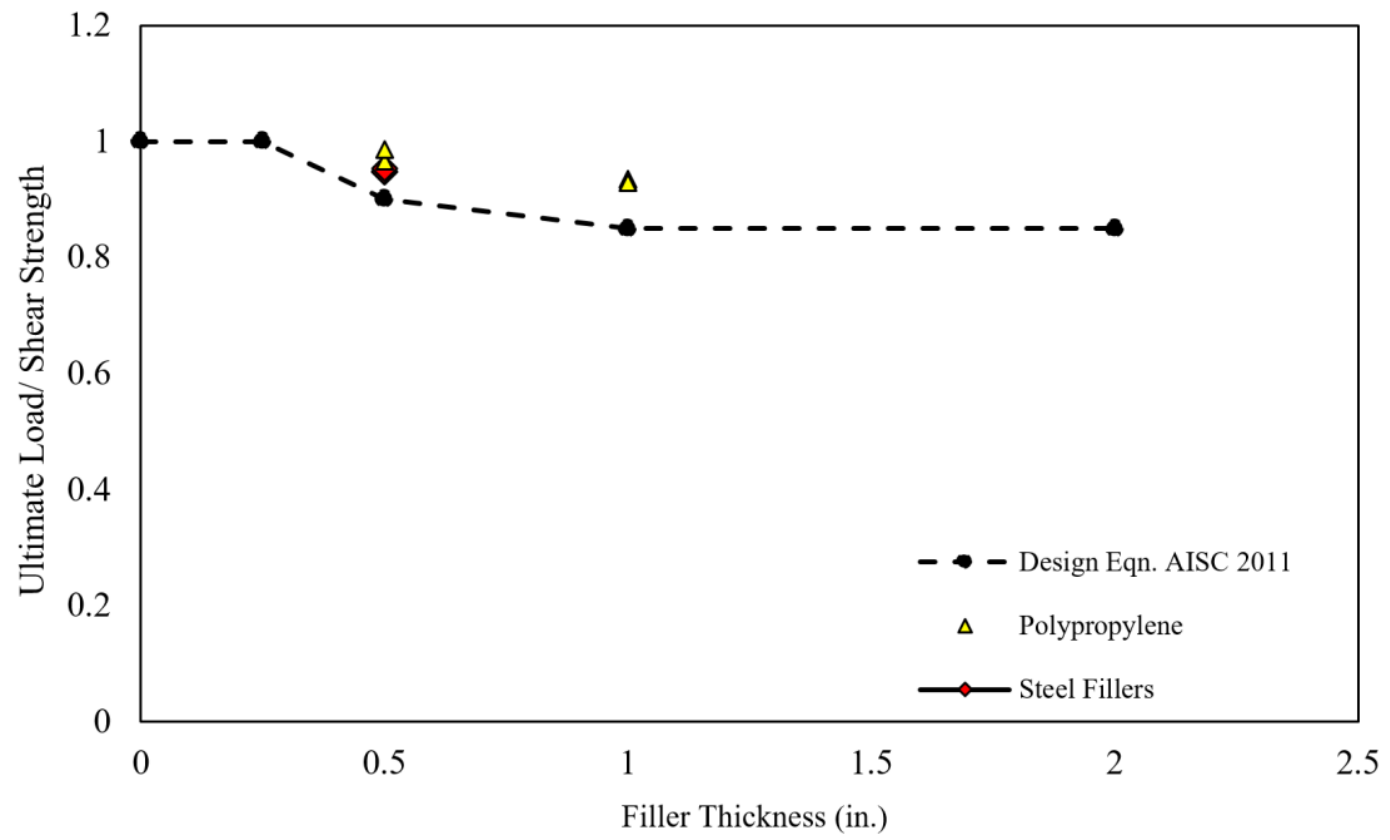

Fig. 4-5: Normalized ultimate load compared to the design equation (dashed line).

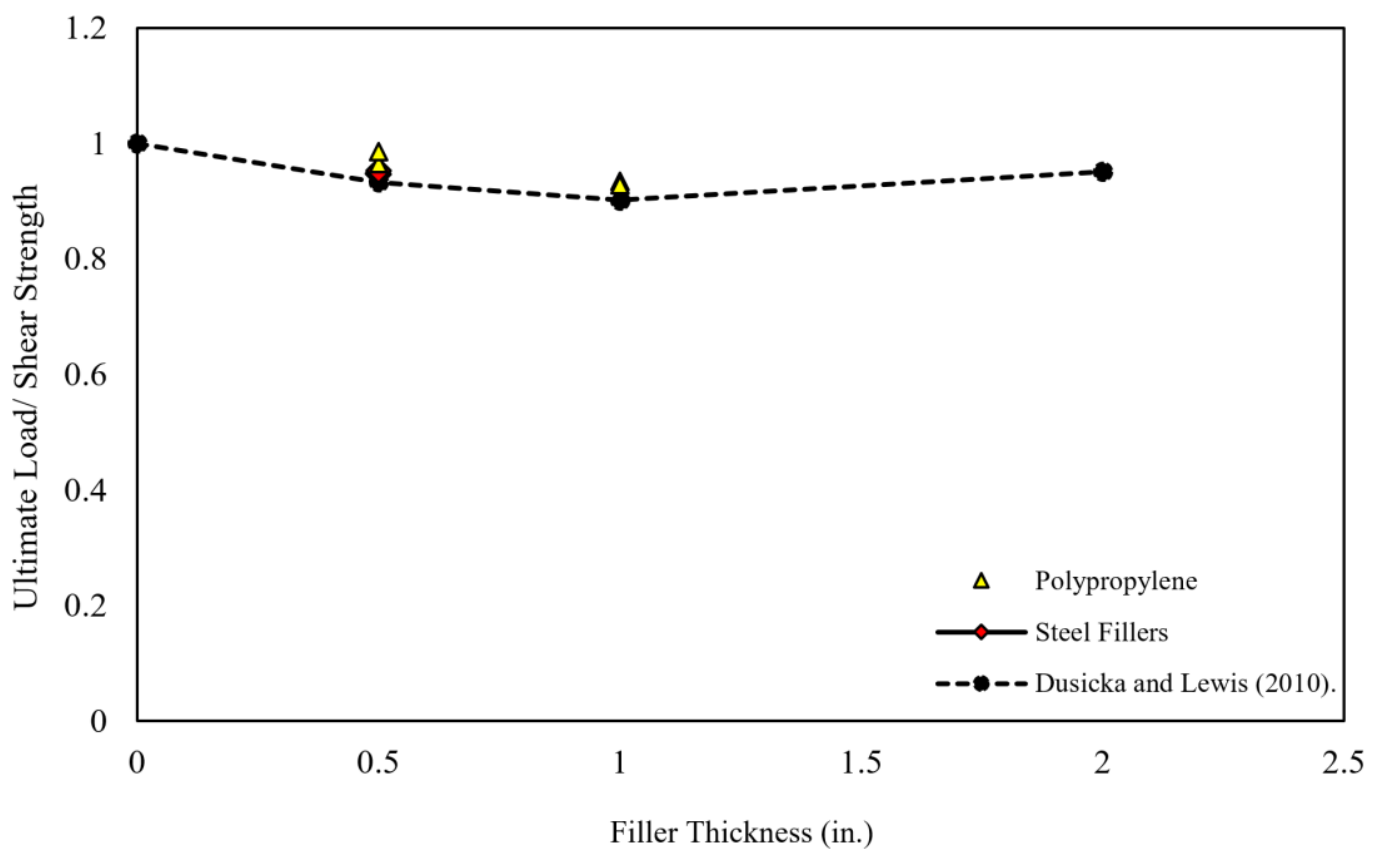

Fig. 4-6: Normalized load compared to Dusicka and Lewis' (2010) Eq. 


\section{Finite Element Analysis}

ABAQUS software 6.14-4 was used for all Finite Element Analyses (FEA), with both explicit and implicit codes. Contact, friction, sliding, bolt hole deformation, bolt bending, bolt clamping force (pretension) and material non-linearity were all considered in the simulation. Details are presented in the following subsections.

\subsection{Introduction}

This research employed of two different FEA models. The first model simulates the experimental tests with the PP fillers, which were conducted as part of this research, and the second one simulates the laboratory tests with steel fillers studied by Dusicka (2010). The two models were used to prove their ability to handle different materials.

\subsection{Model 1}

The connections studied in the experiments conducted as part of this research were modeled in ABAQUS. Only the one-bolt part was considered in the FEA model, without the 3-bolt part, because it was the focus of this research. The 3-bolt part is assumed to have no effect on the results because it is simply a means to transfer the load to the onebolt part through the splice plates (Fig. 5-1). 


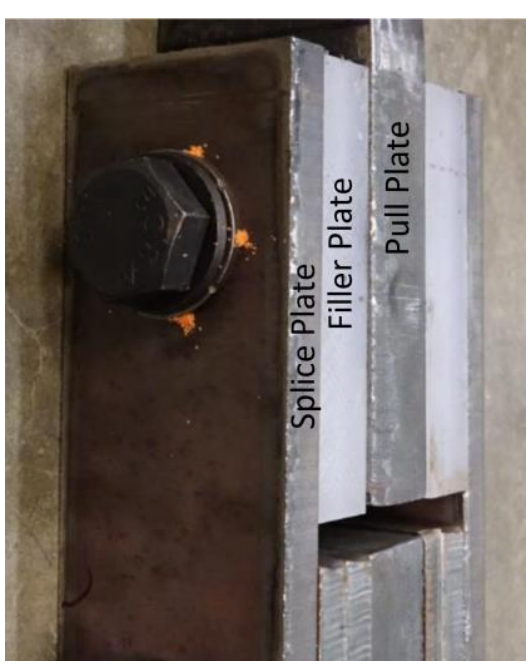

(a) Test specimen.

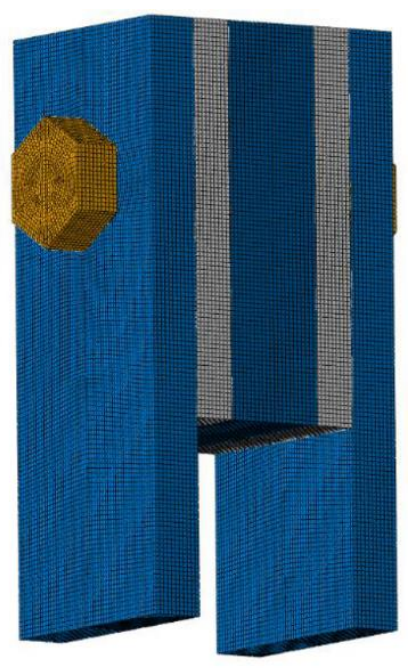

(b) FE model.

Fig. 5-1: Example of one-bolt portion of steel connection with 1-inch PP fillers

One standard hole of 15/16-inch diameter is located in the middle of the plate along the $\mathrm{x}$-axis and 2 inches from the other edge of the plate (Fig. 5-2). The model is constructed from five plates. The splice plates have thicknesses of $0.625 \mathrm{inch}$ while the pull plate has a thickness of 1.25 inches. Filler plates inserted between the pull plate and the splice plates have varying thicknesses of $0,1 / 2,1$ and 2 inches. The plates are connected by one 7/8 A325 bolt with a 39 kip target clamping force. 


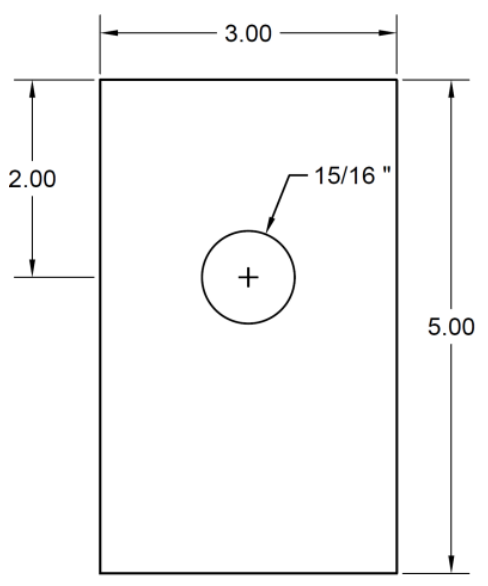

Fig. 5-2: RCSC coupon.

\subsection{Model 2}

Model 2 simulates the specimens from Dusicka and Lewis (2010) using connections with steel fillers. The faying surfaces are the same, but the pull plate and splice plates are from different steel grades and have different thicknesses. The pull plate had a thickness of 1.75 inches while the splice plates had a thickness of 1.125 inches. The steel fillers had thicknesses of $0,1 / 2,1$ and 2 inches and all the plates were connected by $7 / 8$ A490 bolts.

\subsection{Model Simplification}

For large and complex geometries, FEA can be time consuming; therefore, it is necessary to simplify a model if possible, for instance by considering symmetry, without affecting the connection's behavior. Since the bolt's threads were out of the bearing area, they were not considered in the design and this allowed the simulation to account for 
symmetry along the $x-y$ plane. Symmetry along the z-y plane was also taken into consideration, as the bolt was in the middle of the plate. In the end, only one-quarter of the connection was simulated (Fig. 5-3 (a)) and the results were then multiplied by a factor of 4 when obtained from ABAQUS. Fig. 5-3 (b) shows the full model for comparison. The fixed end of the splice plates was assumed to be at the center of the first bolt of the 3-bolt portion, while fillers were free to move and the displacement was applied through the pull plate (Fig. 5-3 (a)).

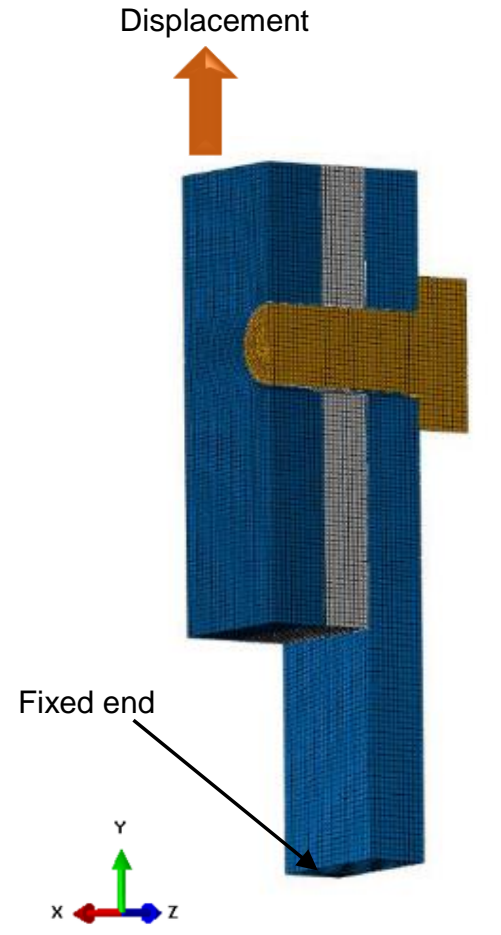

(a) Simplified Model

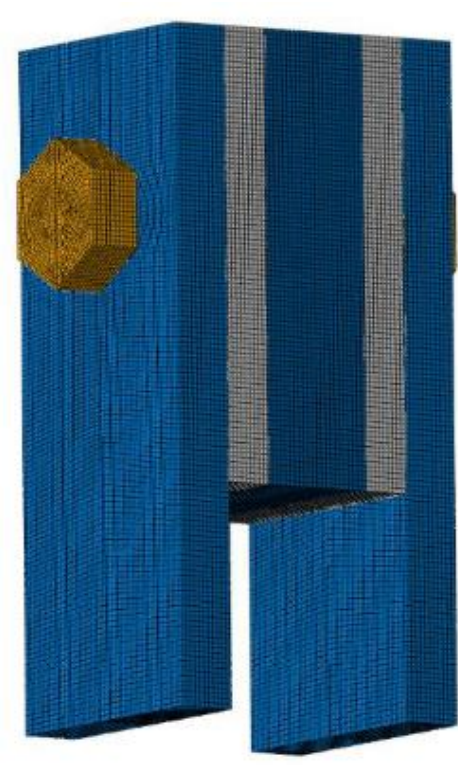

(b) Full Model.

Fig. 5-3: FEA Model 


\subsection{Elements and Staging}

Eight-node linear brick reduced integration hourglass control elements (C3D8R) were used in the FEA (Fig 5-4). Although the bolt is subjected to a large bending deformation, first order elements were used but with more refinement to capture a more accurate picture of the behavior of the connection. First order reduced elements were used in order to reduce $\mathrm{CPU}$ demand.

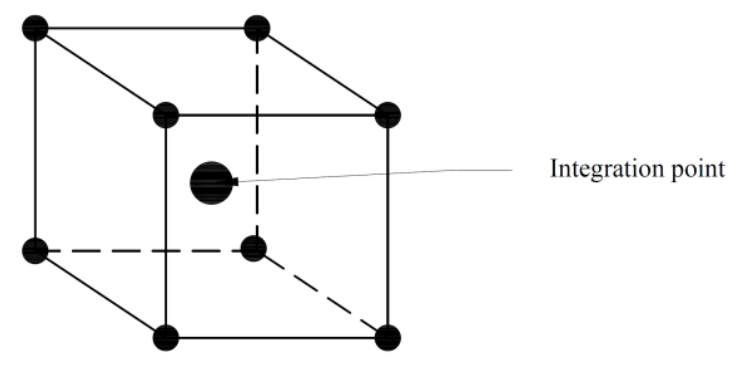

Fig. 5-4: C3D8R element used for all FEA.

Unlike regular bolted connection models, a bolted connection model with fillers represents a true contact problem. When only a quarter of the assembly is considered, there are six contact surfaces, which slide on each other. The implicit code in ABAQUS/ STANDARD cannot handle such problems and therefore explicit code is needed to solve the problem. Explicit code is robust at solving dynamic and quasi-static problems, but ABAQUS/EXPLICIT does not have a direct method to model the bolt's pretention load. Therefore, the FEA was divided into two stages. The first one used the implicit code to model the bolt clamping force; the results were then transferred to the second stage 
(explicit code) where the displacement was applied at the end of the pull plate. When transferring from ABAQUS/Implicit to ABAQUS/EXPLICIT, a limited number of elements are available. For the case of 3D modeling, the only available element was the C3D8R.

\subsection{Modeling of Bolts and Plates}

The 7/8 inch bolts were modeled using the previously introduced C3D8R elements. Only half of the geometry was considered, due to the symmetry, as shown in Fig. 5-5. The shank lengths of the bolts varied from 2 to 4.5 inches, depending on the thickness of the filler plate. Because of symmetry, half of the clamping force was applied. A clamping force of 19.5 kips and 24.5 kips was used for Model 1 and Model 2, respectively. The bolt was placed in reverse bearing with the plates, as it was in the experimental test, to provide a larger distance for the bolt to slide (Fig. 5-6).

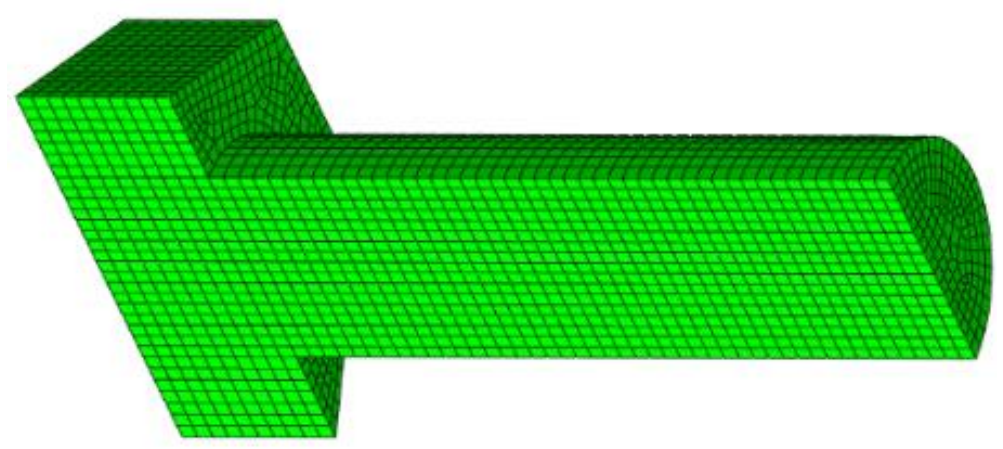

Fig. 5-5: Half-bolt model geometry. 


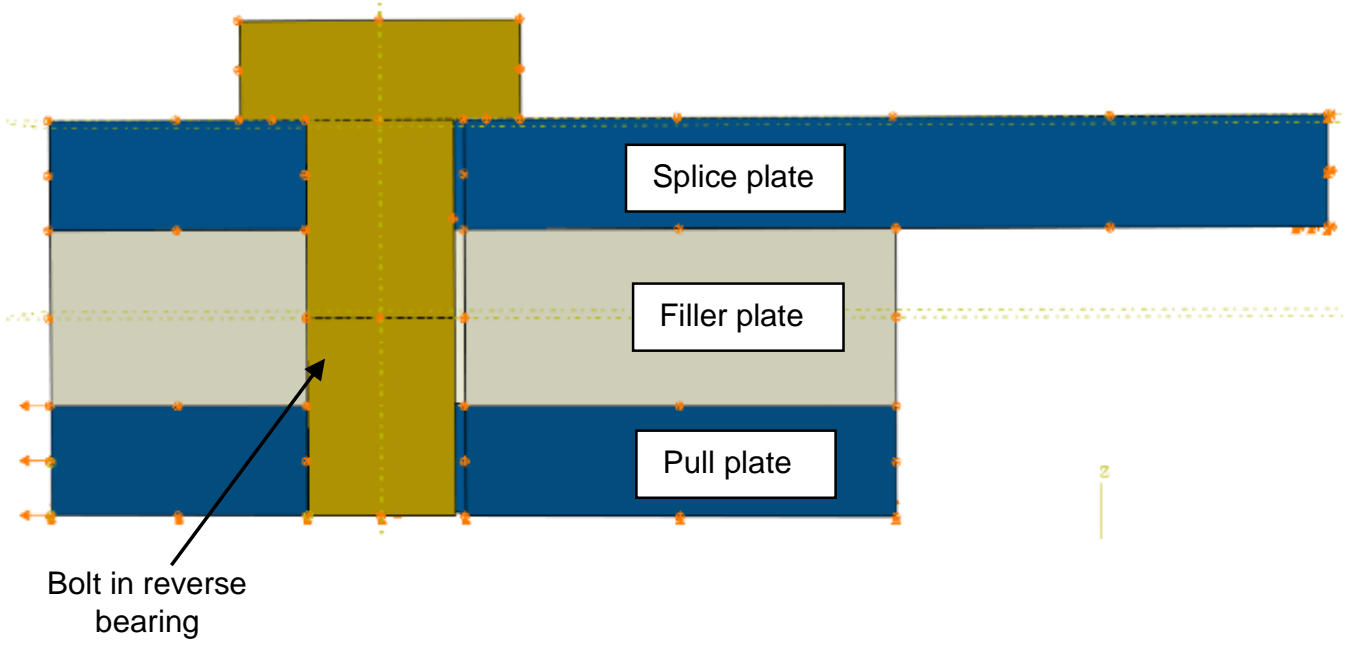

Fig. 5-6: Bolted assembly with bolt in reverse bearing.

All plates were $2.5 \times 1.5$ inch in area (Fig. 5-7.) and were modeled using the same element type as described earlier. The splice plate and pull plate had thicknesses of 1.125 and 0.875 inch, respectively. Filler plates had thicknesses ranging from 0.5 to 2 inches.

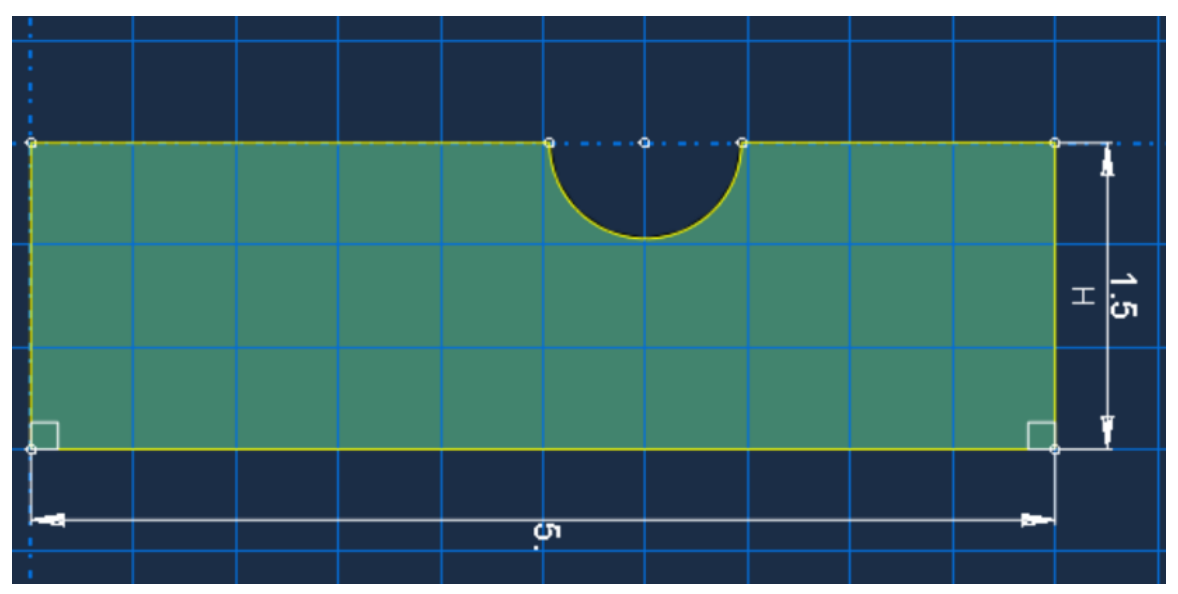

Fig. 5-7: plates geometry. 


\subsection{Modeling of Contact Surfaces}

ABAQUS offers two different options to simulate the relative tangential movement of the contact surfaces: small sliding and finite sliding. Small sliding only allows for minimal movement between the contact surfaces, although the motion of the bodies could be large while Finite sliding allows for any movement between the surfaces. In this research, the bolted connection with fillers is a severe contact problem. Since the problem involves complex tangential movements and sliding, finite sliding was used because it allows for any arbitrary movement between the contact surfaces.

The initial state involved contact between the bolt head and the top surface of the splice plate as well as contact between the bolt shank and the bolt holes of the splice plate, filler plate, and pull plate. The problem also involves contact between the splice plate and the filler plates and between the filler plate and the pull plate. When applying the displacement at the end of the pull plate, the pull plate slides on the filler plate, which is free to move in the applied displacement direction, when the applied load exceeds the friction force between the plates. After that, the pull plate goes into bearing with the bolt. A very small amount of sliding also occurred between the filler plate and splice plate at the beginning of the load application. After the pull plate goes into bearing with the bolt, the filler continues to slide on the splice plate until the upper corner of the filler plate goes into bearing with the bolt shank. For assemblies with no filler plates, when the plates go into bearing with the bolt, the bolt experiences shear deformation until it fails. When filler plates are used, the bolt experiences bending deformation until it fails. 
Friction coefficients of 0.26 and 0.37 were used for steel-on-steel and steel-on-PP, respectively.

\subsection{Mesh}

An optimal mesh study was carried out on all parts of the assembly. The bolt and all plates have the same element size. Unlike ABAQUS/ STANDARD, refinement in ABAQUS/EXPLICIT should be applied on all models instead of refining certain areas, because the wave speed is a function of the element size and having different sizes gives unreliable results. A convergence study was conducted using element sizes of $0.055,0.1$, and 0.2 in. (Fig. 5-8). An element size of 0.055 inch (blue curve) with second order accuracy was used in the FEA, as it was found to satisfy the convergence criteria as well as run with reasonable speed. 


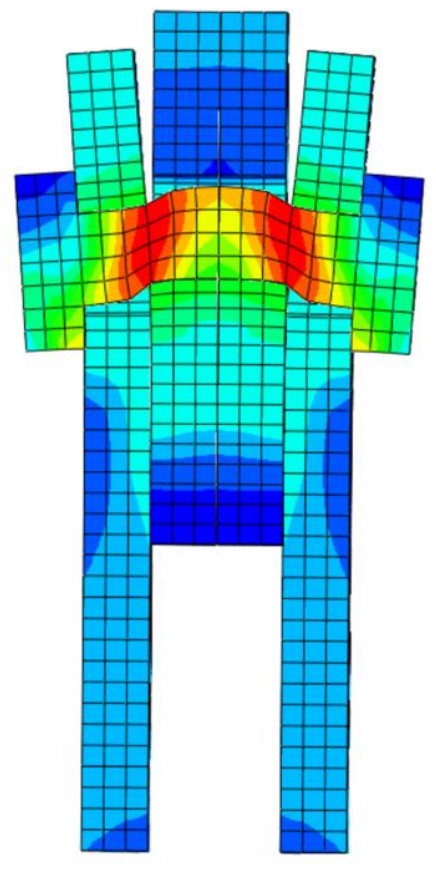

(a) 0.2 inch seeds

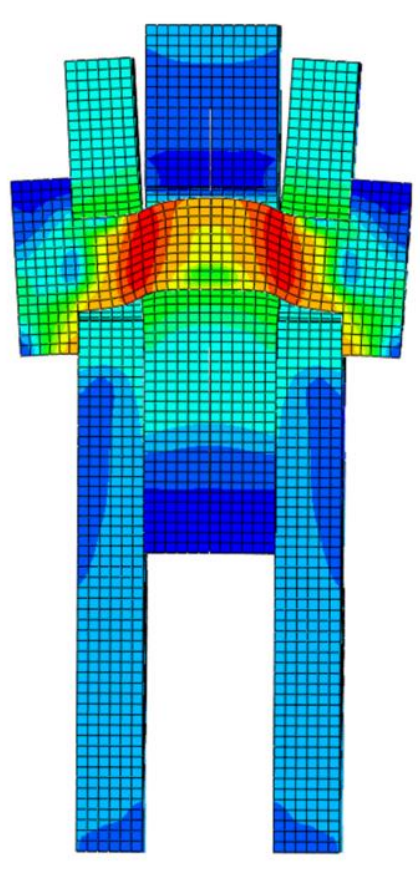

(a) 0.1 inch seeds

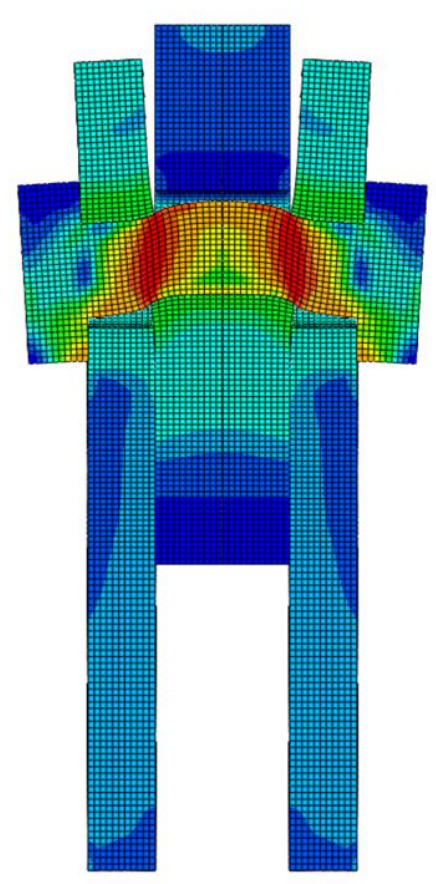

(c) 0.055 inch seeds

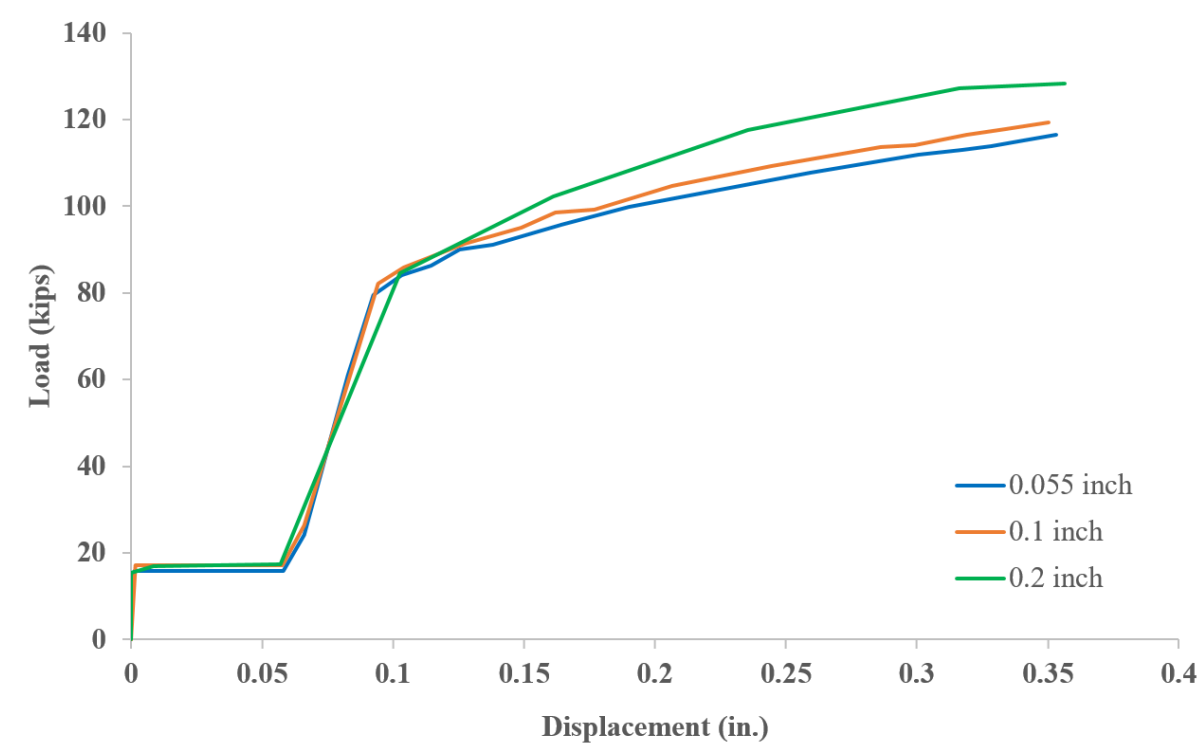

(b) Load vs. deformation

Fig. 5-8: Convergence study for a connection with no fillers. 


\subsection{Material properties}

Five different types of materials were used. The splice plates, pull plates and steel fillers in Model 1 are A572 GR50 while plastic fillers; bolts are PP and A325 respectively. In Model 2, steel A572 GR50 and A490 are used for the filler plate and bolts respectively. Steel A709 GR70 is used for the splice plate and pull plate.

All types of steel were assumed to have a modulus of elasticity around 29,600 ksi. The data obtained from the tensile test provided engineering stress-strain relationships, ABAQUS requires the material properties to be true stress-plastic strain. The following equations were used to transform the stresses and strains:

$$
\begin{gathered}
\sigma_{\text {eng }}=\frac{P}{A} \ldots \ldots \ldots \ldots \ldots \ldots \ldots \\
\sigma_{\text {True }}=\sigma_{\text {eng }} *\left(1+\varepsilon_{\text {eng }}\right) \ldots \ldots \ldots \ldots \\
\varepsilon_{\text {True }}=\ln \left(1+\varepsilon_{\text {eng }}\right) \ldots \ldots \ldots \ldots \\
\varepsilon_{\text {effective plastic }}=\varepsilon_{\text {True }}-\left(\frac{\sigma_{\text {True }}}{E}\right) .
\end{gathered}
$$

where:

$p=$ applied tensile load

$\sigma_{\text {eng }}=$ engineering stress

$\sigma_{\text {True }}=$ true stress

$\varepsilon_{\text {True }}=$ true strain

$\varepsilon_{\text {effective plastic }}=$ effective plastic strain 


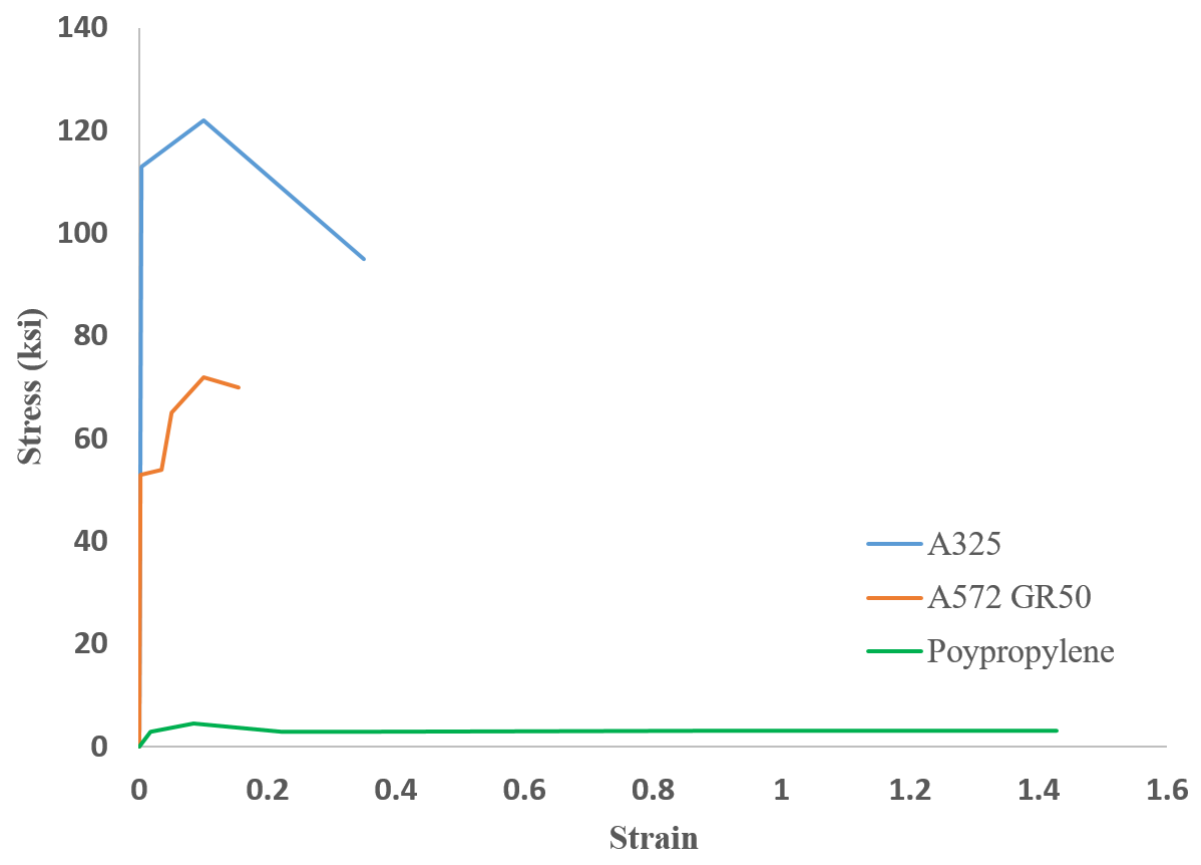

Fig. 5-9: Engineering stress-strain diagrams for used materials.

A stable time increment in ABAQUS/EXPLICIT is governed by three factors: element size, material modulus of elasticity, and material density. Increasing the element size can have a significant effect on the results because the contact between the bolt shank and the bolt hole requires a fine mesh to capture stresses accurately in that area. Otherwise, stress concentrations resulting from bearing between bolt and plates would change the results significantly. Changes of the modulus of elasticity change the element stiffness, which can lead to false results. The only factor that can be manipulated without affecting the results is material density. The reason for this is explained later in this section.

Since using the exact steel density $\left(0.009 \mathrm{lbf} \mathrm{s}^{2} / \mathrm{in}^{4}\right)$ in the FEA is very time consuming, a higher density is needed to reduce CPU time. Using a higher material density results in 
lower wave velocity. As a result, a larger time increment can be used, which reduces the running time according to the following equations:

$$
\begin{aligned}
\Delta_{t} & =\left(\frac{l}{C_{d}}\right) \ldots \ldots \ldots \ldots \ldots \ldots \ldots \\
C_{d} & =\sqrt{\frac{E}{\rho}} \ldots \ldots \ldots \ldots \ldots \ldots \ldots
\end{aligned}
$$

where:

$$
\begin{aligned}
& \Delta_{t}=\text { time increment } \\
& l=\text { element size } \\
& C_{d}=\text { wave speed } \\
& E=\text { Modulus of Elasticity } \\
& \rho=\text { material density }
\end{aligned}
$$

The equilibrium equation in ABAQUS/EXPLICIT involves the effect of inertial forces (Eq. 5.7). Since the problem is quasi-static, the acceleration is very small. Hence, the inertia force contribution is very small as well; therefore, increasing the mass within certain limits results in very small changes in the equilibrium equation. 


$$
M \ddot{\mathrm{u}}=\mathrm{P}-\mathrm{I}
$$

$$
\begin{aligned}
& \text { where: } \\
& M=\text { mass } \\
& \ddot{\mathrm{u}}=\text { acceleration } \\
& \mathrm{P}=\text { external forces } \\
& I=\text { Internal forces }
\end{aligned}
$$

\begin{abstract}
A mass sensitivity study was also conducted by using different material densities $(0.009$ and $1 \mathrm{lbf} \mathrm{s}^{2} / \mathrm{in}^{4}$ ) to illustrate the density effects. Load versus deformation for the two models is shown in Figure 5.10. The model with 1 slug/inch ${ }^{3}$ density shows a similar behavior to that of $0.009 \mathrm{lbf} \mathrm{s}^{2} / \mathrm{in}^{4}$ density. A density of $1 \mathrm{slug} / \mathrm{inch}^{3}$ was used for all FEA to save CPU time. Using this mass density increased the running time significantly.
\end{abstract}




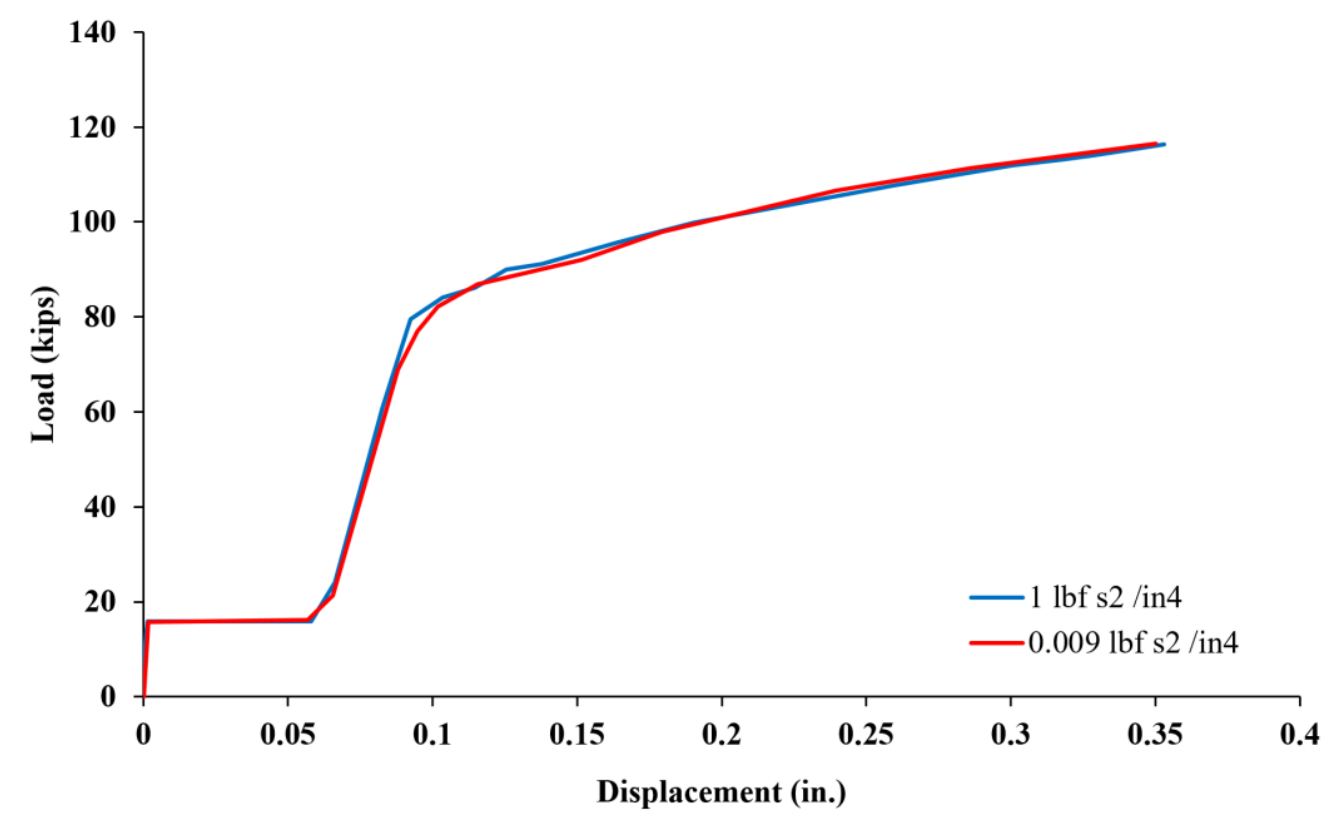

Fig. 5-10: Mass sensitivity study for a bolted connection with no fillers.

\subsection{Load and Boundary Conditions}

Since only a quarter of the connection is considered, the assembly is restrained in the $\mathrm{x}$ direction and z-direction. The end of the splice plate is restrained in all directions to resemble a fixed-end condition. A linear displacement is applied on the opposite end of the pull plate (displacement-control). The upper and lower surfaces of the filler plate are in contact with the splice plate and pull plate while it is free to move along the y-axis as shown in Fig 5-11. As mentioned earlier in section 5.3, the simulation was carried out in two steps. The first step is bolt preload modeling using ABAQUS/STANDARD. Since the bolt load is a function of the bolt area, half of the bolt load is assigned to the bolt shank using the BOLT LOAD option in the ABAQUS/STANDARD (as only half of the 
bolt area is simulated due to the symmetry). In the second step, the model with all of the stresses resulting from the bolt clamping force is transferred to the ABAQUS/EXPLICIT to assign the applied load (in terms of displacement control) on the end of the pull plate as shown in Figure 5-10.
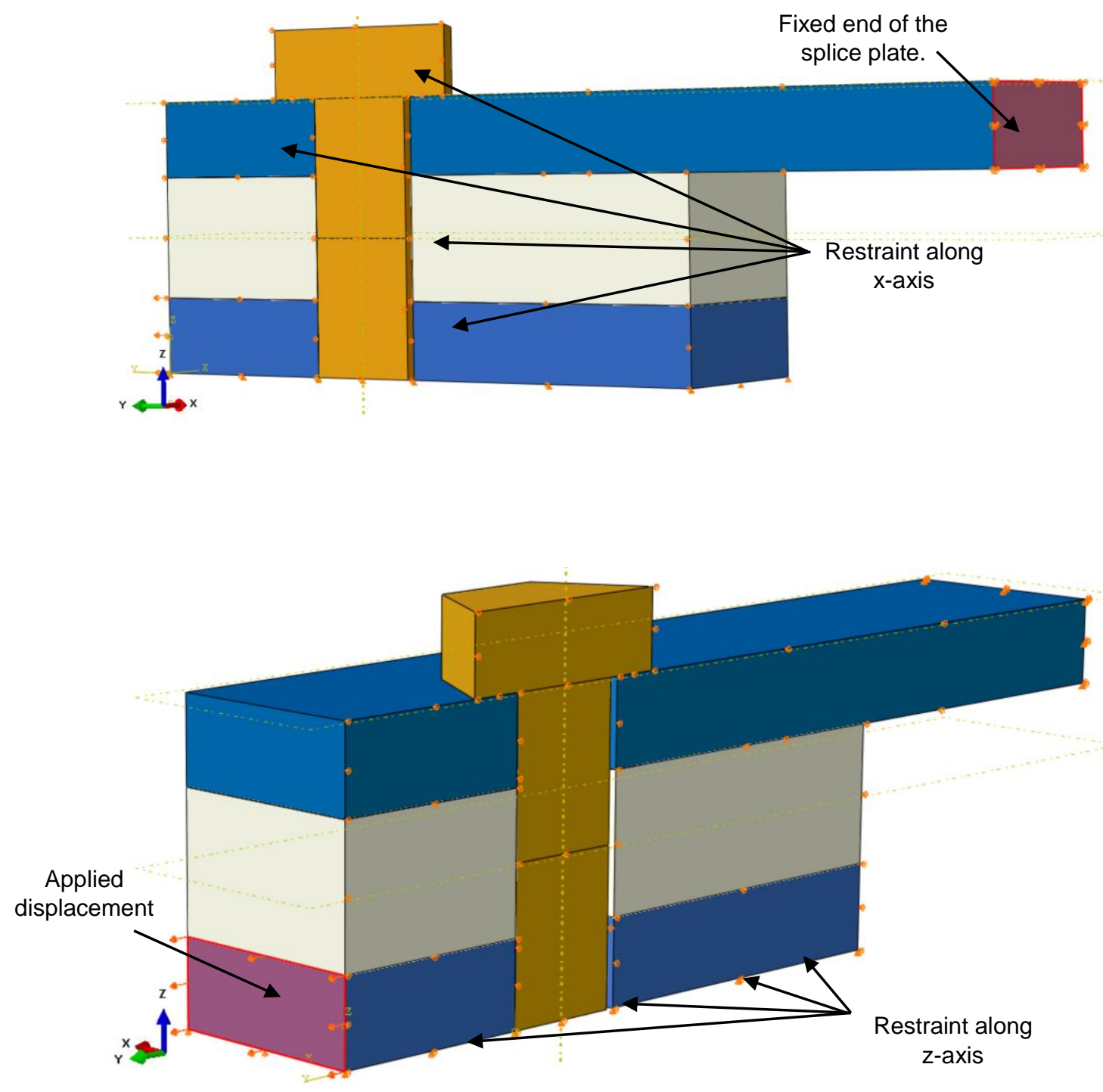

Fig. 5-11: Boundary conditions of a bolted connection with 1/2 steel filler plates. 


\section{Finite Element Analysis}

To prove the robustness of the FEA model for predicting the behavior of the bolted connection, model validation of the experimental work is required. For this purpose, eight FE sub-models were created to simulate connections with PP fillers and connections with steel fillers.

\subsection{Validation of FEA Models.}

Four FE sub-models were created and compared with the experimental tests for validation. These sub-models are summarized in Table 6.1.

Table 6-1: Details of the FEA quarter model.

\begin{tabular}{|c|c|c|c|c|c|c|c|c|c|}
\hline \multirow[t]{3}{*}{ Model } & \multirow{3}{*}{$\begin{array}{l}\text { Sub- } \\
\text { Model }\end{array}$} & \multicolumn{2}{|c|}{ Bolt } & \multicolumn{6}{|c|}{ Plates } \\
\hline & & \multirow[t]{2}{*}{ Type } & \multirow{2}{*}{$\begin{array}{c}\text { Length } \\
\text { (in.) }\end{array}$} & \multicolumn{2}{|c|}{ Filler plate } & \multicolumn{2}{|c|}{ Pull plate } & \multicolumn{2}{|c|}{ Splice plate } \\
\hline & & & & Material & $\begin{array}{c}\mathrm{T} \\
\text { (in.) }\end{array}$ & Material & $\begin{array}{c}\mathrm{T} \\
\text { (in.) }\end{array}$ & Material & $\begin{array}{c}\mathrm{T} \\
\text { (in.) }\end{array}$ \\
\hline \multirow{4}{*}{1} & 1 & $\begin{array}{c}7 / 8 \\
\text { A325x }\end{array}$ & 1.25 & - & - & $\begin{array}{l}\text { A572 } \\
\text { GR50 }\end{array}$ & 0.625 & $\begin{array}{l}\text { A572 } \\
\text { GR50 }\end{array}$ & 0.625 \\
\hline & 2 & $\begin{array}{c}7 / 8 \\
\text { A325x }\end{array}$ & 1.75 & A572 GR50 & 0.5 & $\begin{array}{l}\text { A572 } \\
\text { GR50 }\end{array}$ & 0.625 & $\begin{array}{l}\text { A572 } \\
\text { GR50 }\end{array}$ & 0.625 \\
\hline & 3 & $\begin{array}{c}7 / 8 \\
\text { A325x }\end{array}$ & 1.75 & Polypropylene & 0.5 & $\begin{array}{l}\text { A572 } \\
\text { GR50 }\end{array}$ & 0.625 & $\begin{array}{l}\text { A572 } \\
\text { GR50 }\end{array}$ & 0.625 \\
\hline & 4 & $\begin{array}{c}7 / 8 \\
\text { A325x }\end{array}$ & 2.25 & Polypropylene & 1 & $\begin{array}{l}\text { A572 } \\
\text { GR50 }\end{array}$ & 0.625 & $\begin{array}{l}\text { A572 } \\
\text { GR50 }\end{array}$ & 0.625 \\
\hline
\end{tabular}

The resistance load was recorded at the fixed end of the splice plate while the displacement was recorded at the free end of the pull plate as shown in Fig. 5-11. Load versus connection deformation curves for both experimental as well as FEA results are shown in Figs. 6-1, 6-2, 6-3 and 6-4 for comparison. Bolt failure was considered when 
the equivalent plastic strain of the innermost element reached the ultimate plastic stain of the tensile stress test of 0.29. In general, the FEA was able to capture frictional bearing behavior before the slip well but after that it started to diverge until the plastic deformation region started. This may be attributed to two different reasons: the first one is the use of DTI washers. The second reason may be that the hour glass control added more stiffness to the elements. Overall, the FE model was still able to capture the overall behavior and important features such as deformation at 0.25 -inch and ultimate strength.

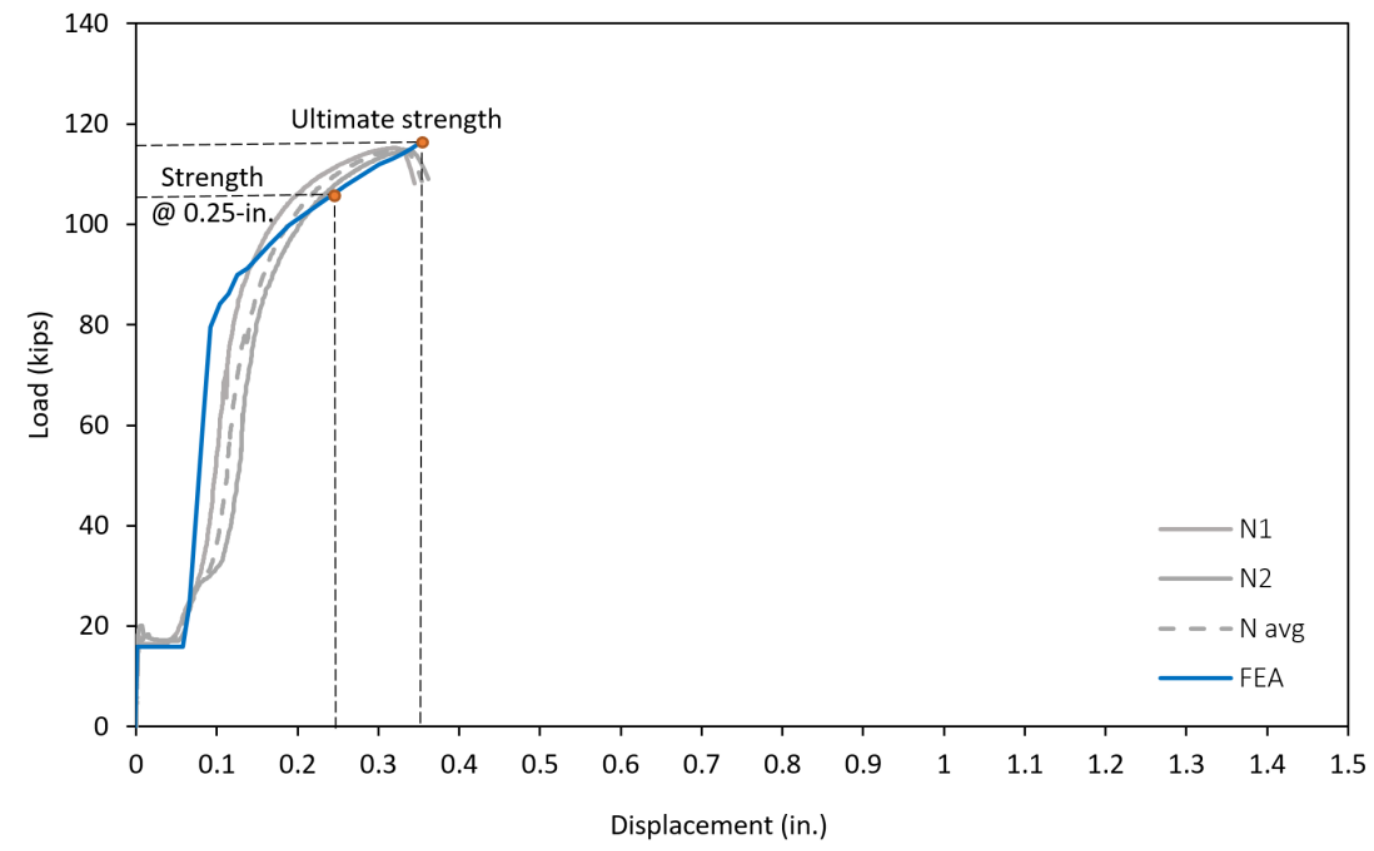

Fig. 6-1: FEA and experimental results for load-deformation curves for no-filler specimen. 


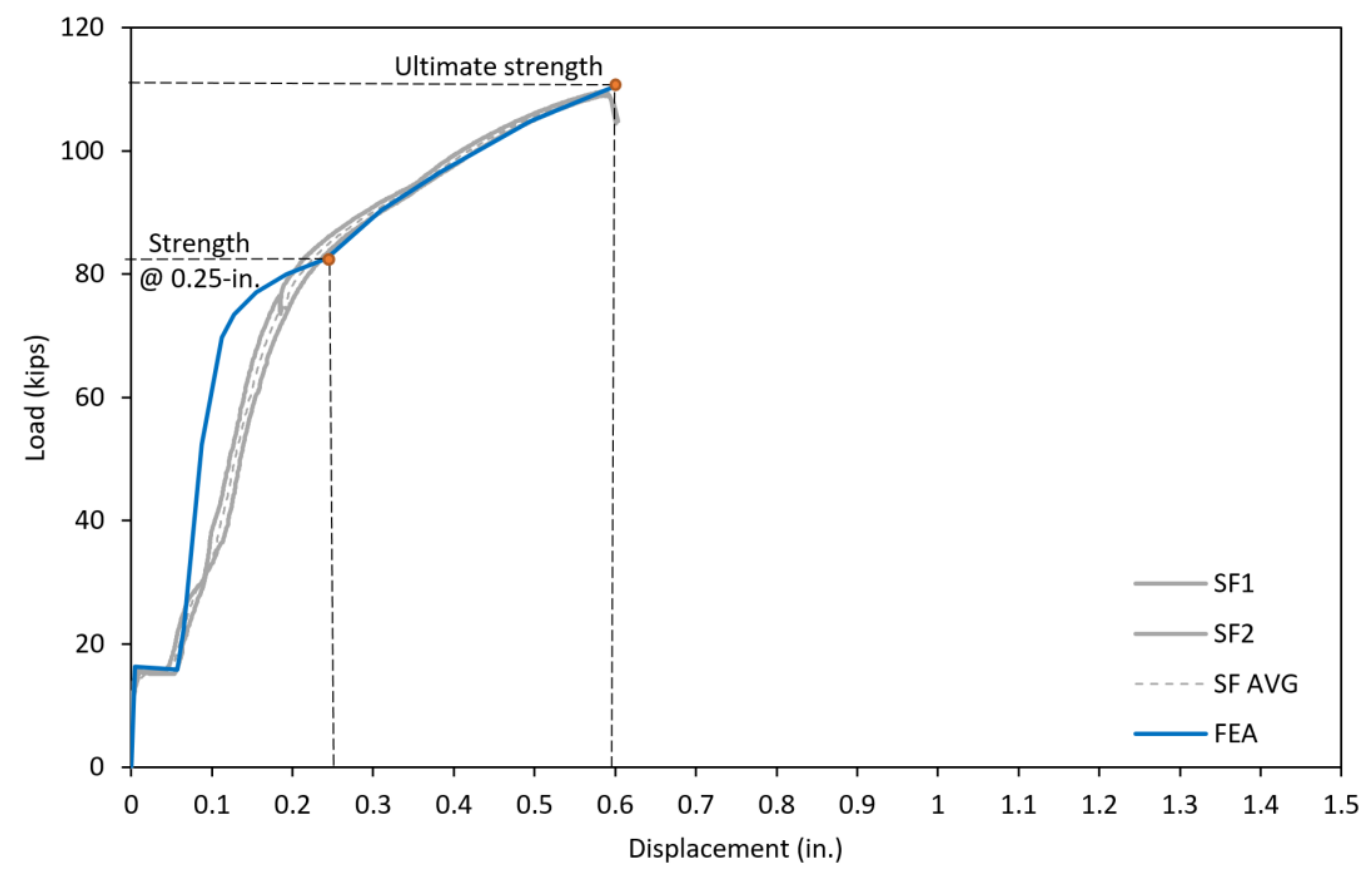

Fig. 6-2: FEA and experimental results for load-deformation curves for $1 / 2$ " steel filler plate specimen.

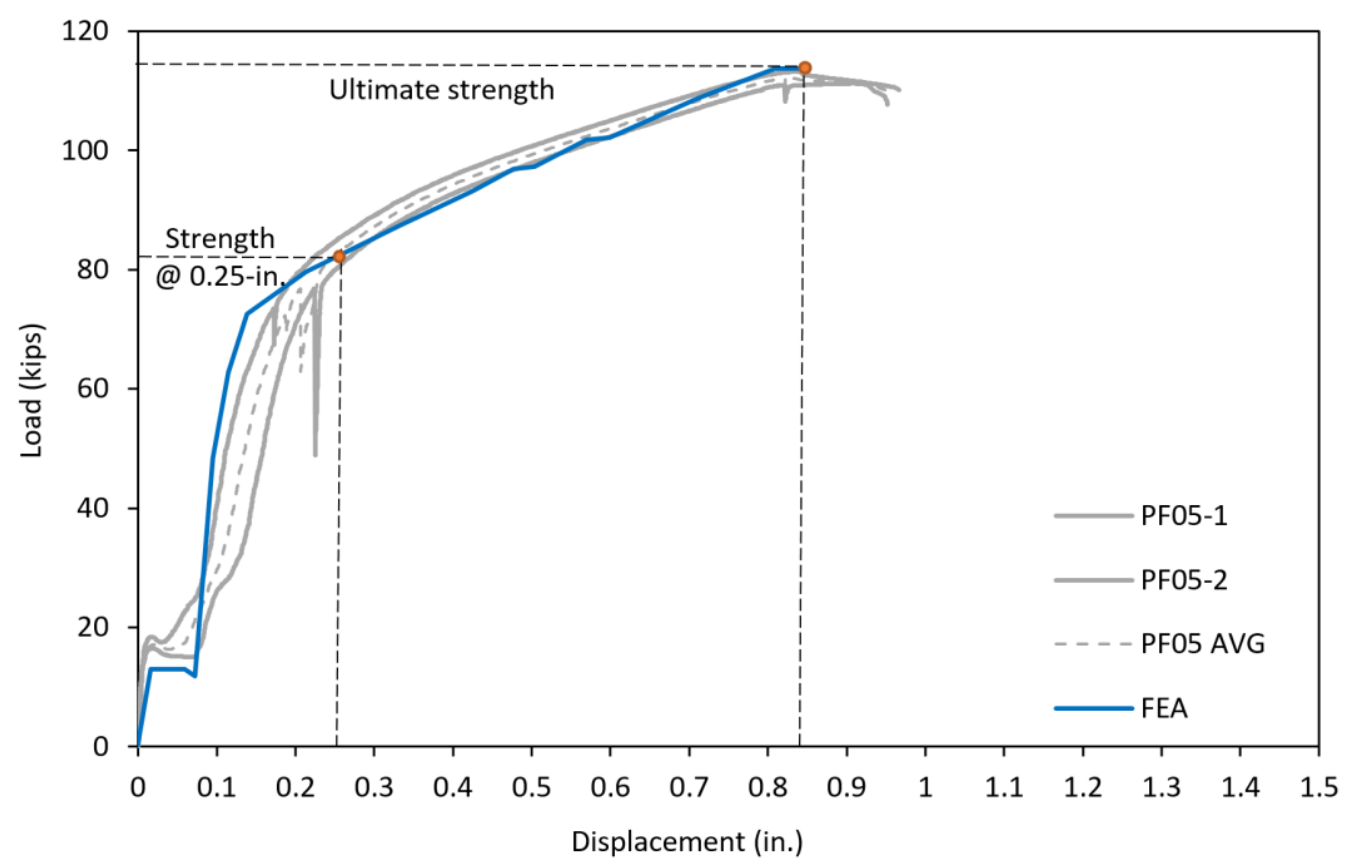

Fig. 6-3: FEA and experimental results for load-deformation curves for $1 / 2$ PP filler plate specimen. 


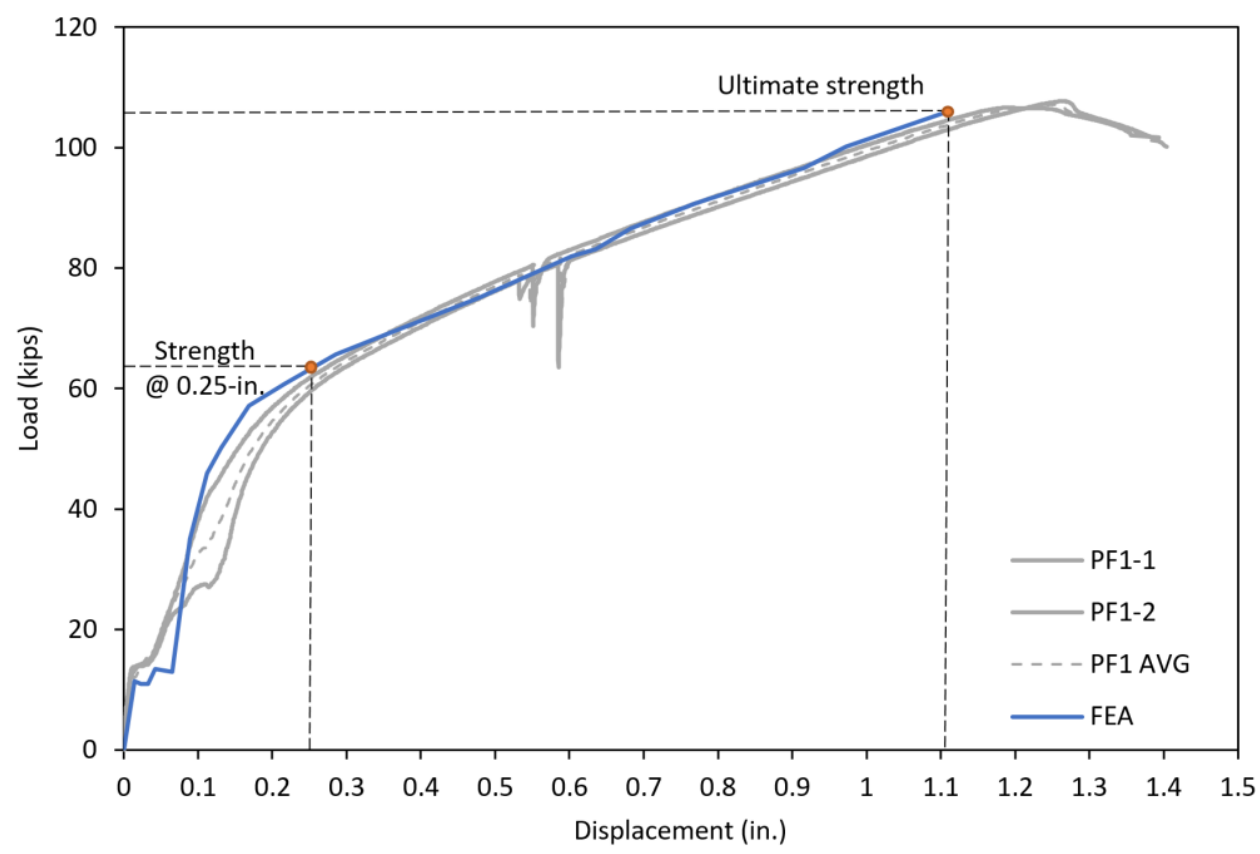

Fig. 6-4: FEA and experimental results for load-deformation curves for 1" PP filler plate specimen.

Fig. 6-5 shows a comparison between the ultimate connection strengths (experimental as well as FEA) for all test specimens. For the no-filler connection, the FEA predicted a $1.19 \%$ higher ultimate strength than the average of the experimental test, while for $1 \frac{1}{2}$ inch steel fillers, the FEA predicted a $1.1 \%$ higher strength than the experimental test. For connections with PP filler plates, the FEA model predicted a 1.3\% higher ultimate strength than the experiment for $1 / 2$-inch filler, while a $1.1 \%$ lower strength is predicted for 1-inch filler plates. 


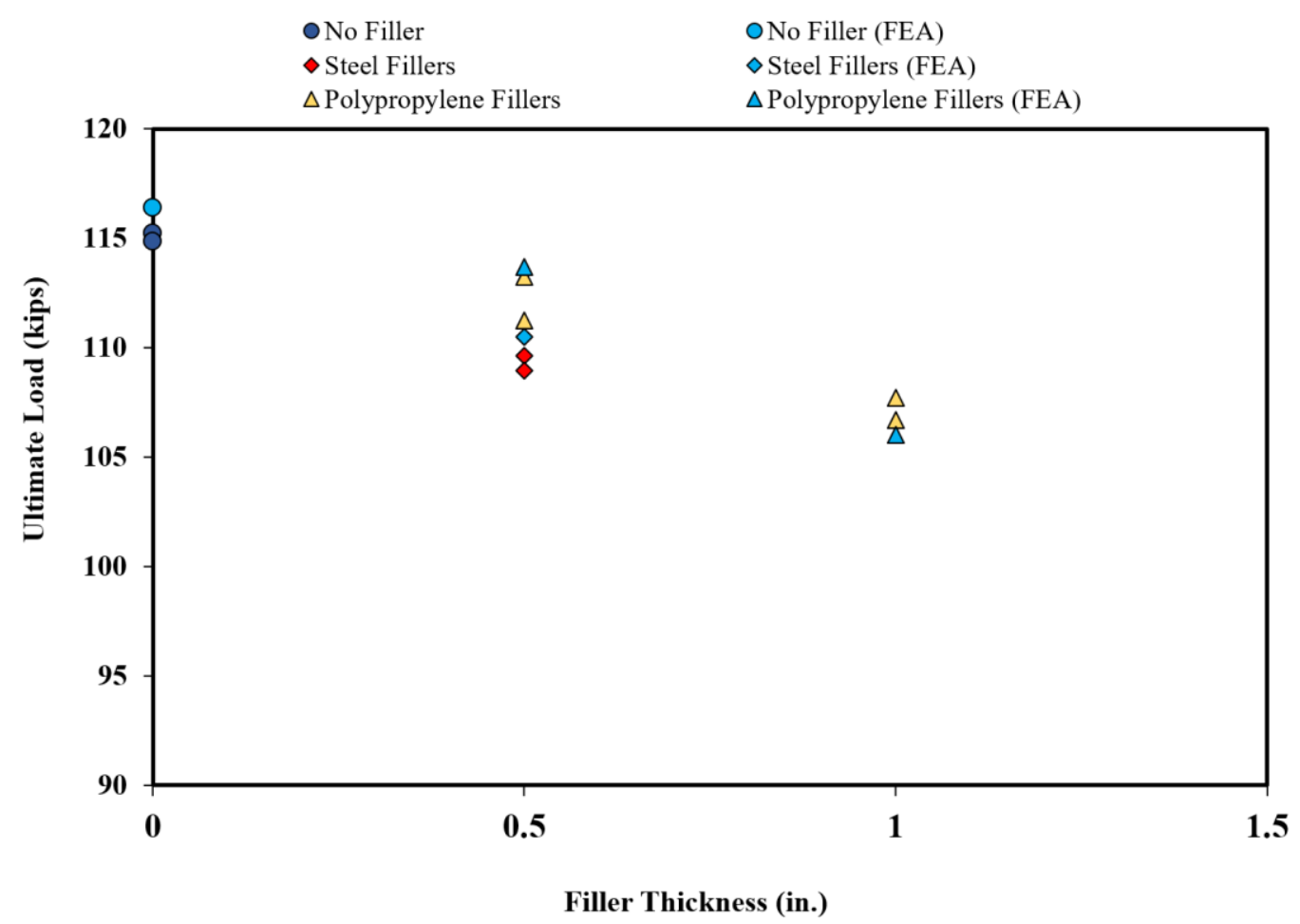

Fig. 6-5: Comparison of ultimate connections strength for all test specimens. Both experimental and FEA results are shown for comparison.

The load at 0.25 -inch deformation was also extracted from the FEA model and compared to the experimental results, as shown in Fig. 6-6. It was found that the FE model predicted a $2.7 \%$ lower ultimate strength than what was observed from the experiment for no-filler connection. The FEA model predicted exactly the same ultimate connection strength for the specimen with $1 / 2$ inch PP filler plates. For the 1 inch PP filler plate specimen, the FEA predicted a $2.04 \%$ higher strength than the experimental counterpart. For $1 / 2$ inch steel filler, the FEA predicts a $3.65 \%$ lower strength than the experiment. 


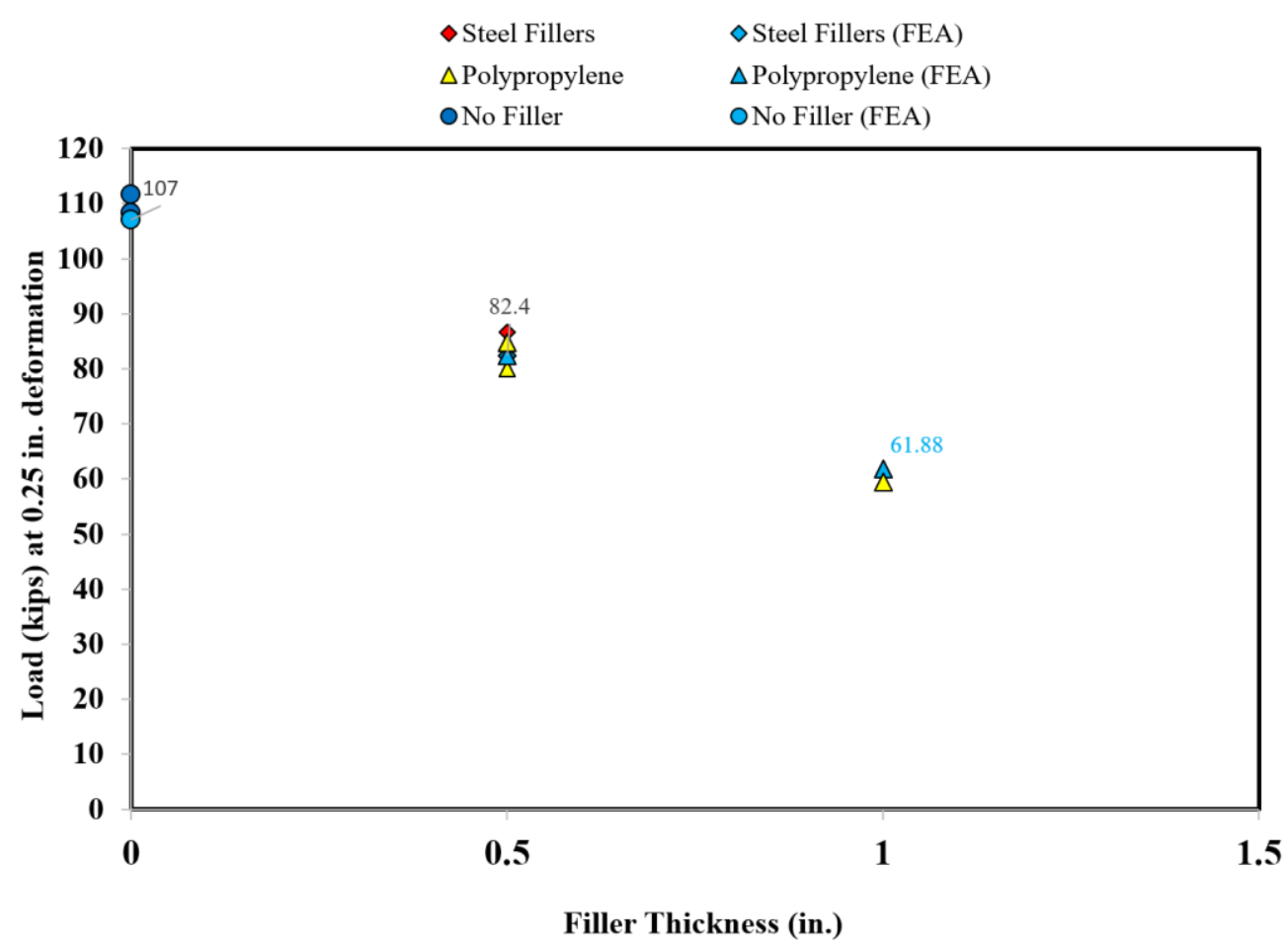

Fig. 6-6: Comparison of force in connection at 0.25 inch deformation for all test specimens. Both experimental and FEA results are shown for comparison.

Fig. 6-7 shows an example of a deformed connection with 1-inch PP filler plates upon failure. The plastic deformations and the failure of the bolts from the FEA is compared to the test in Fig. 6-8. The FEA results show similar shear planes to what was observed in the experimental test. For connections with no fillers, the bolt was subjected to pure shear force represented by the shear planes between the pull-plates and splice-plates. The presence of steel fillers added two more shear planes to the bolt. The presence of these shear planes was not simultaneous. The first shear plane (1 and 2) occurred between the splice plates and the pull plates after the slip, as shown in Fig. 6-9(a), and is represented 
by the diagonal dashed lines. The second shear planes ( 3 and 4 ) occurred later at a deformation of 0.3 inches, between the filler and pull-plate. The failure of the bolt occurred through the second shear plane at a deformation of 0.6 inches.

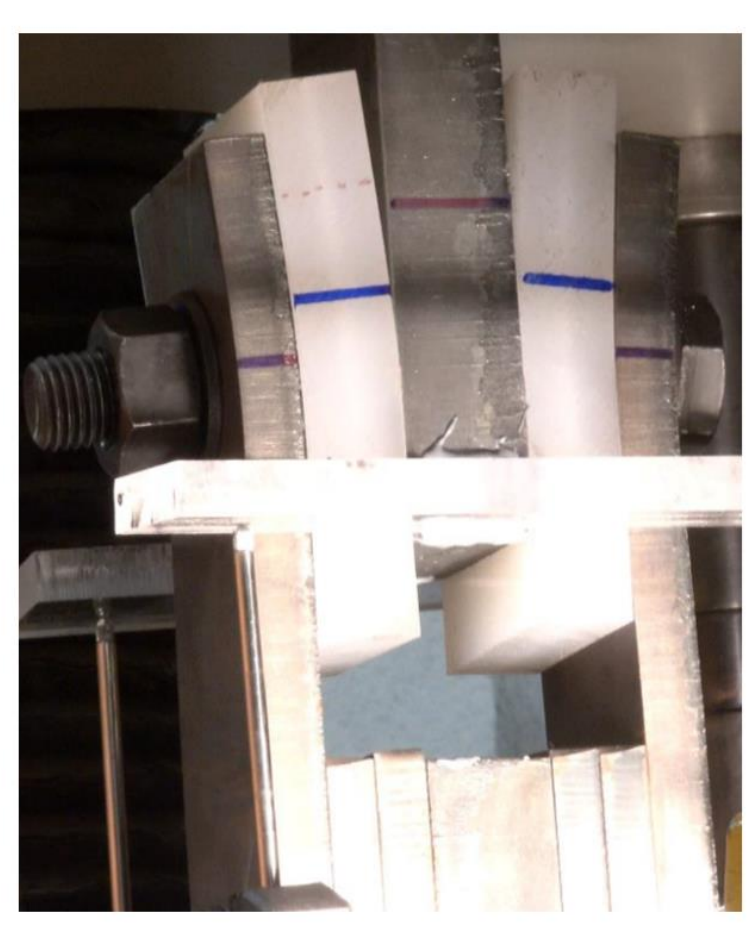

(a)

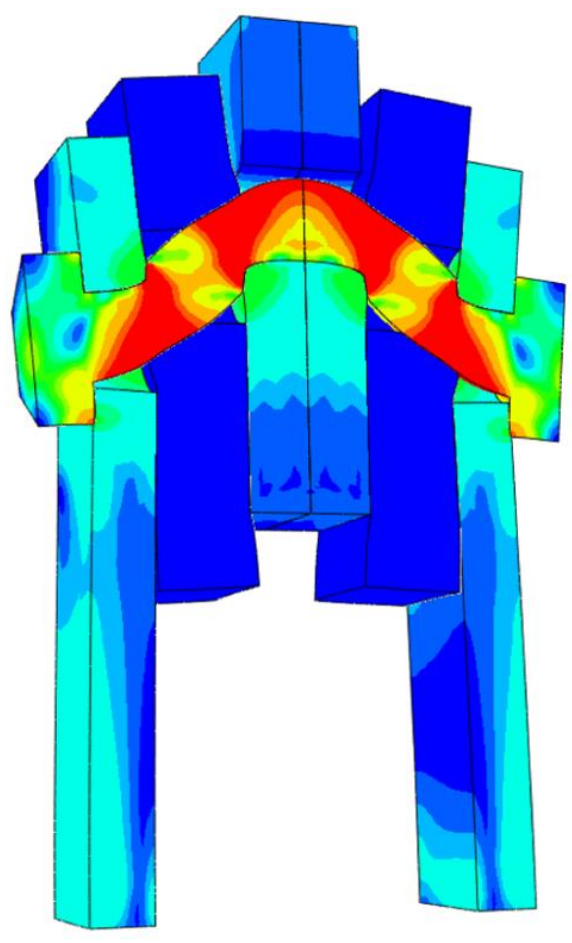

(b)

Fig. 6-7: Example of (a) test specimen and (b) corresponding FEA model at ultimate connection strength. 


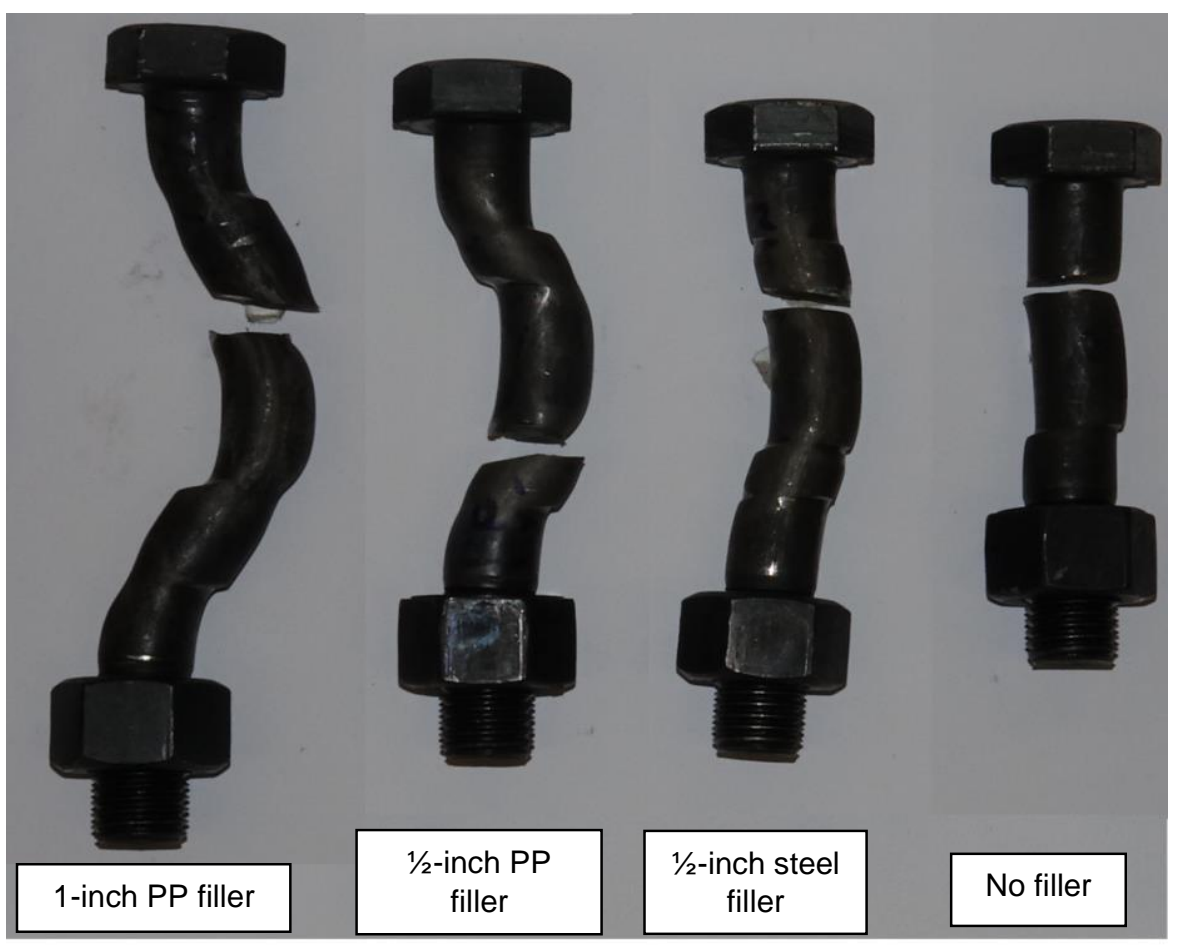

(a)
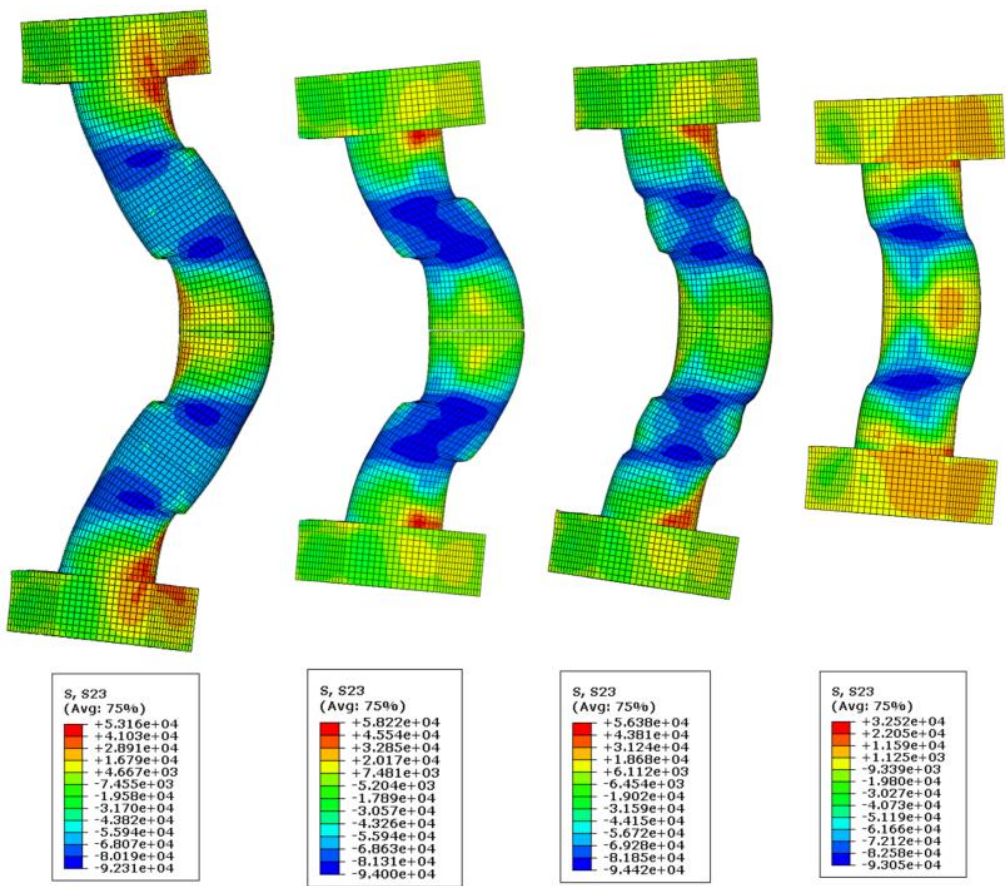

(b)

Fig. 6-8: Example of (a) bolt and (b) corresponding FEA model at ultimate connection strength. 


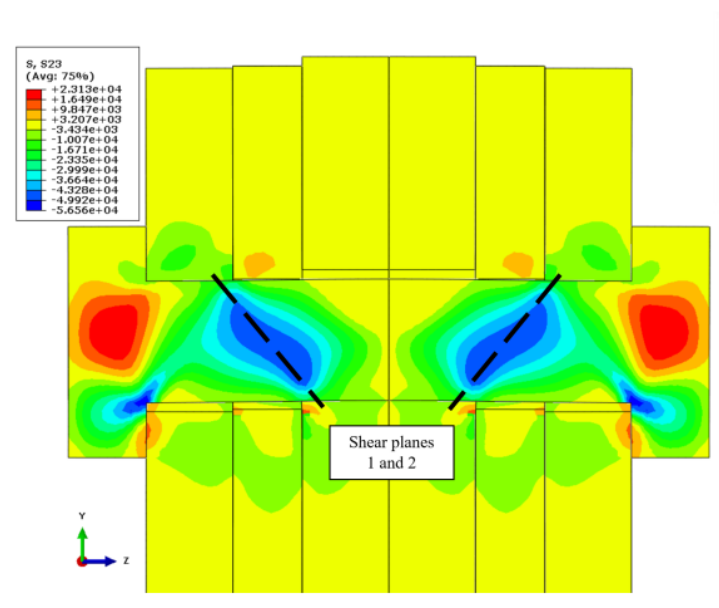

(a)

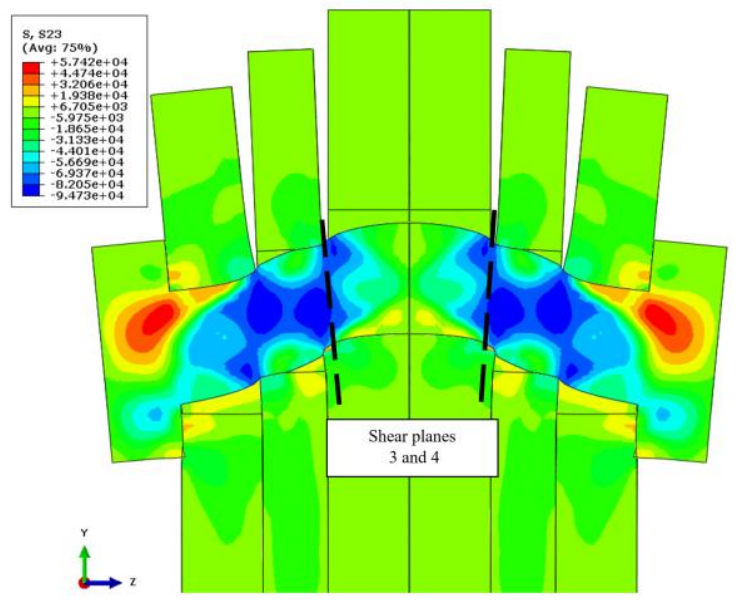

(b)

Fig. 6-9: Example of connection with 1/2-inch steel fillers shows:

(a) Shear planes at bearing. (b) Shear planes at failure.

Like steel fillers, shear planes in connections with PP fillers occurred first between the pull plates and splice plates and later failure occurred between the fillers and the pull plates. The presence of PP fillers distributed the shear stresses on a larger portion of the bolt because they experienced more bearing deformation at the bolt hole, which resulted in a larger contact area between the bolt hole and the bolt shank unlike the connection with steel fillers (Fig. 6-10). However, bolts in connections with fillers resisted the load through two mechanisms: catenary mechanism and shear in the bolt. In the catenary mechanism the bolt resists the load through the vertical component of the axial forces that develop in the bolt due to bolt bending as shown in Fig. 6-11. When the bolt deforms, bending stresses build up in the bolt and bolt failure is a combination of bending stresses and shear stresses. Since bolts in connections with PP fillers expressed more deformation than connection with steel fillers, bolts in connection with PP fillers experienced larger 
bending stresses and this is why it showed lower strength than connections with steel fillers. On the other hand, connections with steel fillers showed higher strength because the bolt engaged in shear faster than connections with PP fillers did.

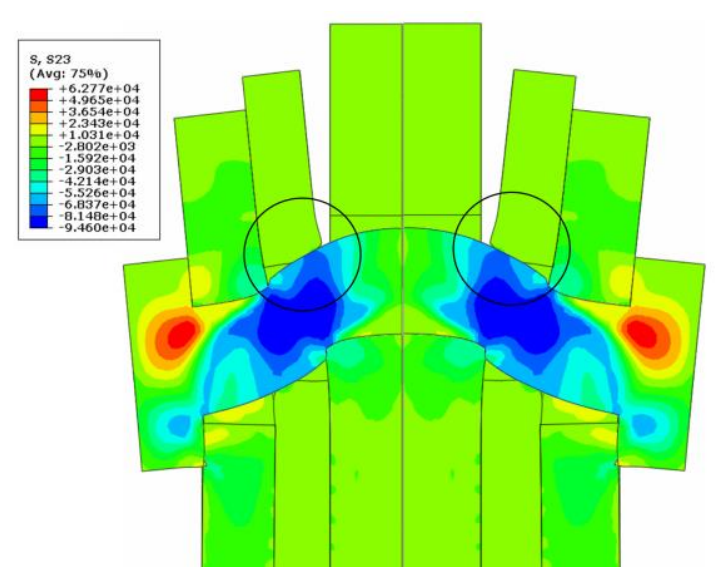

(a)

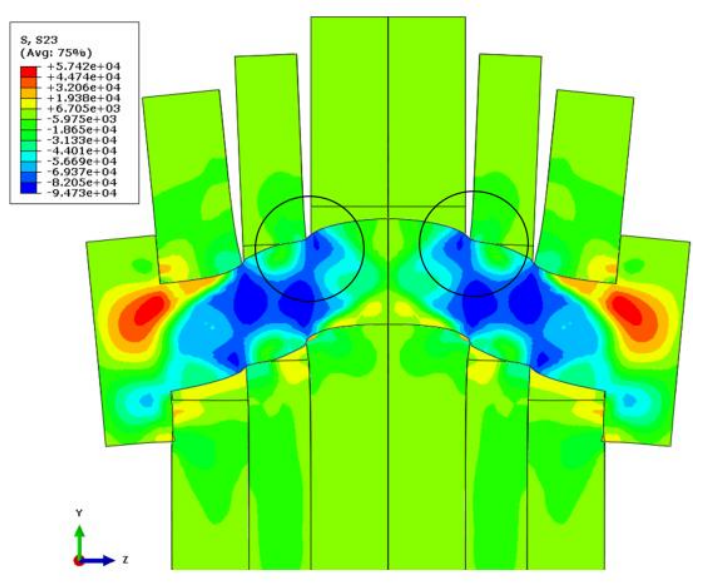

(b)

Fig. 6-10: Example of connections with 1/2-inch fillers shows the deformation in the bolt hole of: (a) PP fillers (b) Steel fillers.

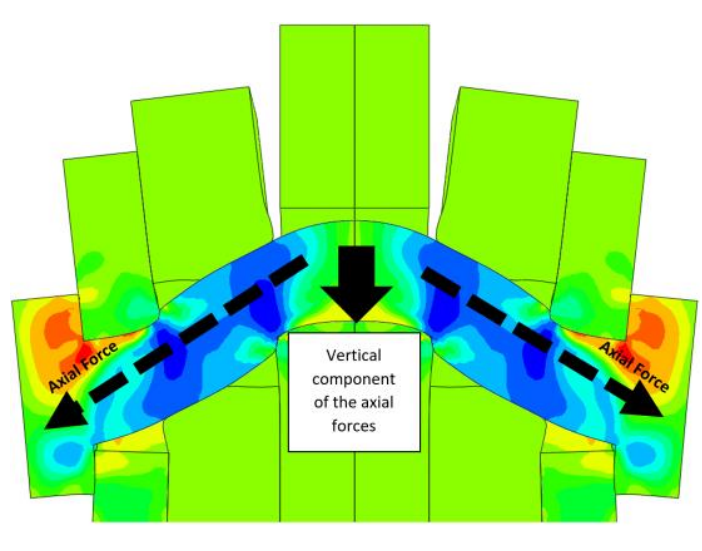

(a)

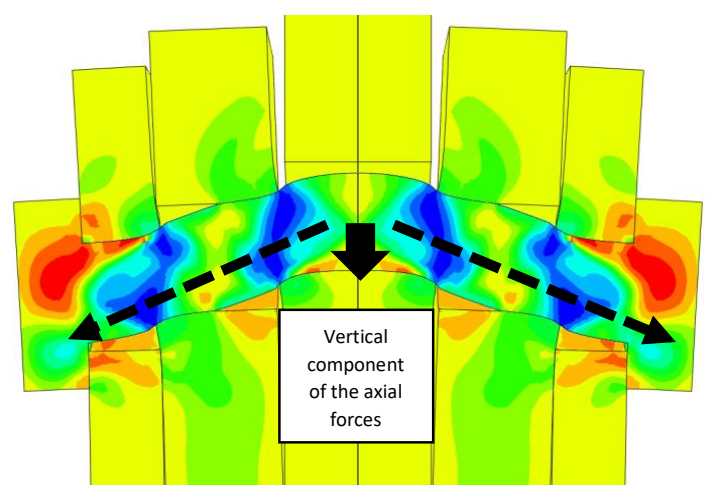

(b)

Fig. 6-11:Catenary mechanism: (a) PP fillers (b) Steel fillers. 


\subsection{Validation of FEA Models for Steel Filler Plates}

To evaluate the FEA model's ability to predict the behavior of other bolted connection configurations, additional FEA simulations were run and compared with the tests performed by Dusicka (2010). Four FEA sub-models were created to simulate connections with steel fillers. These four models are summarized in Table 6-2.

A plot of ultimate load vs. connection deformation was constructed for each FEA simulation and then compared with the experimental results. The load was recorded at the fixed end of the splice plate while the displacement was read at the point of the load application at the end of the pull plate. Bolt failure was considered when the equivalent plastic strain of the innermost element reached the ultimate plastic stain of the tensile stress test (0.18).

Table 6-2: Details of the FEA models used for model validation.

\begin{tabular}{|c|c|c|c|c|c|c|c|c|}
\hline \multirow[t]{3}{*}{ Model } & \multicolumn{2}{|c|}{ Bolt } & \multicolumn{6}{|c|}{ Plates } \\
\hline & \multirow[t]{2}{*}{ No. } & \multirow[t]{2}{*}{ Type } & \multicolumn{2}{|c|}{ Filler plate } & \multicolumn{2}{|c|}{ Pull plate } & \multicolumn{2}{|c|}{ Splice plate } \\
\hline & & & Material & $\begin{array}{l}\text { Dimensions } \\
\text { (in.) }\end{array}$ & Material & $\begin{array}{c}\text { Dimensions } \\
\text { (in.) }\end{array}$ & Material & $\begin{array}{c}\text { Dimensions } \\
\text { (in.) }\end{array}$ \\
\hline 1 & 1 & $\begin{array}{c}7 / 8 \\
\text { A325x }\end{array}$ & - & - & $\begin{array}{l}\text { A709 } \\
\text { GR70 }\end{array}$ & $\begin{array}{c}2.5 \times 1.5 \times \\
0.875\end{array}$ & A709 GR70 & $\begin{array}{c}2.5 \times 1.5 \times \\
1.125\end{array}$ \\
\hline 2 & 1 & $\begin{array}{c}7 / 8 \\
\text { A325x }\end{array}$ & $\begin{array}{l}\text { A572 } \\
\text { GR50 }\end{array}$ & $\begin{array}{c}2.5 \times 1.5 \times \\
0.5\end{array}$ & $\begin{array}{l}\text { A709 } \\
\text { GR70 }\end{array}$ & $\begin{array}{c}2.5 \times 1.5 \times \\
0.875\end{array}$ & A709 GR70 & $\begin{array}{c}2.5 \times 1.5 \times \\
1.125\end{array}$ \\
\hline 3 & 1 & $\begin{array}{c}7 / 8 \\
\text { A325x }\end{array}$ & $\begin{array}{l}\text { A572 } \\
\text { GR50 }\end{array}$ & $2.5 \times 1.5 \times 1$ & $\begin{array}{l}\text { A709 } \\
\text { GR70 }\end{array}$ & $\begin{array}{c}2.5 \times 1.5 \times \\
0.875\end{array}$ & A709 GR70 & $\begin{array}{c}2.5 \times 1.5 \times \\
1.125\end{array}$ \\
\hline 4 & 1 & $\begin{array}{c}7 / 8 \\
\text { A325x }\end{array}$ & $\begin{array}{l}\text { A572 } \\
\text { GR50 }\end{array}$ & $2.5 \times 1.5 \times 2$ & $\begin{array}{l}\text { A709 } \\
\text { GR70 }\end{array}$ & $\begin{array}{c}2.5 \times 1.5 \times \\
0.875\end{array}$ & A709 GR70 & $\begin{array}{c}2.5 \times 1.5 \times \\
1.125\end{array}$ \\
\hline
\end{tabular}


Figure (6-12) shows load versus deformation for connections with different filler plates.

Load-deformation curves were compared the FEA in Fig. 6-13, Fig. 6-14 and Fig. 6-15. with the following observations:

- $\quad$ FEA results closely match the experimental results in the case of steel fillers.

- In the case of no fillers, FEA predicts a 7.7\% lower strength than the experimental values.

- For most of the steel fillers, the FEA showed larger deformation but very close ultimate strength compared with those obtained by the experimental values.

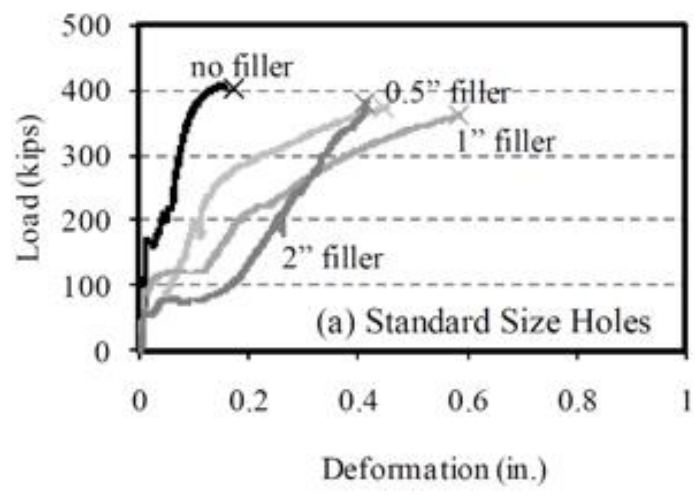

(a) Experimental results From Dusicka and Lewis (2010).

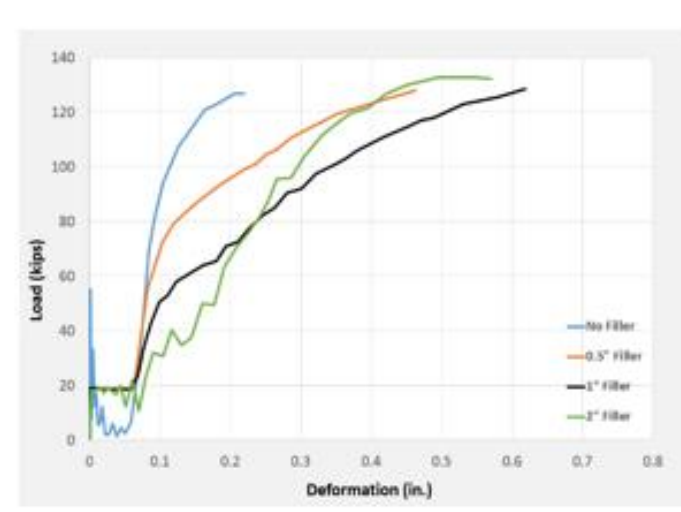

(b) FEA results for 1-bolt assemblies.

Fig. 6-12: load vs deformation for four assemblies with different filler thicknesses.
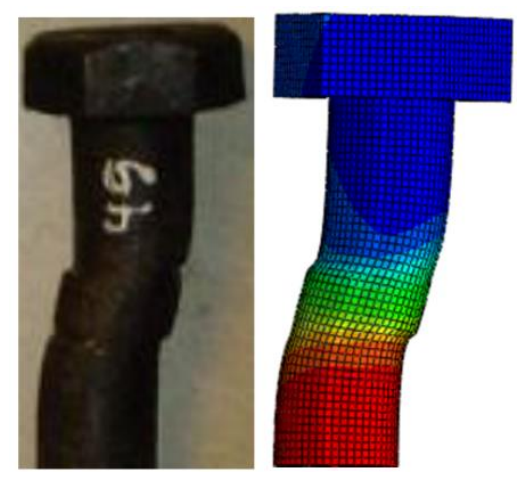

(a) Failed bolt.

(b) FEA model.

Fig. 6-13: Bolt deformation of connection with $1 / 2$ inch steel filler plates. 


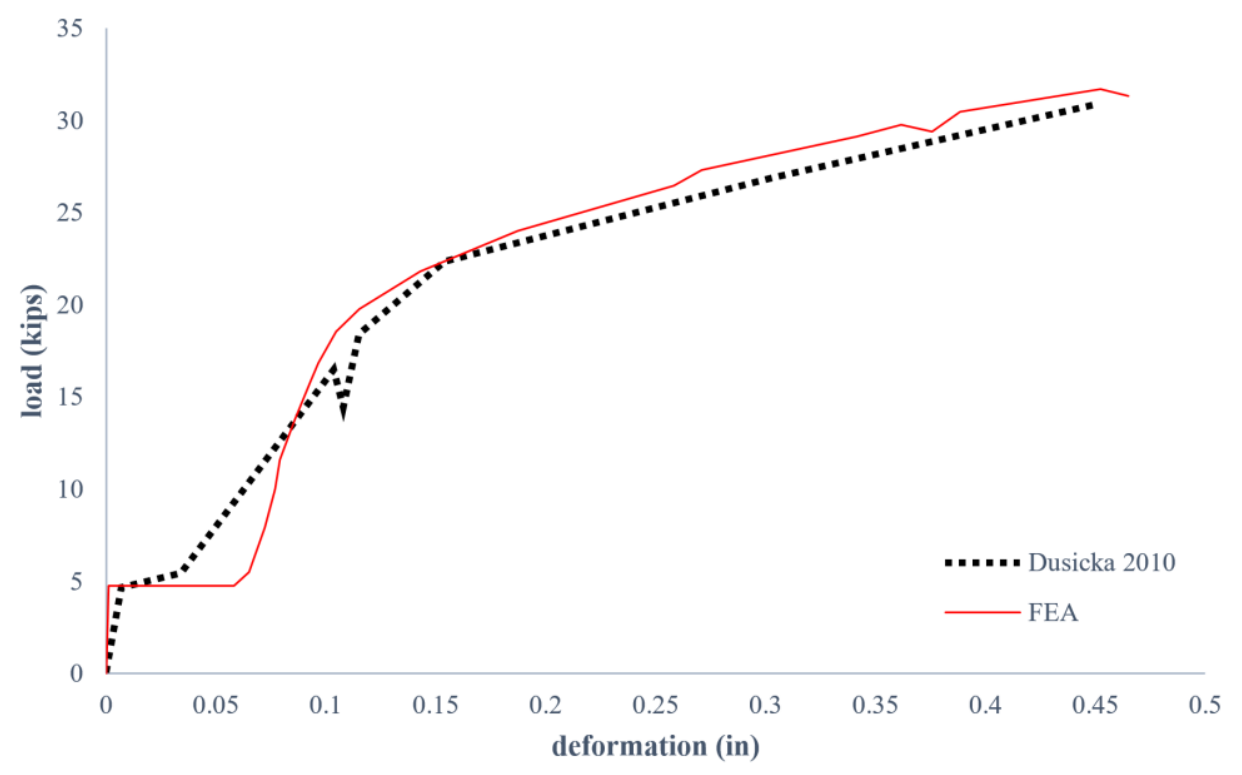

Fig. 6-14: Connection with $1 / 2$ inch steel filler plates.

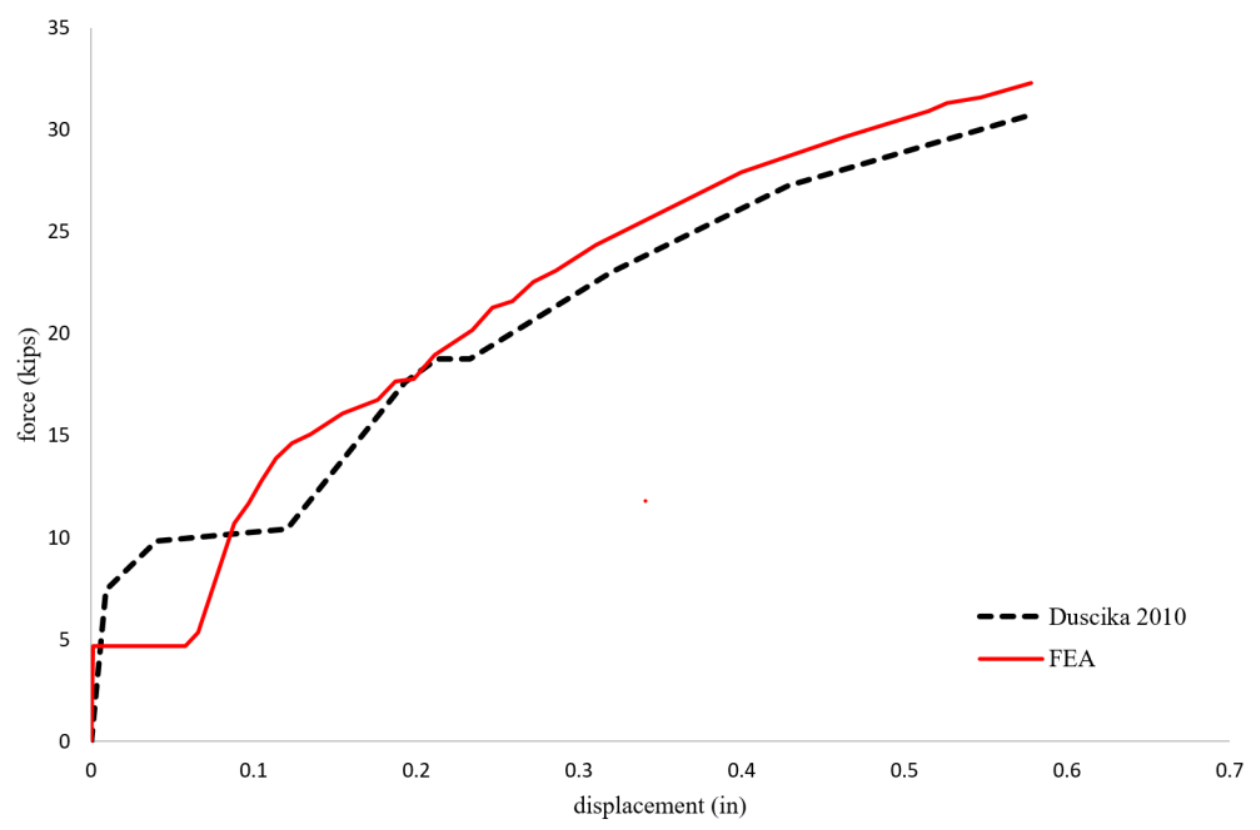

Fig. 6-15: Connection with 1 inch steel filler plates. 


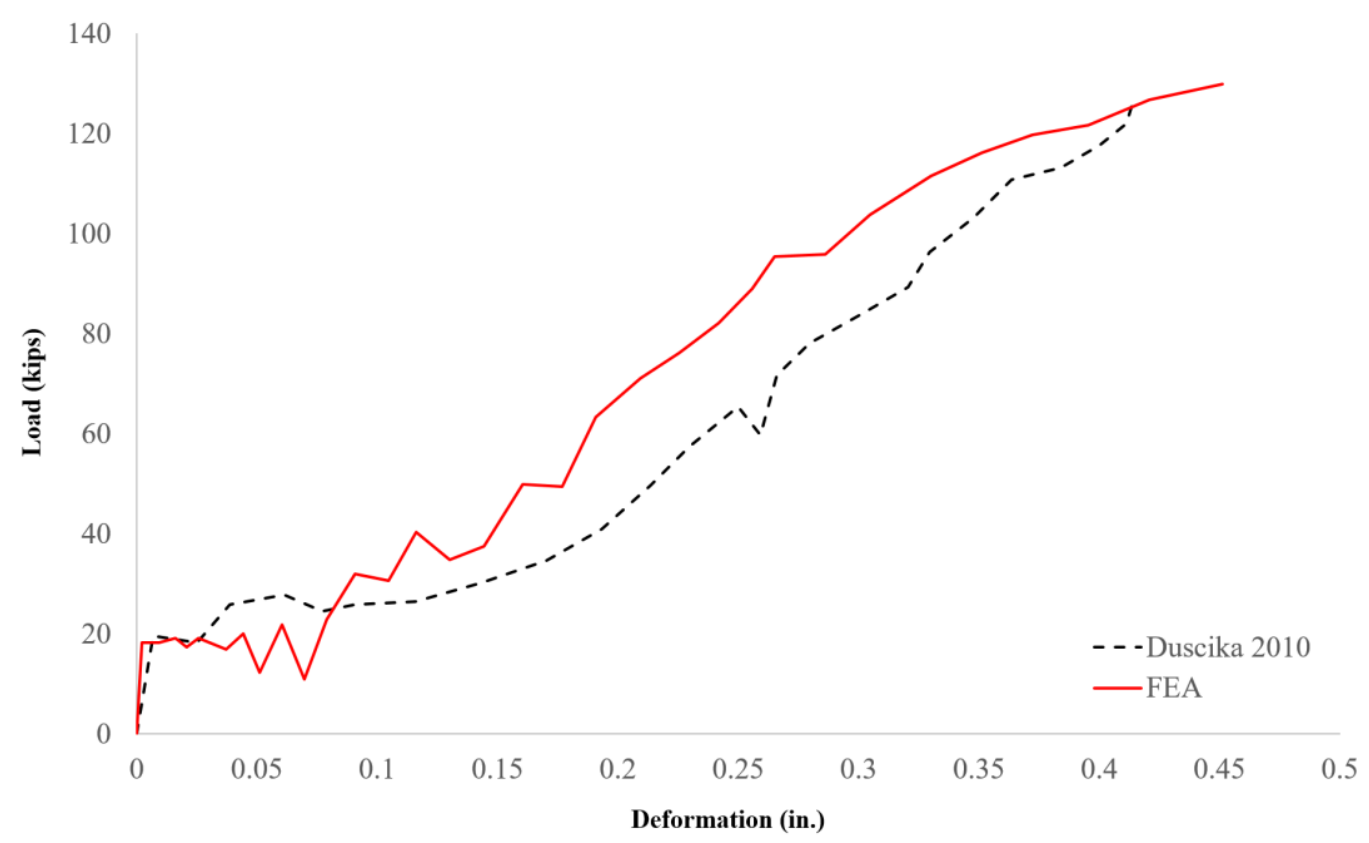

Fig. 6-16: FEA results for assemblies with 2 steel filler. 


\subsection{Comparison with Code Design Equation}

Ultimate strengths of connections with steel filler plates of 1 and 2 inch thickness and 2 inch thick PP filler plates were predicted using the FEA model and compared to the Code Design Equation (Eq. 4.1). Ultimate strength and load at 0.25 inch deformation were normalized to the ultimate strength of the connection with no fillers and compared to Eq. 4.2, 4.3 and 443 in Figs 6-17, 6-18, and 6-19.

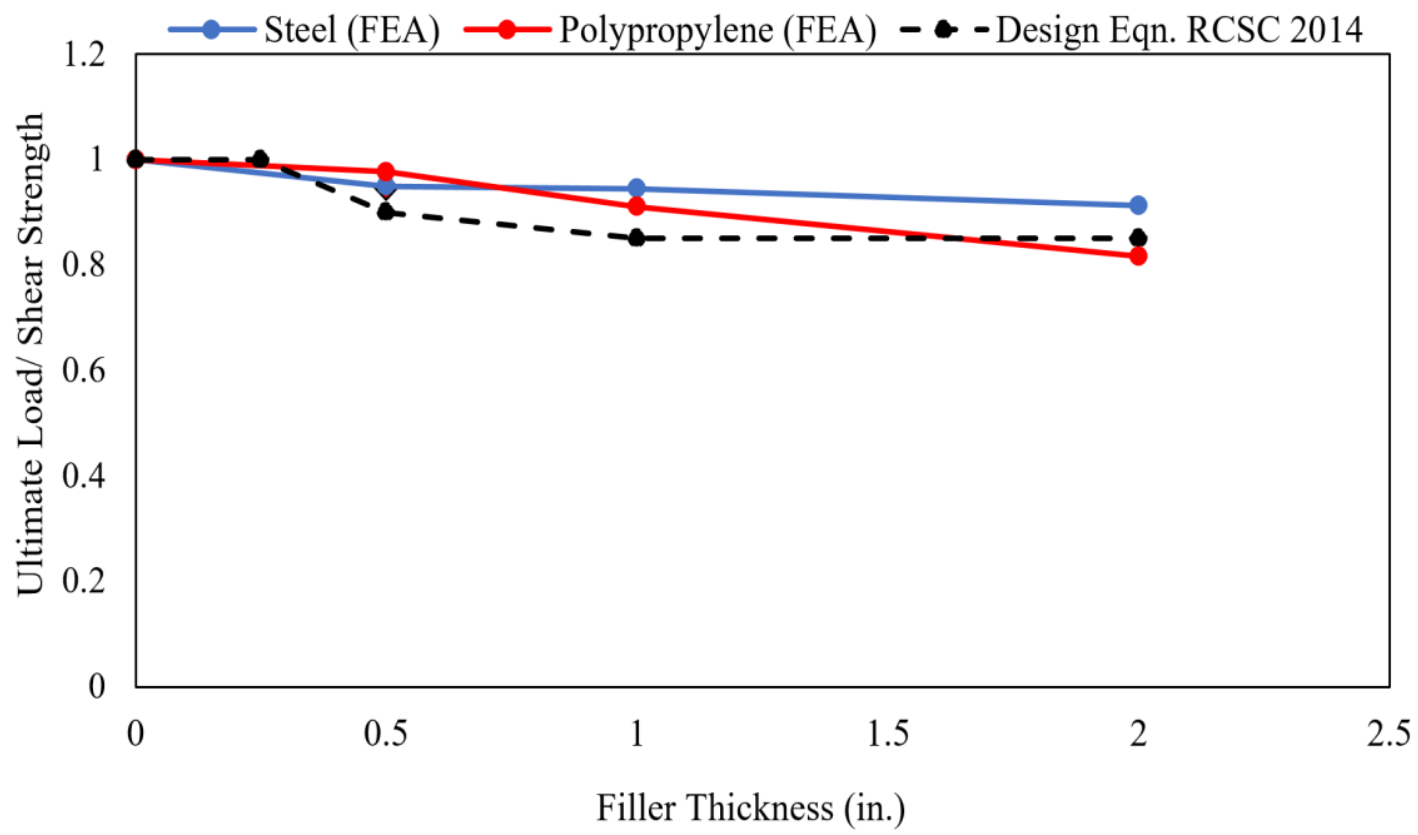

Fig. 6-17: Normalized ultimate strength and design equation (RCSC 2014). 


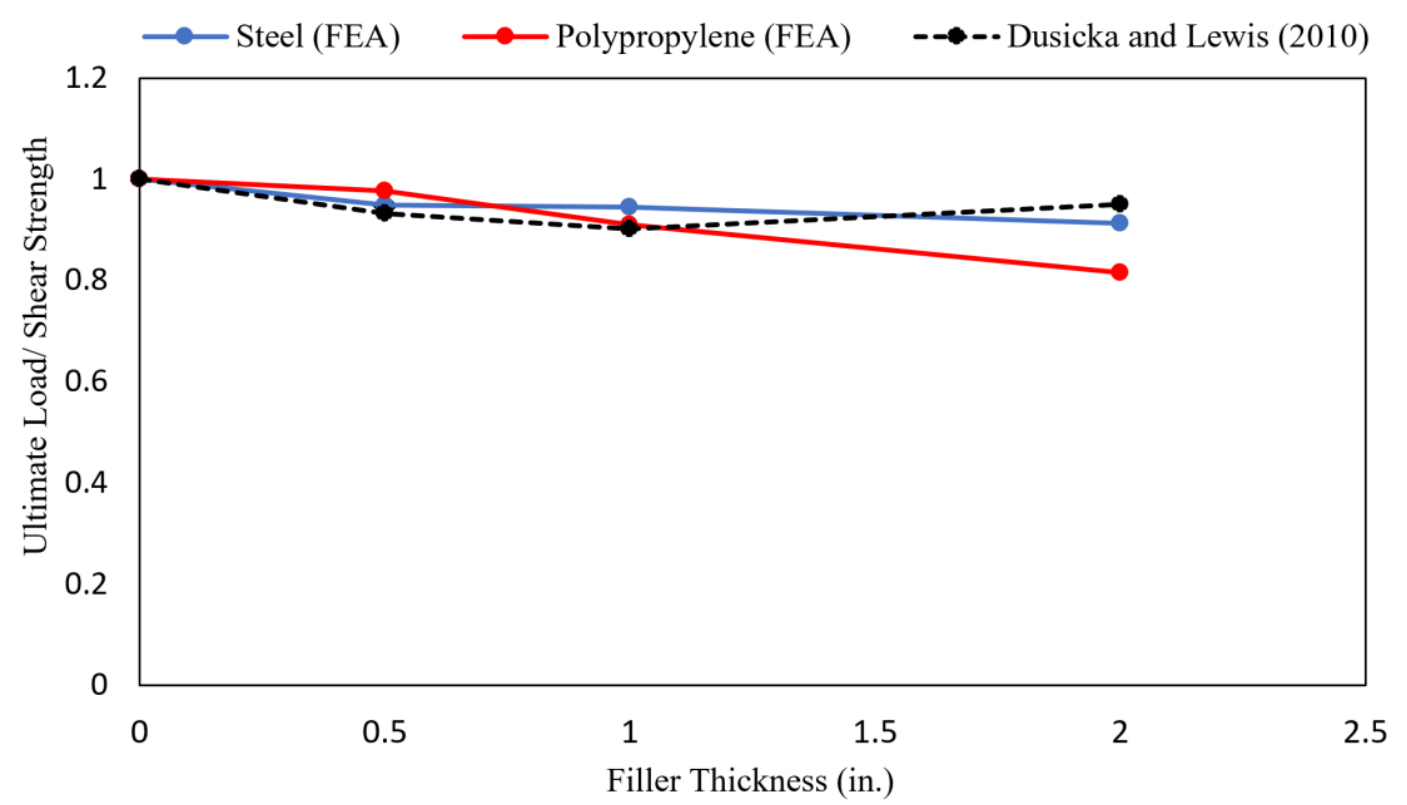

Fig. 6-18: Normalized ultimate strength and Dusicka and Lewis (2010) reduction equation.

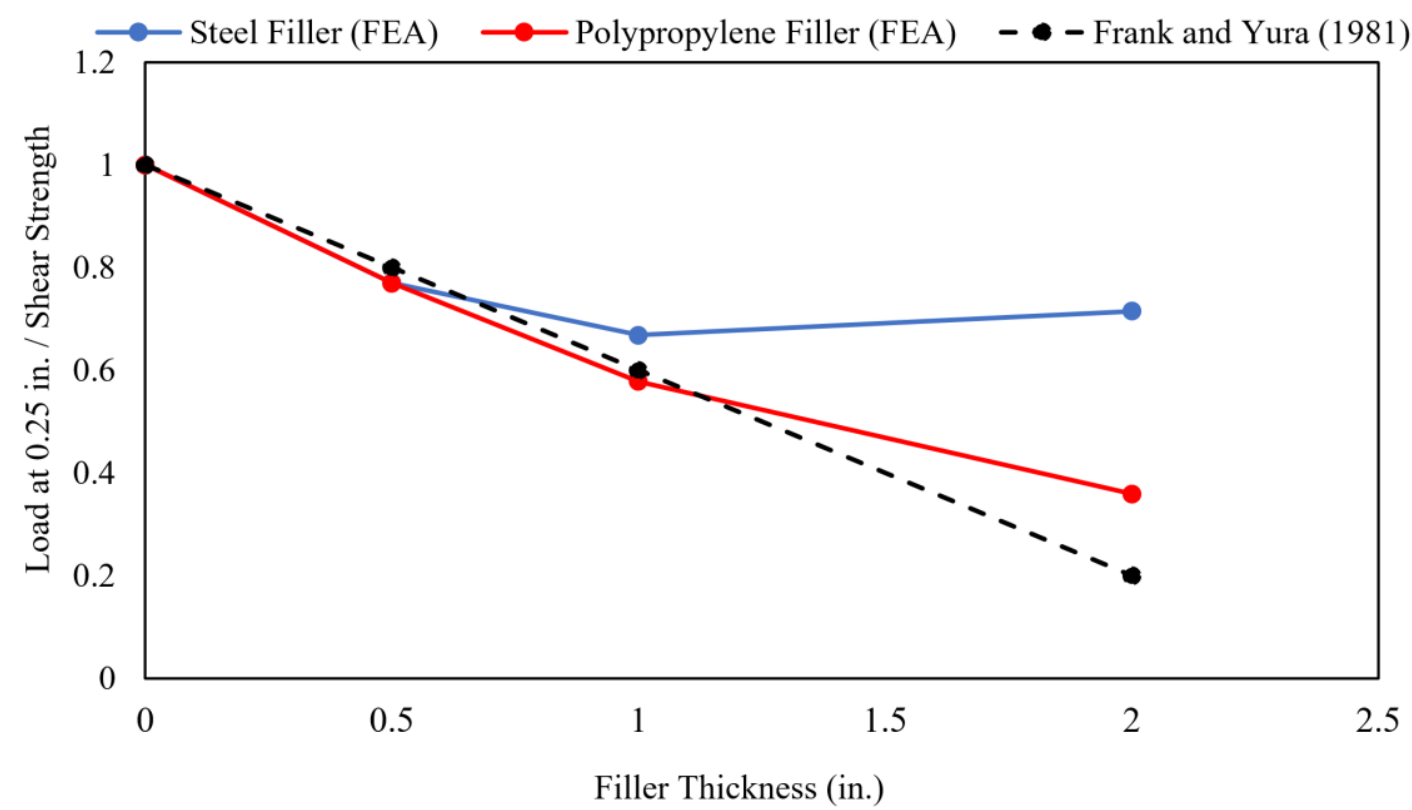

Fig. 6-19: Normalized ultimate strength at 0.25 in deformation and Frank and Yura's (1981) reduction equation. 
Both steel and PP filler plates were compared to the code design equation (RCSC 2014).

It can be observed that the design equation is conservative (Fig. 6-17). The minimum reduction proposed by the code is 0.85 for 2-inch steel fillers while the FEA predicts 0.91 reduction for the same thickness. On the other hand, PP filler plates showed conservative results compared to the design equation for filler thicknesses up to $1 \mathrm{inch}$. Two-inch filler plates showed a lower reduction factor than the design equation. Dusicka and Lewis' (2010) reduction equation was relatively conservative for fillers up to 1 inch but for 2 inch fillers showed more reduction. Comparing FEA results to the Frank and Yura's (1981) equation (Fig. 6.13), 1/2 inch steel fillers showed a 3.8\% lower reduction factor while a higher reduction factor is found for 1 inch steel fillers. PP filler plates showed a 3.8\% lower reduction factor than the equation for $1 / 2$ inch and 1 inch fillers. For 2 inch fillers, the FEA showed a higher reduction factor. Table 6-3 shows a comparison between the FEA results for steel and PP fillers versus reduction equations.

Table 6-3: FEA vs. reduction equations.

\begin{tabular}{|c|c|c|c|c|}
\hline \multicolumn{2}{|c|}{} & \multicolumn{3}{|c|}{ Difference between FEA and reduction equations (\%) } \\
\hline Filler thickness & Material & RCSC (2014) & $\begin{array}{c}\text { Duscika and Lewis } \\
(2010)\end{array}$ & $\begin{array}{c}\text { Frank and Yura } \\
(1981)\end{array}$ \\
\hline \multirow{2}{*}{$1 / 2 "$} & Steel & $5.19 \%$ & $1.75 \%$ & $-3.88 \%$ \\
\cline { 2 - 5 } & PP & $7.86 \%$ & $4.52 \%$ & $-3.94 \%$ \\
\hline $1 "$ & Steel & 10.02 & $4.51 \%$ & 10.21 \\
\cline { 2 - 5 } & PP & $6.66 \%$ & $0.95 \%$ & $-3.75 \%$ \\
\hline \multirow{2}{*}{$2 "$} & Steel & $6.92 \%$ & $-4.14 \%$ & $72.03 \%$ \\
& & & & $44.31 \%$ \\
\cline { 2 - 5 } & PP & $-4.15 \%$ & $-16.53 \%$ & \\
\hline
\end{tabular}


This drives us to the conclusion that up to 1 inch filler thickness, PP fillers behave like steel fillers and for design consideration, all equations can be used to predict connection strength. 


\section{Parametric Study}

Four parametric studies were considered in this research: The first one considers the effect of the absence of filler plats by separating the bolted plates with air gaps. The second and third parameters were performed using hypothetical materials that have stiffness somewhere between air and steel. The last parameter was stiffening the splice plates to simulate the case of multiple bolts.

\subsection{Air Gap Fillers}

Replacing steel fillers with air gaps was an attempt to find the lower bound connection strength assuming a hypothetical material with no stiffness. Gaps were $1 / 2,1$, and 2 inch. It was found that using air gaps reduces the connection's ultimate strength by 16.2, 19.0, and $32.4 \%$ for $1 / 2,1$, and 2 inch gaps, respectively, as shown in Fig. 7-1. Replacing the steel fillers with gaps increased the ductility of the connections by $2.67 \%, 69.67 \%$ and $151.2 \%$ for $1 \frac{1}{2}$ inch, 1 inch and 2 inch gaps, respectively.

The load at 0.25 -inch deformation was also extracted and plotted versus filler thickness and is shown Fig. 7-2. It was found that the connection strength was reduced by $23 \%$, $42.2 \%$ and $64 \%$ for $1 / 2$ inch, 1 inch and 2 inch gaps respectively. 


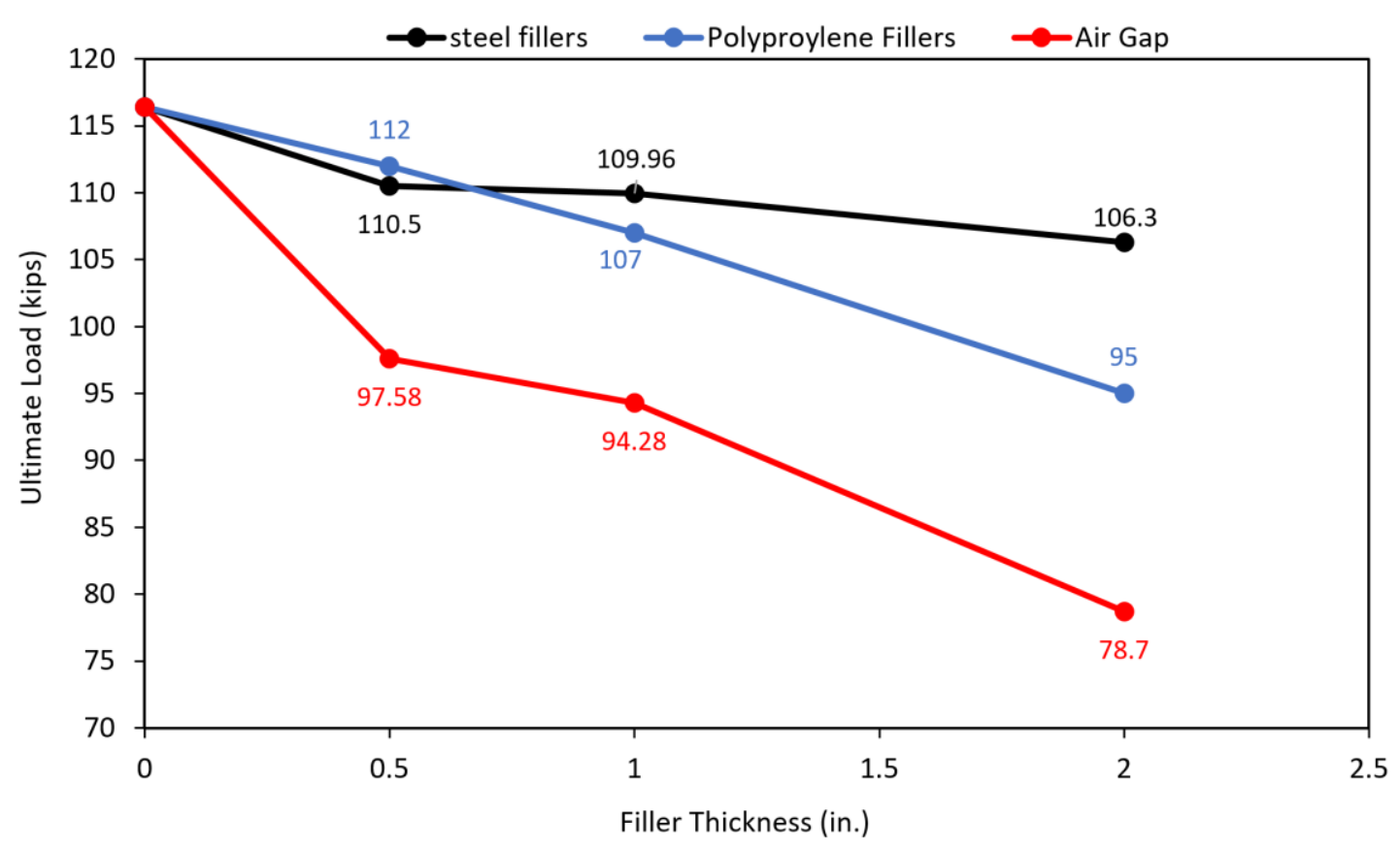

Fig. 7-1: Ultimate strength vs. filler thickness for air gaps compared to steel and PP filler plates.

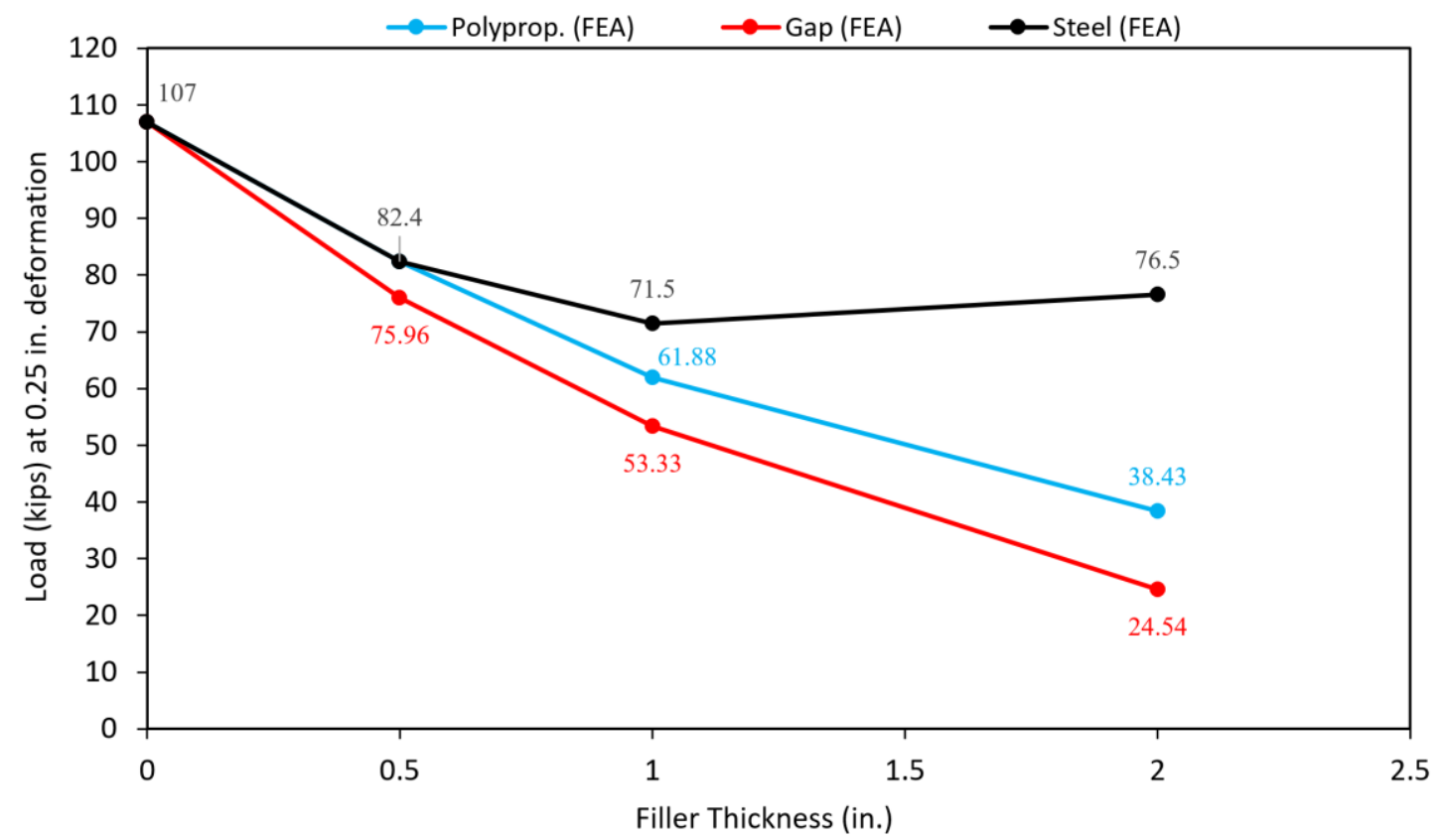

Fig. 7-2: Load at 0.25 in. deformation vs. filler thickness for air gaps compared to steel and PP filler plates. 
Connections with air gaps represent a true case of the catenary action because the excessive bending in the splice plate along with the absence of bearing resistance of the filler plates at the bolt hole allowed the bolt to exhibit larger deformation, as shown in Fig. 7-3. Because of the excessive bending in the bolt, larger bending stresses build up in the bolt and this reduced the bolt strength before it failed in shear. 

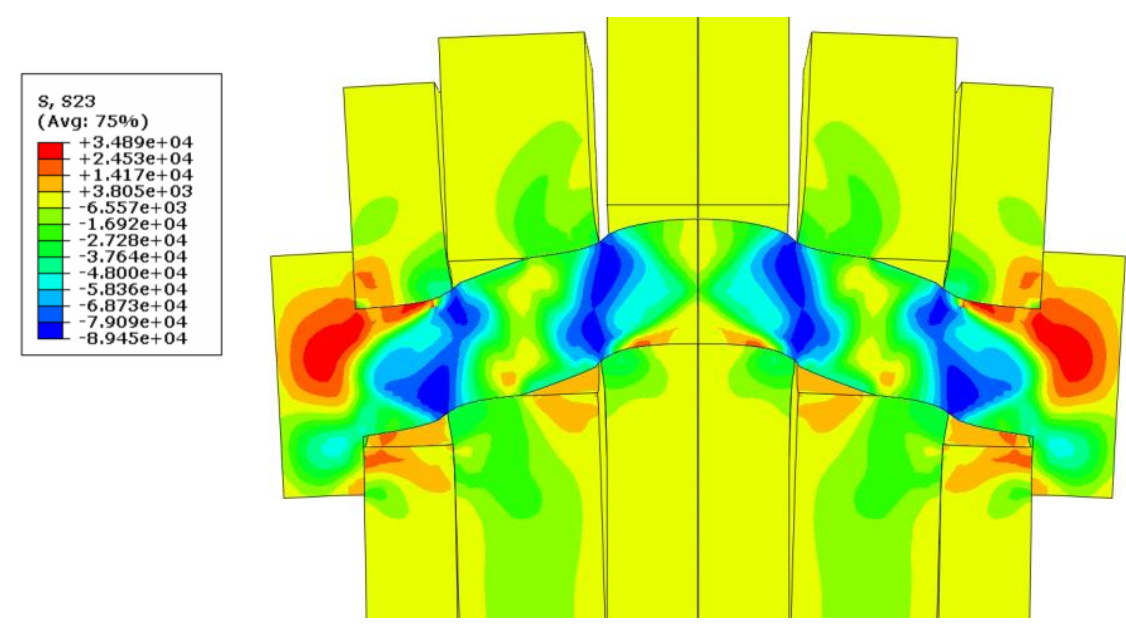

(a) Steel filler plates.
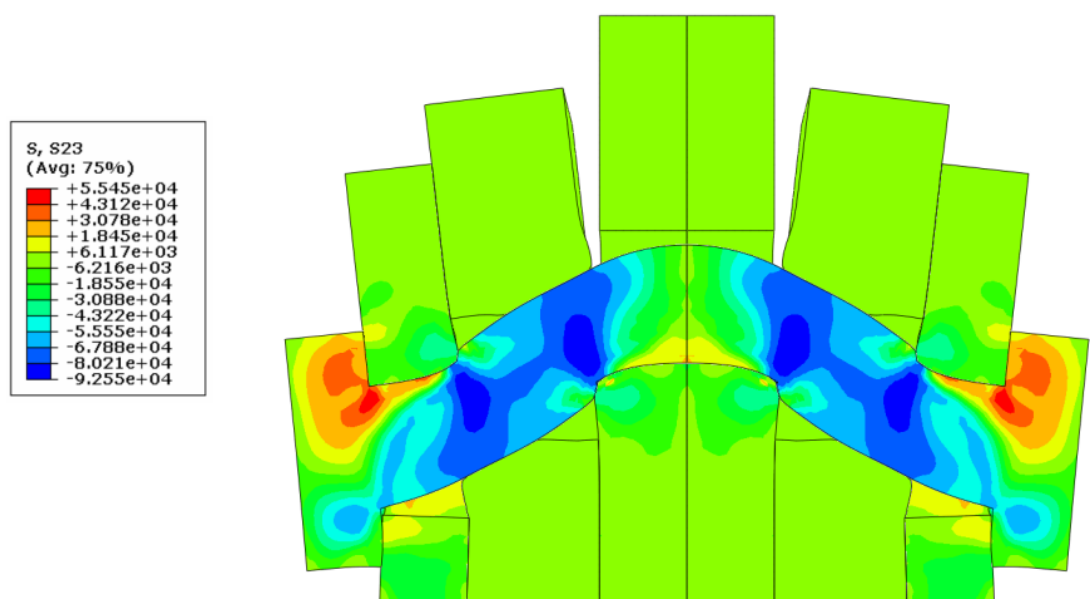

(b) PP filler plates
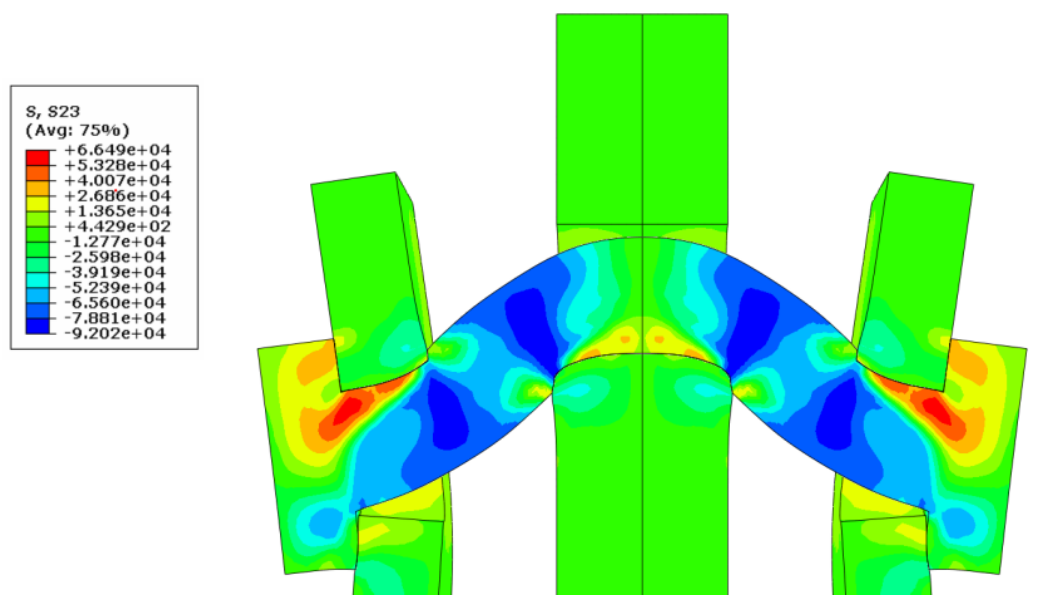

(d) Air gaps.

Fig. 7-3: FEA models (deformed) of three types of connections when ultimate strength is reached. Colors in the bolts show the shear stress. 


\subsection{Ultimate Strength}

The effect of the varying material strength of the filler plates was studied by using hypothetical materials that have $50 \%$ and $25 \%$ of steel yield strength but the same modulus of elasticity (29,000 ksi) as shown in Fig. 7-4.

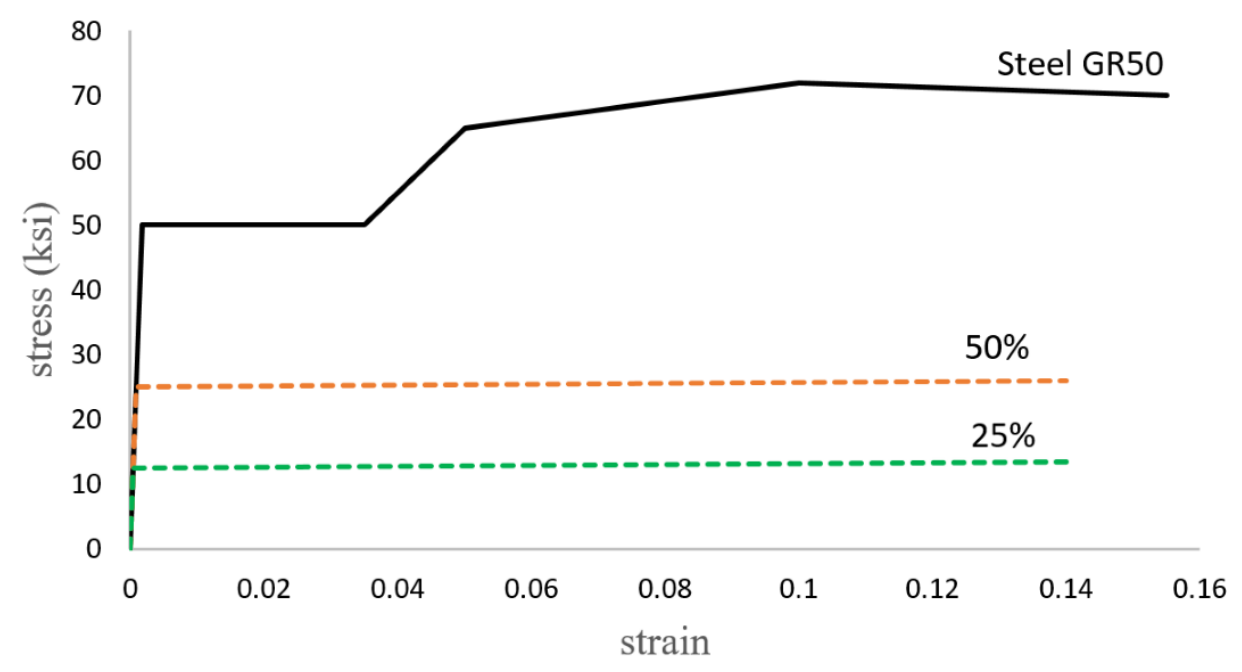

Fig. 7-4: Filler plate materials with varying strength.

Reducing the steel yield strength by $50 \%$ and $25 \%$ while keeping the same modulus of elasticity has no significant effect on the ultimate connection strength compared to using steel fillers of A572 GR50 as shown in Fig 7-5. However, load measured at 0.25-inch deformation appears more sensitive for fillers larger than $1 \mathrm{inch}$. It was found that for 1 inch fillers, reducing filler plate strength down to 50 and $25 \%$ resulted in 8.5 and $8.5 \%$ (both were the same) lower shear strengths, respectively, compared to when A572 Grade 50 steel is used. For 2-inch filler plates, more significant strength reductions of 15\% and 30\%, respectively, were observed as shown in Fig. 7-6. Additional figures showing all configurations are shown in Appendix B, Figs. B-4 to B-5. 


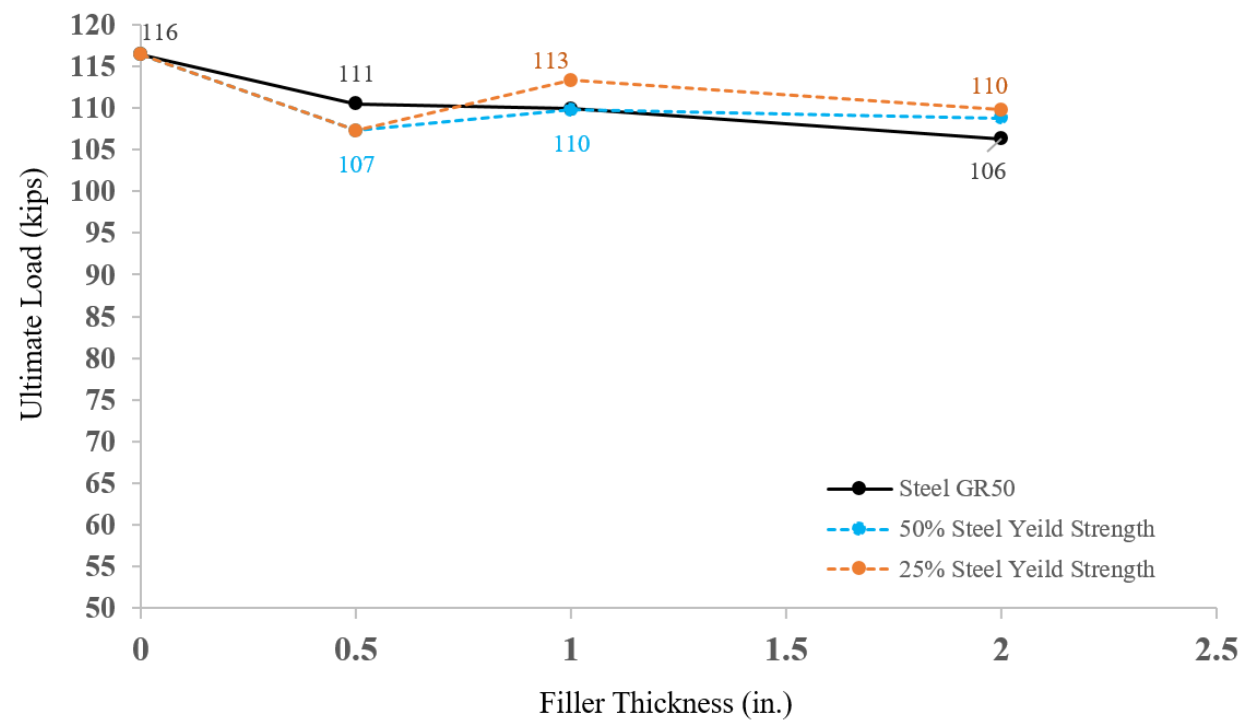

Fig. 7-5: FEA predicted ultimate strength vs. filler plate thickness for varying filler plate strengths.

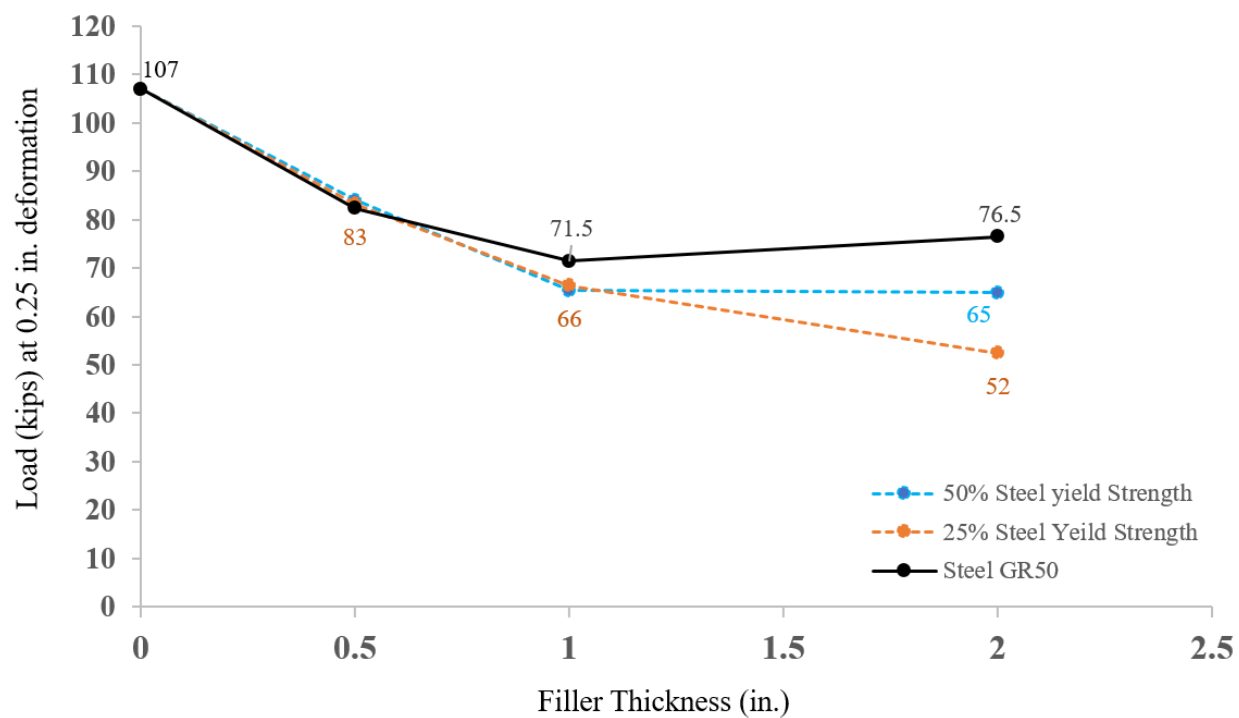

Fig. 7-6: FEA predicted load at 0.25 inch deformation vs. filler plate thickness for varying filler plate strengths. 


\subsection{Modulus of Elasticity}

Two hypothetical materials were introduced with 50 and $25 \%$ of steel modulus of elasticity while keeping the same yield strength of $50 \mathrm{ksi}$ as shown in Fig. 7-7.

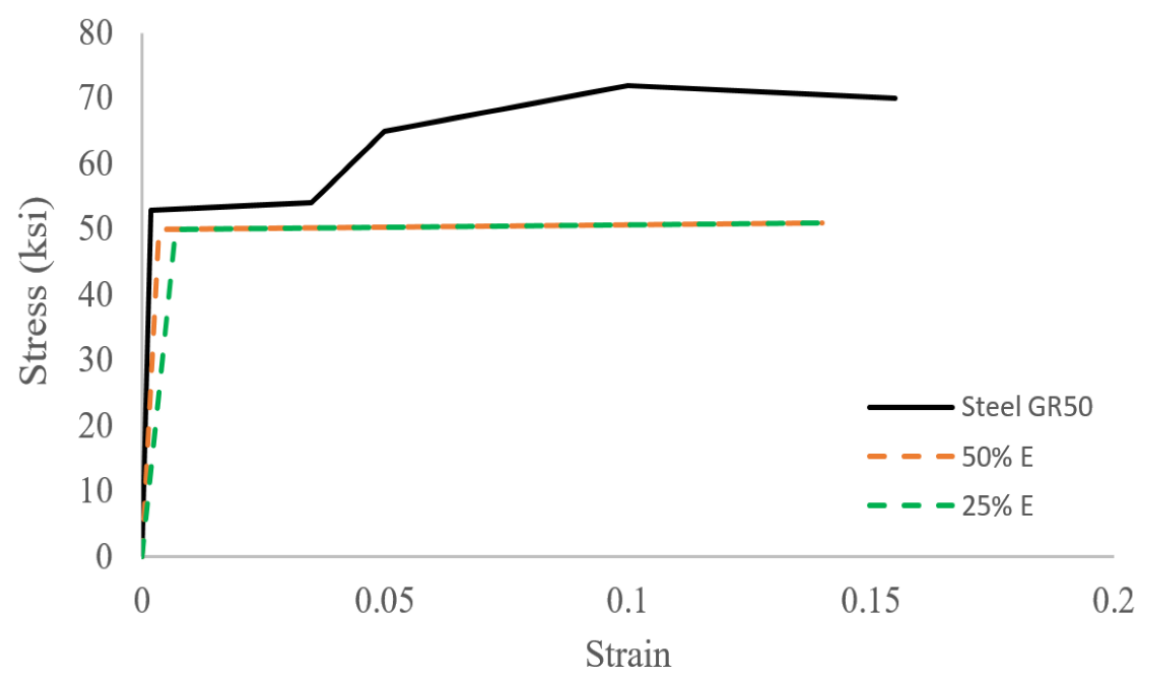

Fig. 7-7: ) Filler plate materials with varying modulus of elasticity.

Reducing the modulus of elasticity by 50 and $25 \%$ has no significant effect on the ultimate connection strength for any filler plate thickness. However, the load at 0.25 -inch deformation showed more sensitivity. The maximum reduction was $11 \%$ for 2 inch filler plates compared to steel fillers as shown in Fig. 7-8. Additional figures showing all configurations are shown in Appendix B, Figs. B-6 to B-7. 


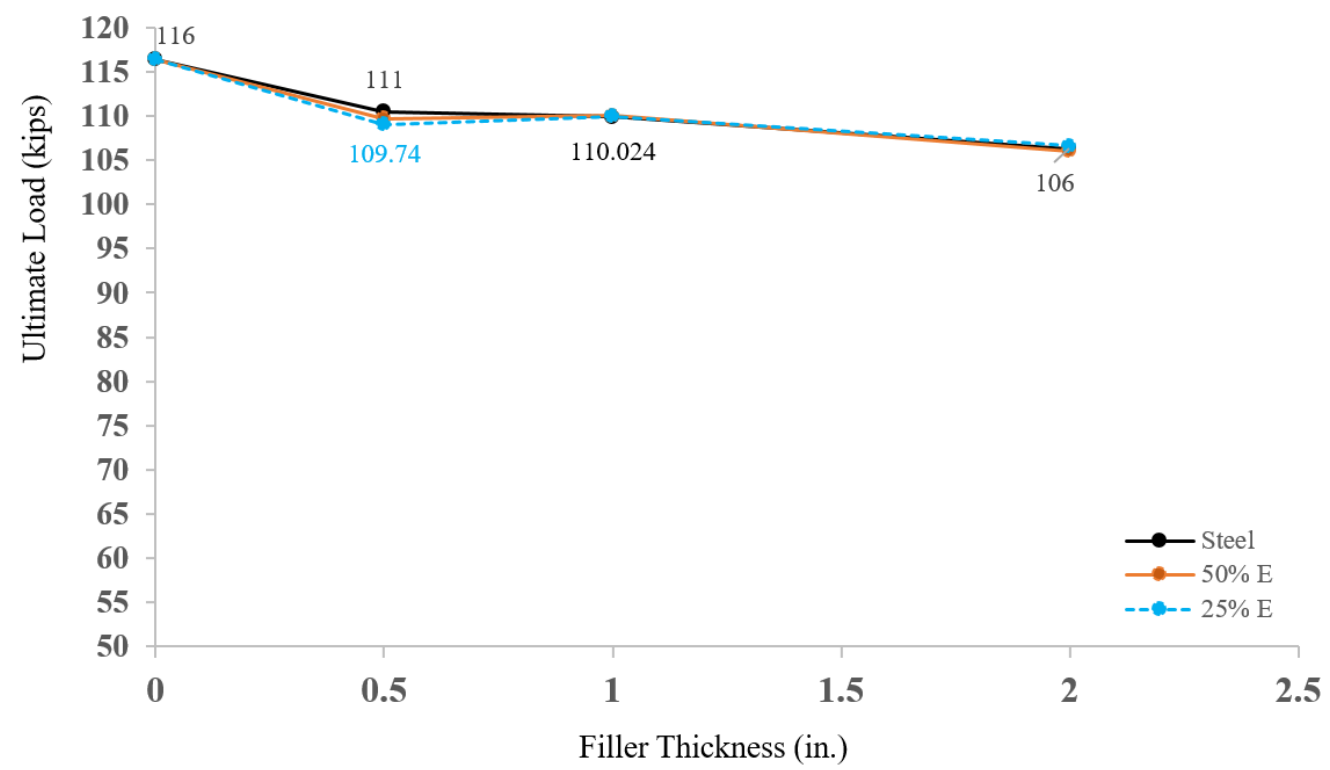

Fig. 7-8: FEA predicted ultimate strength vs. filler plate thickness for varying filler plate moduli of elasticity.

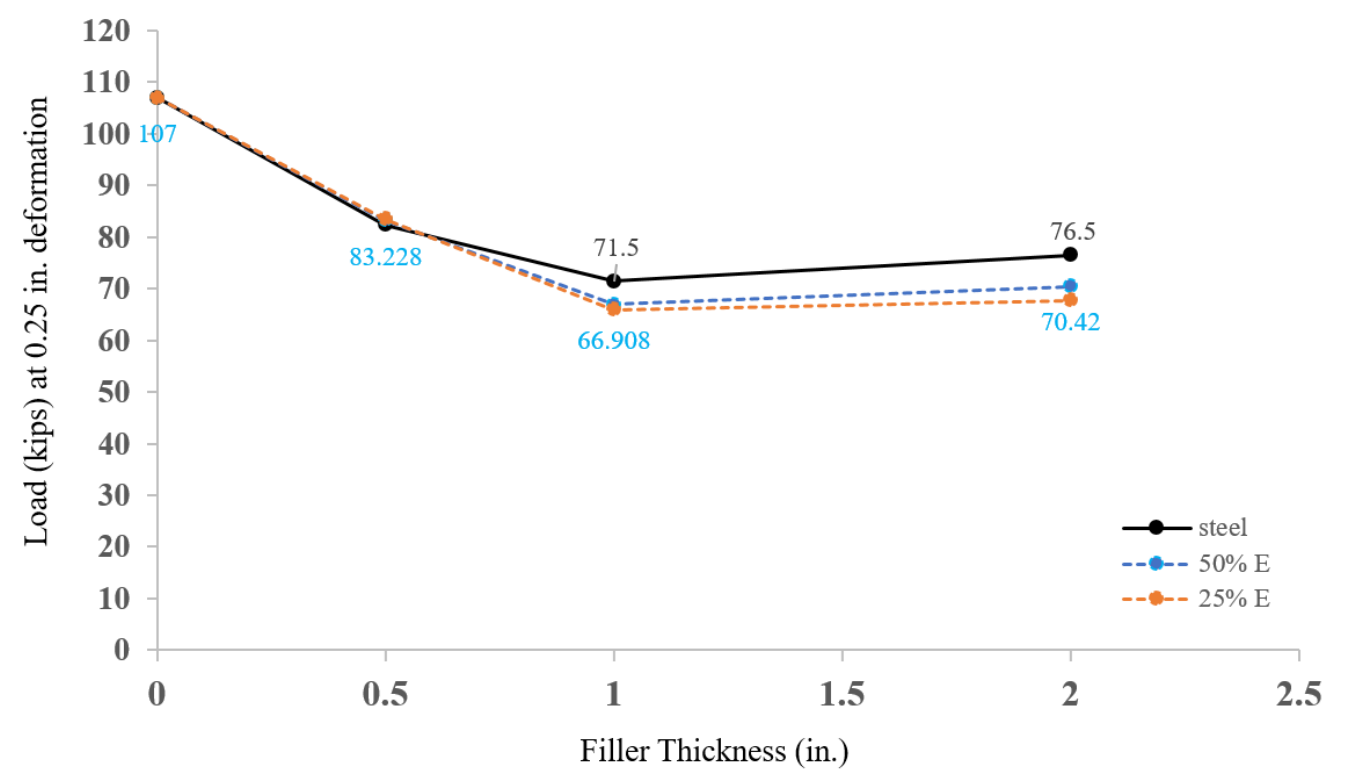

Fig. 7-9: FEA predicted load at 0.25 inch deformation vs. filler plate thickness for varying filler plate moduli of elasticity. 


\subsection{Stiffening the Splice Plates}

In order to address the case of multiple bolts (Group B) when the splice plates do not deform such as in group A shown in Fig. 7-10, the same one-bolt FEA model was used with restraining the splice plate along the z-axis as shown in Fig. 7-11. Connections with PP fillers were chosen to study this parameter.

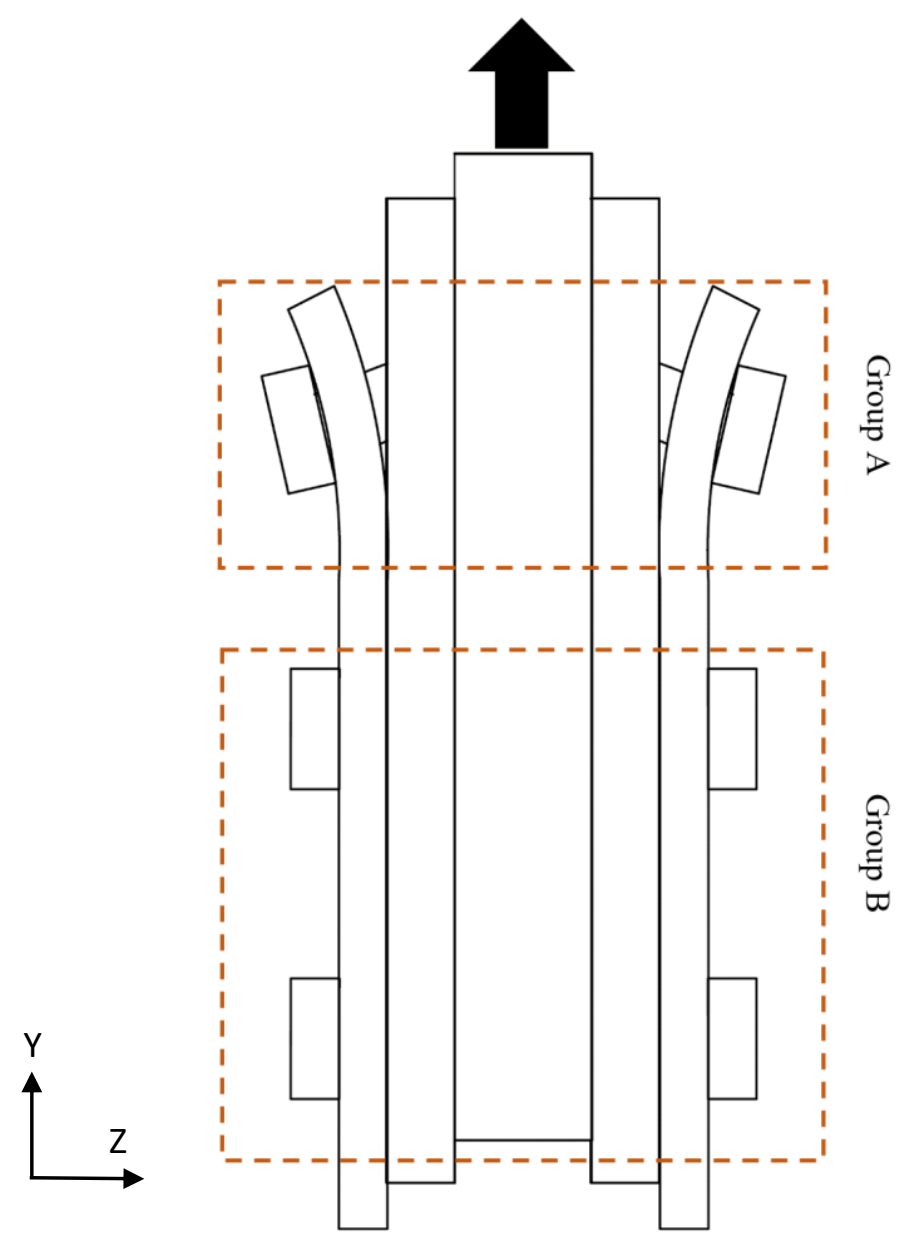

Fig. 7-10: three bolt connection with filler shows two different bolt groups. 


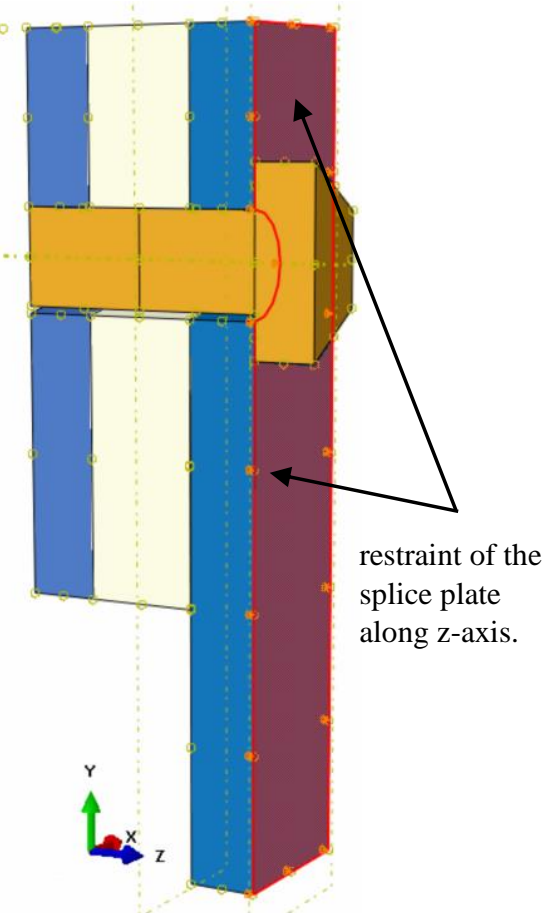

Fig. 7-11: Example of an FEA model with restraint of the splice plate along z-axis.

Fig. 7-12 shows an example for connection with stiffened splice plates and connection unstiffened splice plates. Restraining the splice plates increased the connection strength at 0.25 -inch deformation by $11.7 \%$ for connections with $1 / 2$-inch PP fillers and by $16.7 \%$ for connections with 1-inch and 2-inch PP fillers as shown in Fig. 7-13. It reduced the connection ultimate strength by $2.4 \%, 1.5 \%$ and $8.3 \%$ for $1 / 2$-inch, 1 -inch and 2 -inch PP fillers, respectively, as shown in Fig. 7-14. Also, restraining the splice reduced the ultimate deformation by $41.2 \%, 10 \%$ and $20.3 \%$ for $1 / 2$-inch, 1 -inch and 2 -inches PP fillers, respectively. Additional figures showing all configurations are shown in Appendix B, Figs. B-8 to B-10.

The reason for the increment in the load at the point of 0.25 inch-deformation is because restraining the splice plates reduced the bolt bending. While the reduction in ultimate 
strength is attributed to excessive bolt bending at failure and the stress concentration between the bolt and the splice plate.

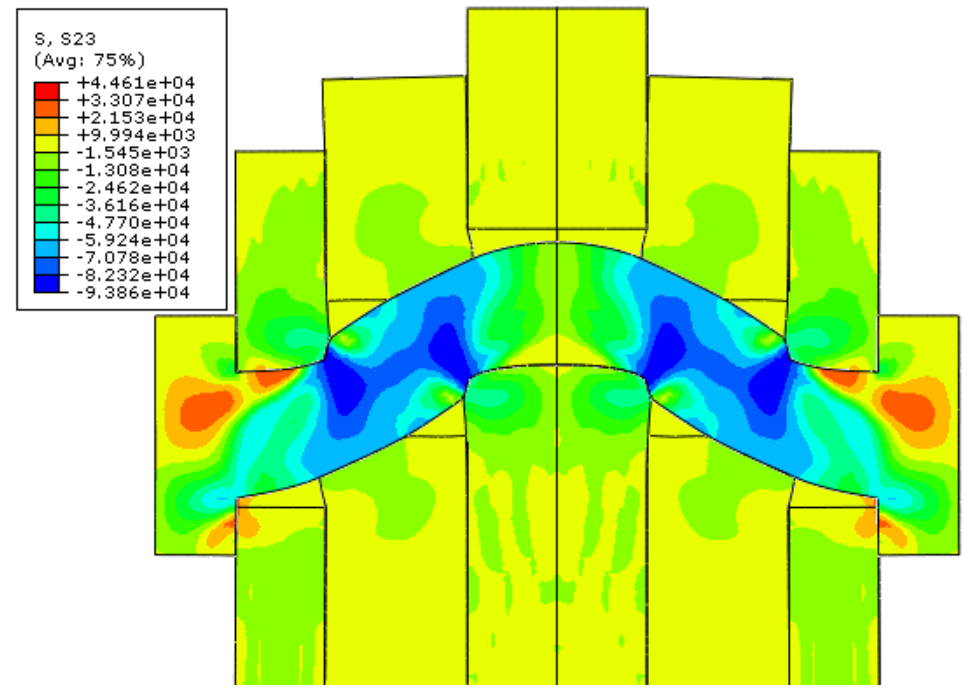

(a)

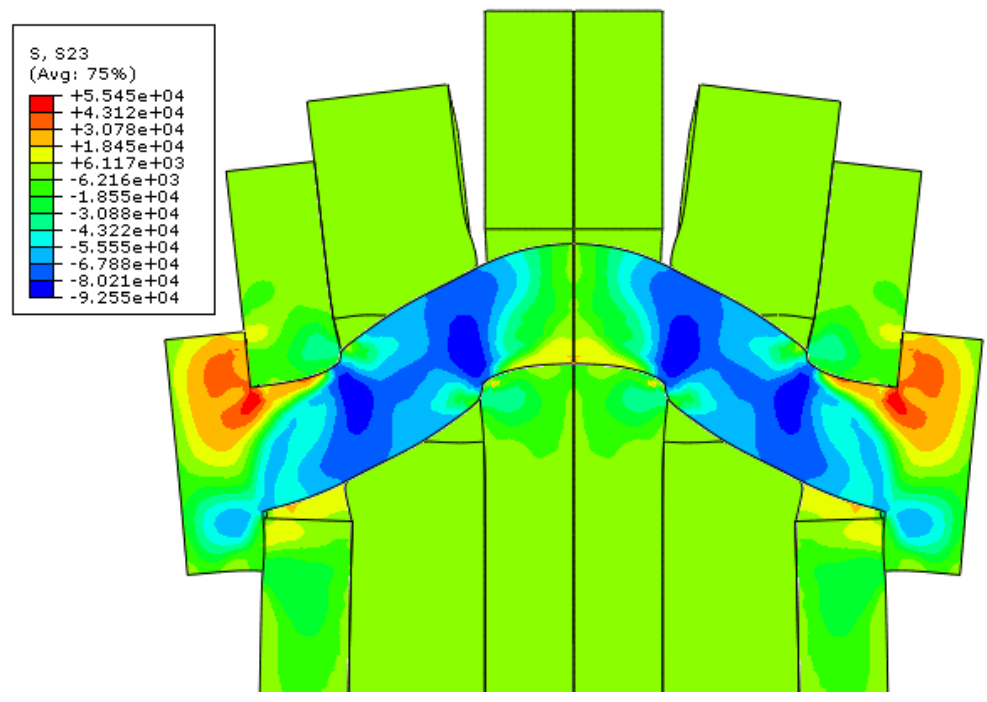

(b)

Fig. 7-12 Example of (a) connection with stiffened splice plates and (b) connection with unstiffened splice plates for 1 inch PP filler. 


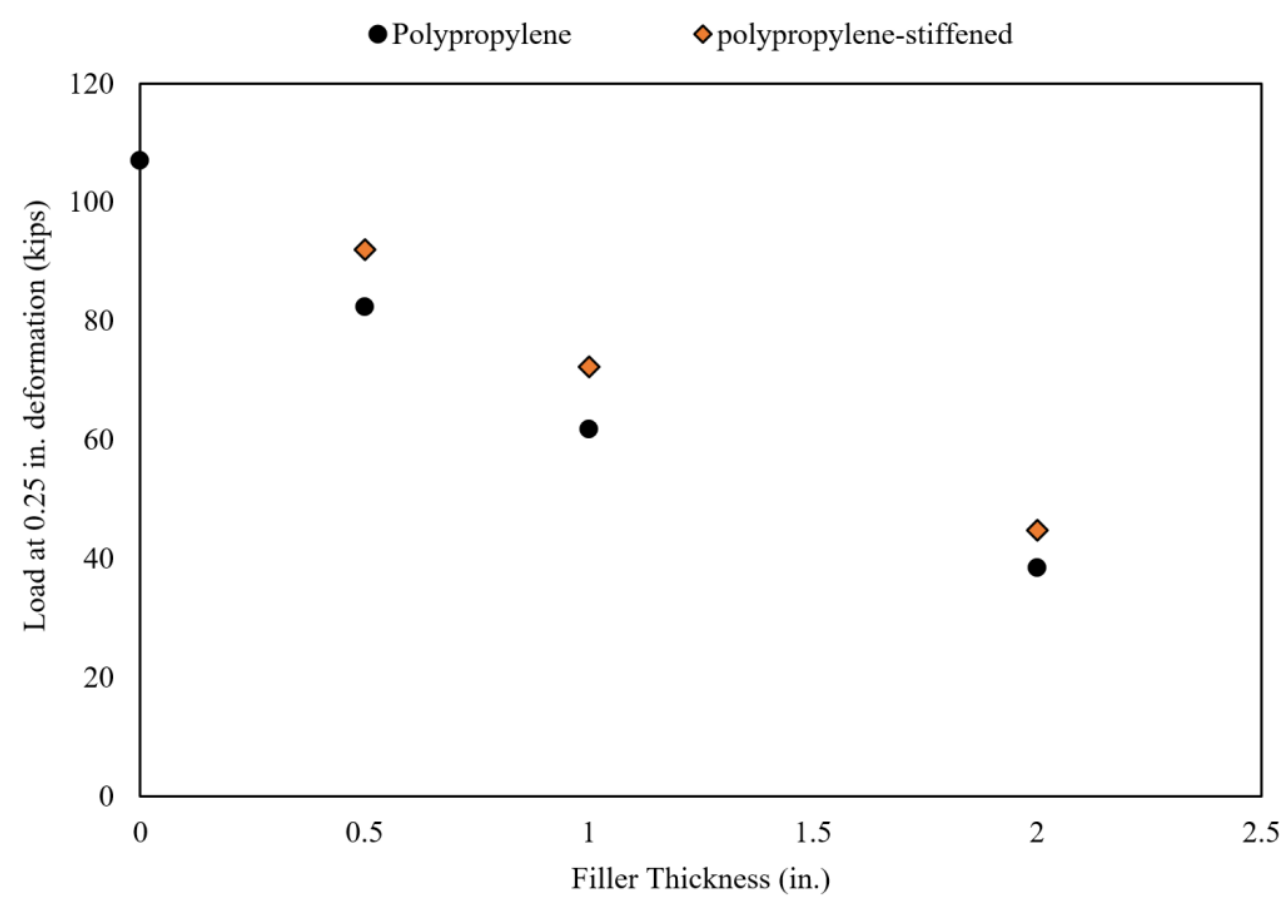

Fig. 7-13: Load at 0.25 inch deformation vs. filler thickness for connections with PP fillers with and without stiffening.

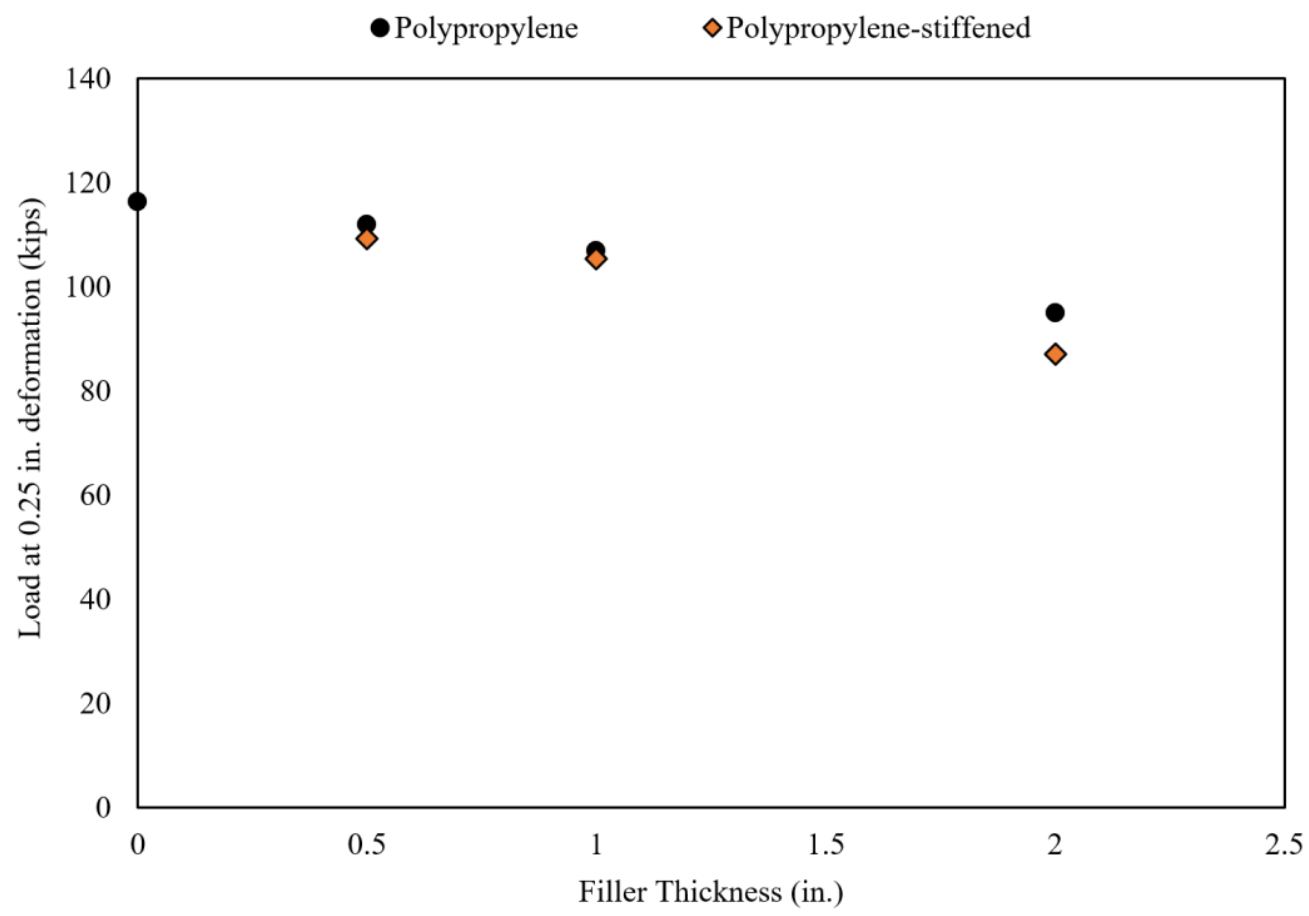

Fig. 7-14: Ultimate load vs. filler thickness for connections with PP fillers with and without stiffening. 


\subsection{Summary}

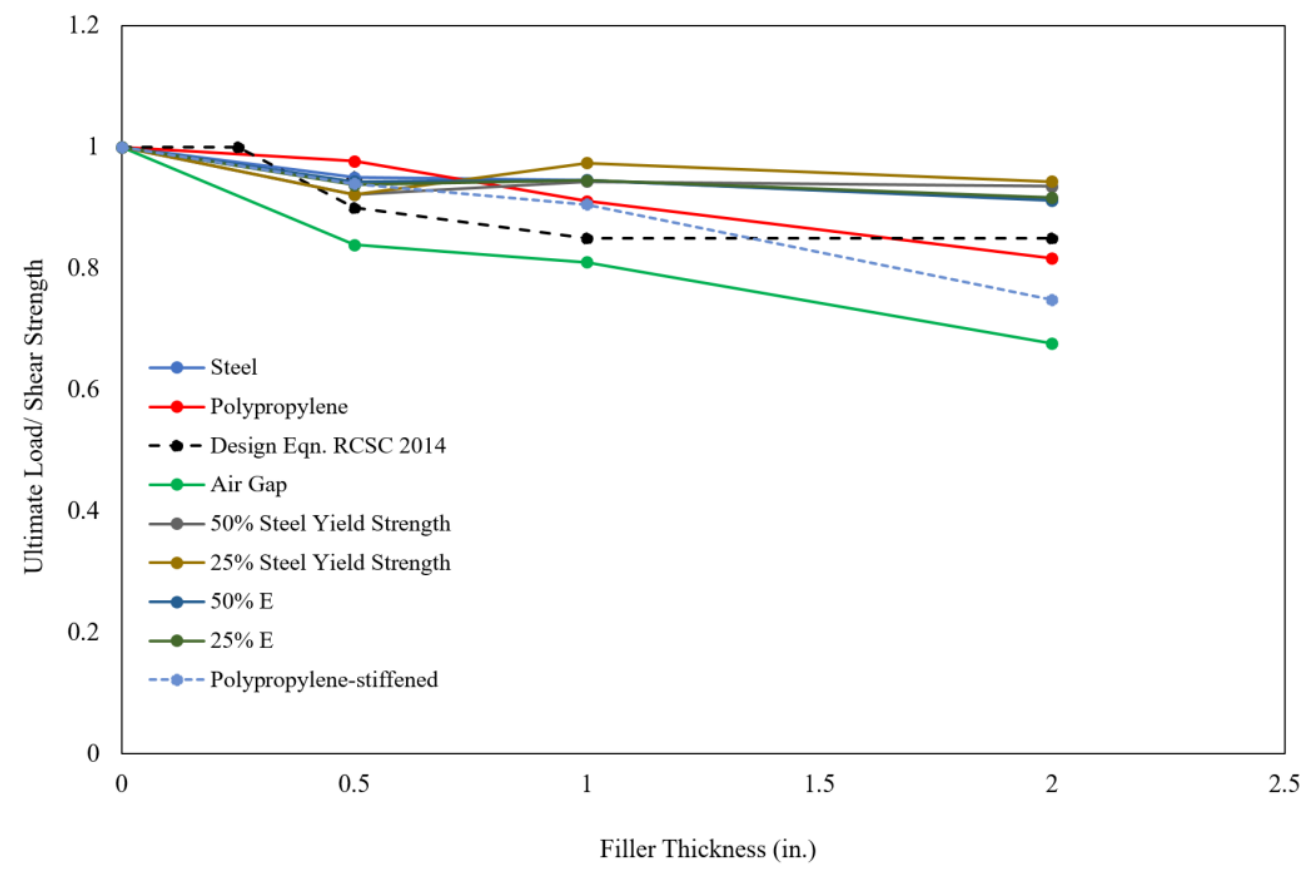

Fig. 7-15: FEA predicted ultimate strength vs. filler plate thickness compared with the code equation.

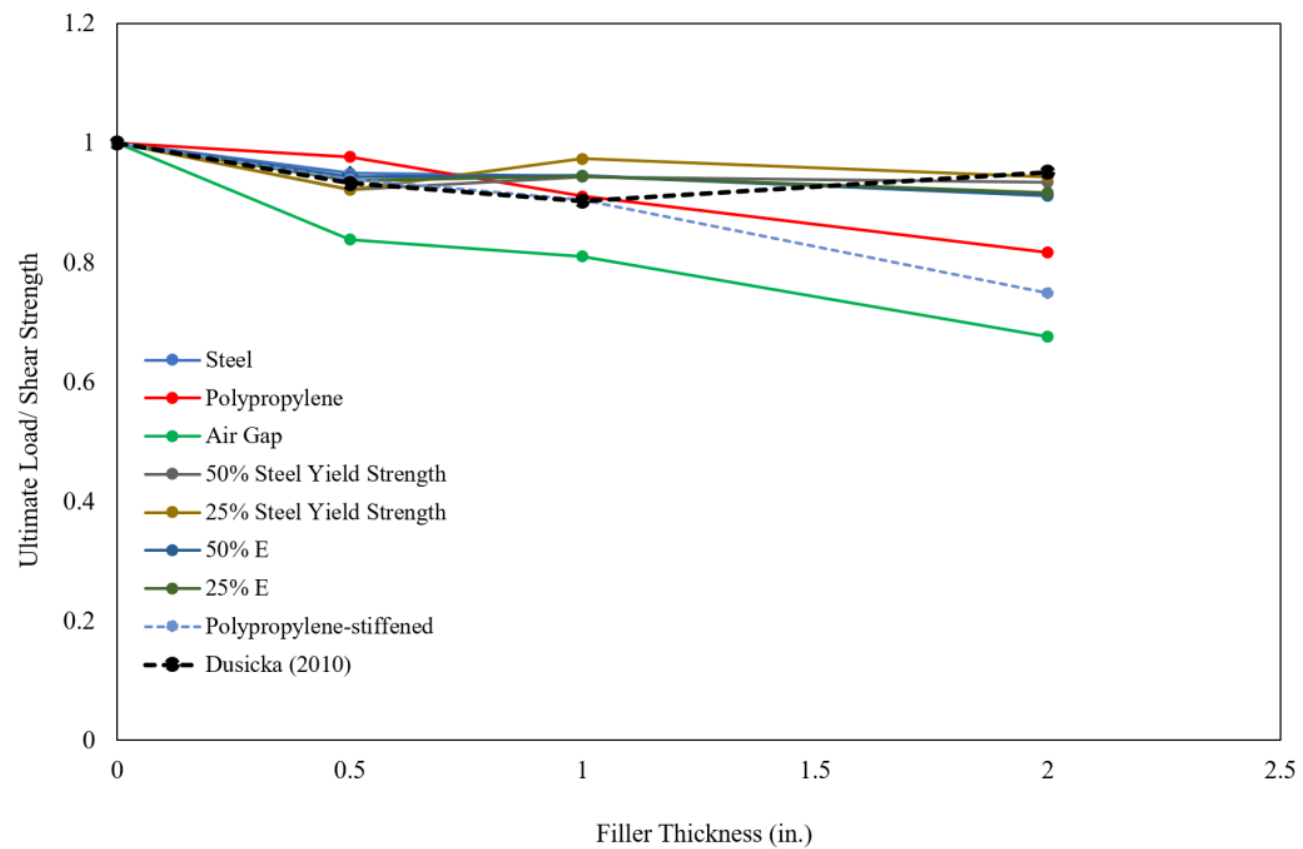

Fig. 7-16: FEA predicted ultimate strength vs. filler plate thickness compared with the Dusicka and Lewis (2010) equation. 


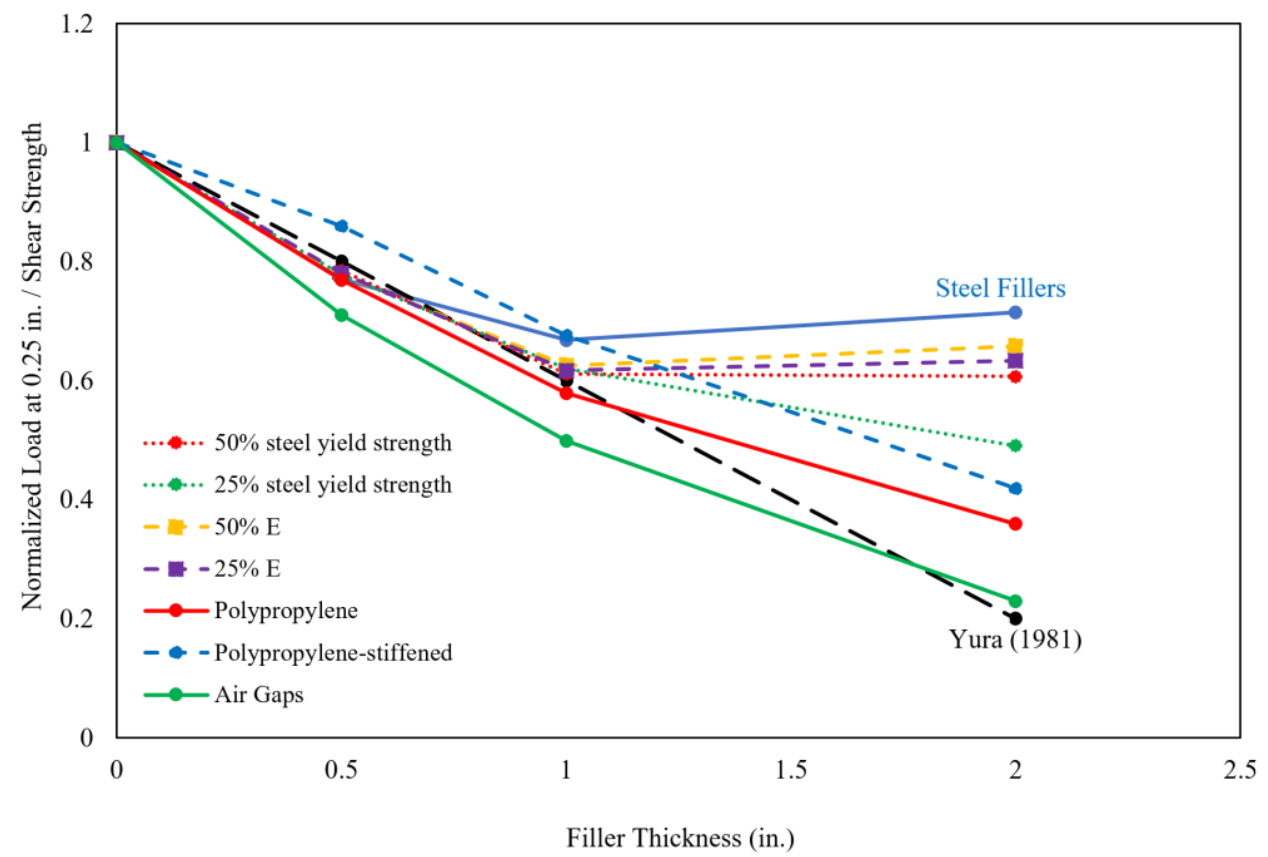

Fig. 7-17: FEA predicted load at 0.25 inch deformation vs. filler plate thickness compared with the Frank and Yura's (1981) equation.

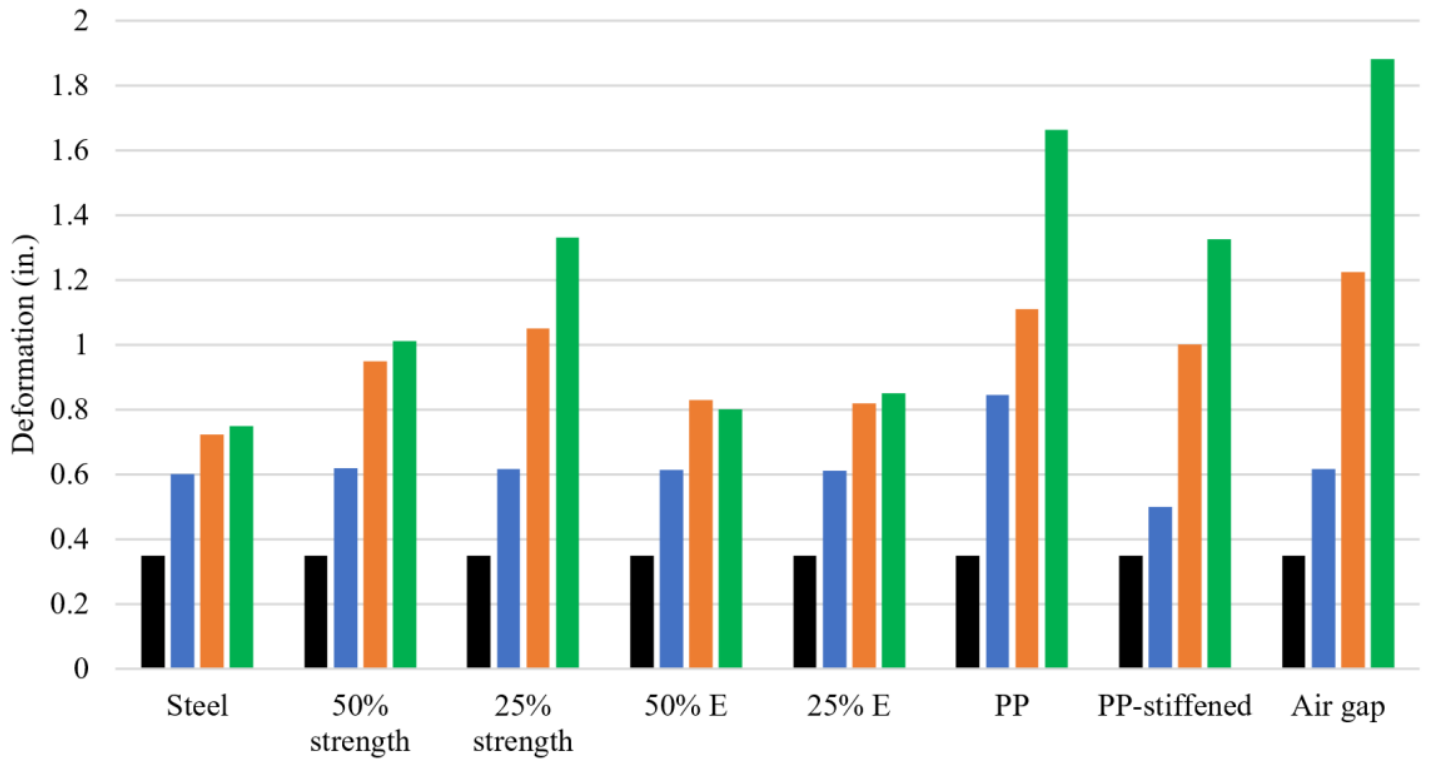

Filler Material

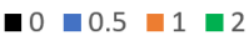

Fig. 7-18: Summary for the connections deformation with different filler thickness and material. 


\section{Summary and Conclusions}

Eight specimens having steel and polypropylene filler plates of various thicknesses were tested in the laboratory. The collected data were compared to a Finite Element Analysis (FEA) using ABAQUS to validate the numerical results. FEA was able to predict the overall behavior and the important features very well with a maximum error of $1.3 \%$. Also, the results from experimental test and FEA were compared to the code design equation (RCSC 2014), Dusicka and Lewis (2010), and Frank and Yura's (1981) reduction equation and discussed below.

The general behavior of a bolted shear-lap connection can be summarized by an initial slip, bolt engagement in bearing, elastic deformation, plastic deformation, and finally bolt failure in shear. Bolts in connections with no fillers experience pure shear without bending but when fillers are introduced between the splice-plate and pull-plate, bolts experience a combined effect of bending and shear. For the case when steel filler plates are used, the bolt experiences bending followed by shear failure generated between the pull-plate and filler plate (Fig. 7-3). This bending reduces the shear strength of the bolt. While when PP fillers are used, more reduction is observed because PP fillers had lower bearing resistance than the steel and allowed more deformation in the bolt accompanied with increased bending stresses that reduced the bolt strength at failure.

- The FEA was found effective for conducting parametric studies of different kinds of fillers.

- The presence of steel fillers reduced the slip strength by $22 \%$ while the presence of PP fillers increased the slip strength by $54 \%$. 
- If the deformation is a problem, Frank and Yura's equation can be used to limit the deformations up to 0.25 inch.

- For the load at 0.25 inch deformation, fillers up to $1 / 2$ inch thickness expressed similar behavior to the steel fillers while a $1 / 2$ inch air gap reduced the connection strength by $29 \%$ (9\% lower than $1 / 2$ inch steel fillers).

- For the load at 0.25 inch, connections with 1-inch fillers and more are more sensitive to the material properties, and a larger reduction factor should be used when low stiffness filler plate materials are used. For example, a reduction factor of 0.58 and 0.67 is needed for PP and steel fillers, respectively.

- The code design equation RCSC 2014 and Dusicka and Lewis' (2010) reduction equation can be used for PP fillers up to 1 inch thickness if excessive deformation is not a problem. For fillers larger than 1 inch Dusicka and Lewis' (2010) equation is not recommended because it gives $16.5 \%$ higher strength while RCSC 2014 equation predicts $4 \%$ higher strength.

- The code design equation RCSC 2104 can be used for materials that have $25 \%$ strength and the elastic modulus of steel because this still gives conservative results. While Duscika and Lewis' (2010) reduction equation can be used only for fillers up to 1 inch.

- Inner bolts in multi-bolted connections with PP fillers (group B in Fig. 7-10) expressed higher strength at 0.25 inch deformation than the bolt in group A due to restraint of the splice plates by other bolts. Therefore, a lower reduction factor is recommended for bolts in group B. For example, if 1 inch PP filler is used in 3-bolt 
connection, then the bolt in group A should be multiplied by a factor of 0.58 while bolts in group B should be multiplied by a factor of 0.68 .

- PP fillers up to 1 inch had miner effects on the ultimate strength for bolts in group B while fillers of 2 inches showed $8.3 \%$ lower strength than bolts in group A. 


\section{Future Work}

Future studies should investigate the effect of bolt diameter to the filler thickness ratio on the ultimate strength and strength at 0.25 -inch deformation. Cyclic loading, creep and fatigue should also be considered in the future studies since the behavior of these materials is not well known. The future studies can consider the effect of soft materials like polypropylene on the connection strength of long connections. 


\section{References}

Lee, J.H. and Fisher, J.W., 1968. Bolted joints with rectangular or circular filters, July $196 b$.

Yura, J.A., Hansen, M.A. and Frank, K.H., 1982. Bolted splice connections with undeveloped fillers. Journal of the Structural Division, 108(12), pp.2837-2849.

Dusicka, P. and Lewis, G., 2010. High strength steel bolted connections with filler plates. Journal of Constructional Steel Research, 66(1), pp.75-84.

Research Council on Structural Connections (2014).

Borello, D.J., Denavit, M.D. and Hajjar, J.F., 2009. Behavior of bolted steel slip-critical connections with fillers. Newmark Structural Engineering Laboratory. University of Illinois at Urbana-Champaign.

Perry WC. Bearing Strength of Bolted Connections. Thesis presented to the University of Texas, at Austin in partial fulfillment of the requirements for the degree of Master of Science 1961.

Valerio, J.A.P., 2007. Impact Assessment of Thermal Bridges on Residential Buildings Performance. Instituto Superior Técnico, DECivil, Av. Rovisco Pais, pp.1049-001.

American Institute of Steel Construction Inc. (2011). Steel Construction Manual, 14th Ed.

Ed Dlugokencky and Pieter Tans, NOAA/ESRL (www.esrl.noaa.gov/gmd/ccgg/trends/)

Mora, C., Frazier, A.G., Longman, R.J., Dacks, R.S., Walton, M.M., Tong, E.J., Sanchez, J.J., Kaiser, L.R., Stender, Y.O., Anderson, J.M. and Ambrosino, C.M., 2013. The 
projected timing of climate departure from recent variability. Nature, 502(7470), pp.183187.

Sulcova, Z., Sokol, Z. and Wald, F., 2010. Integration of the new component into the design method for thermal insulating connections. Portugal SB10-Sustainable Building Affordable to All: Low Cost Sustainable Solutions, Universidade do Minho, Braga, Portugal.

Nasdala, L., Hohn, B. and Rühl, R., 2007. Design of end-plate connections with elastomeric intermediate layer. Journal of Constructional Steel Research, 63(4), pp.494504.

Cleary, D.B., Riddell, W.T., Camishion, N., Downey, P., Marko, S., Neville, G., Oostdyk, M. and Panaro, T., 2016. Steel connections with fiber-reinforced resin thermal barrier filler plates under service loading. Journal of Structural Engineering, 142(11), p.04016095.

Larbi, A.B., Couchaux, M. and Bouchair, A., 2017. Thermal and mechanical analysis of thermal break with end-plate for attached steel structures. Engineering Structures, 131, pp.362-379.

White, S.P., 2016. Thermo-mechanical modeling of thermal breaks in structural steel point transmittances (Doctoral dissertation, University of Alaska Anchorage).

CEN (European Committee for Standardization). (2005). "Eurocode 3:Design of steel structures-Design of joints.” EN 1993-1-8, Brussels,Belgium.

ASTM. (2006). "Standard practice for measuring the change in length of fasteners using the ultrasonic pulse-echotechnique." ASTM E1685-00, West Conshohocken, PA.

ASTM, A., 325(2007a) Standard Specification for Structural Bolts. Steel, Heat Treated, 120, p.105.

ASTM, A., 2009. 490 Standard Specification for Structural Bolts. Alloy Steel, Heat Treated, 150. 
ANSI (American National Standards Institute). (2012). "Standard specification for the size of abrasive grain-grinding wheels, polishing, and general industrial use." ANSI 874.12-2012, Washington, DC.

SSPC, S., 7/NACE No. 4, SSPC SP 6/NACE No. 3, and SSPC SP 10/NACE No. 2. As a 


\section{Appendix}

\section{A- Appendix A: Experimental results}

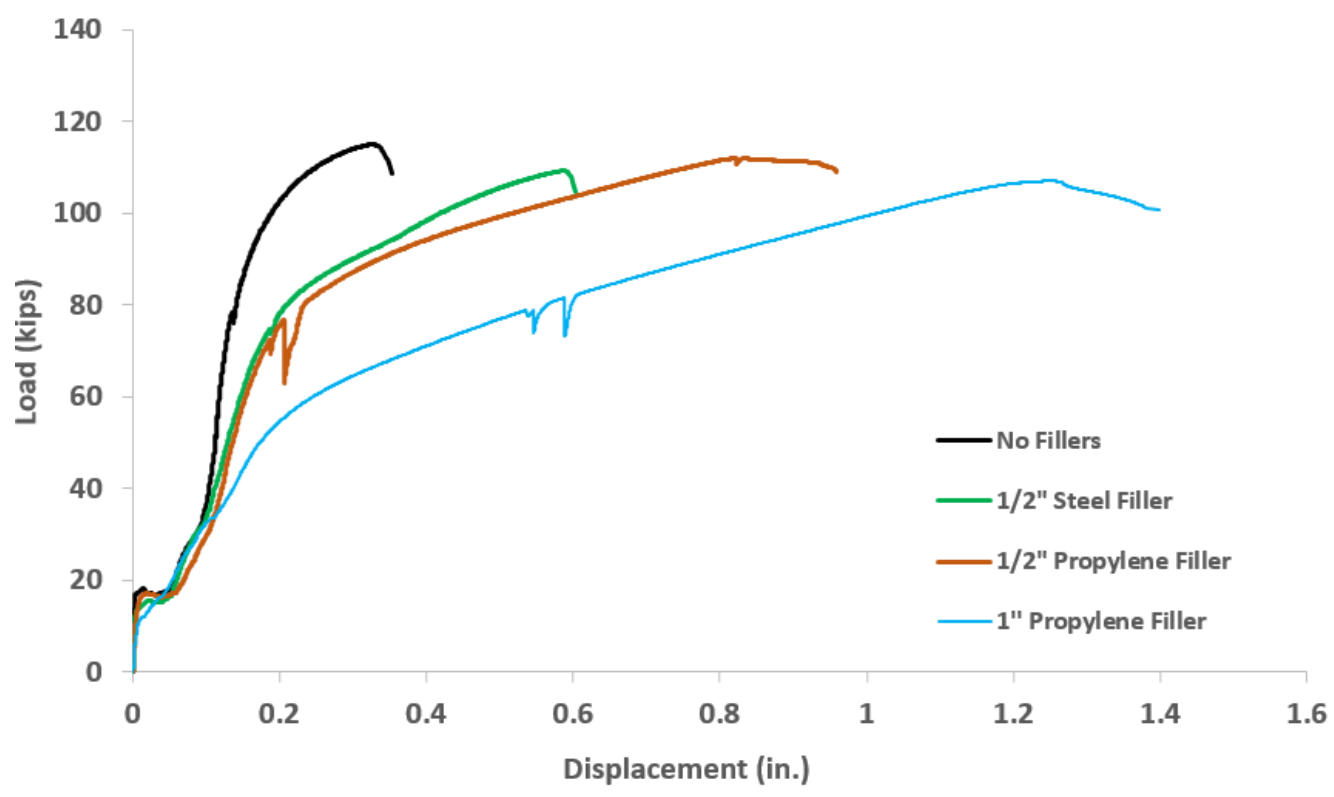

Fig. A-1: Experimental results of load vs. deformation for steel connection with different material. 


\section{B- Appendix B: Finite Element Analysis}

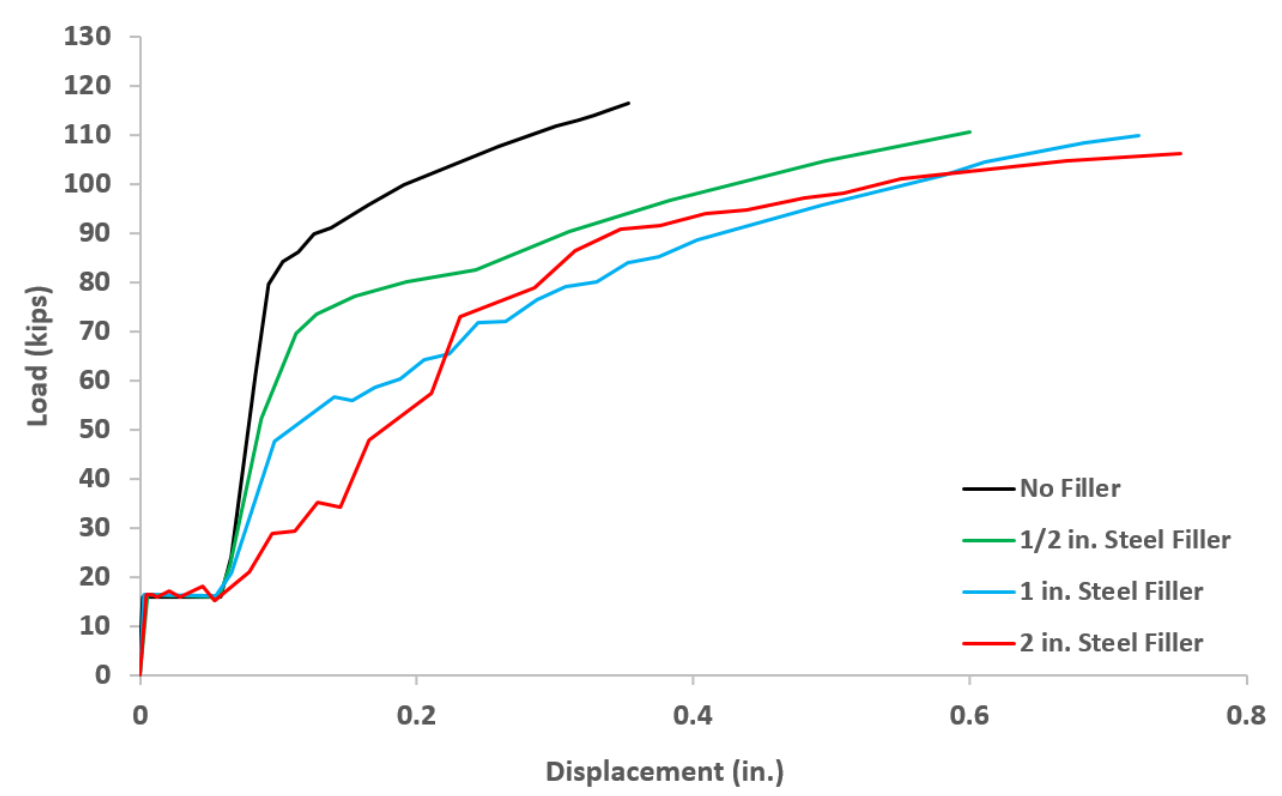

Fig. B-1: FEA results of load vs. deformation for connection with steel fillers.

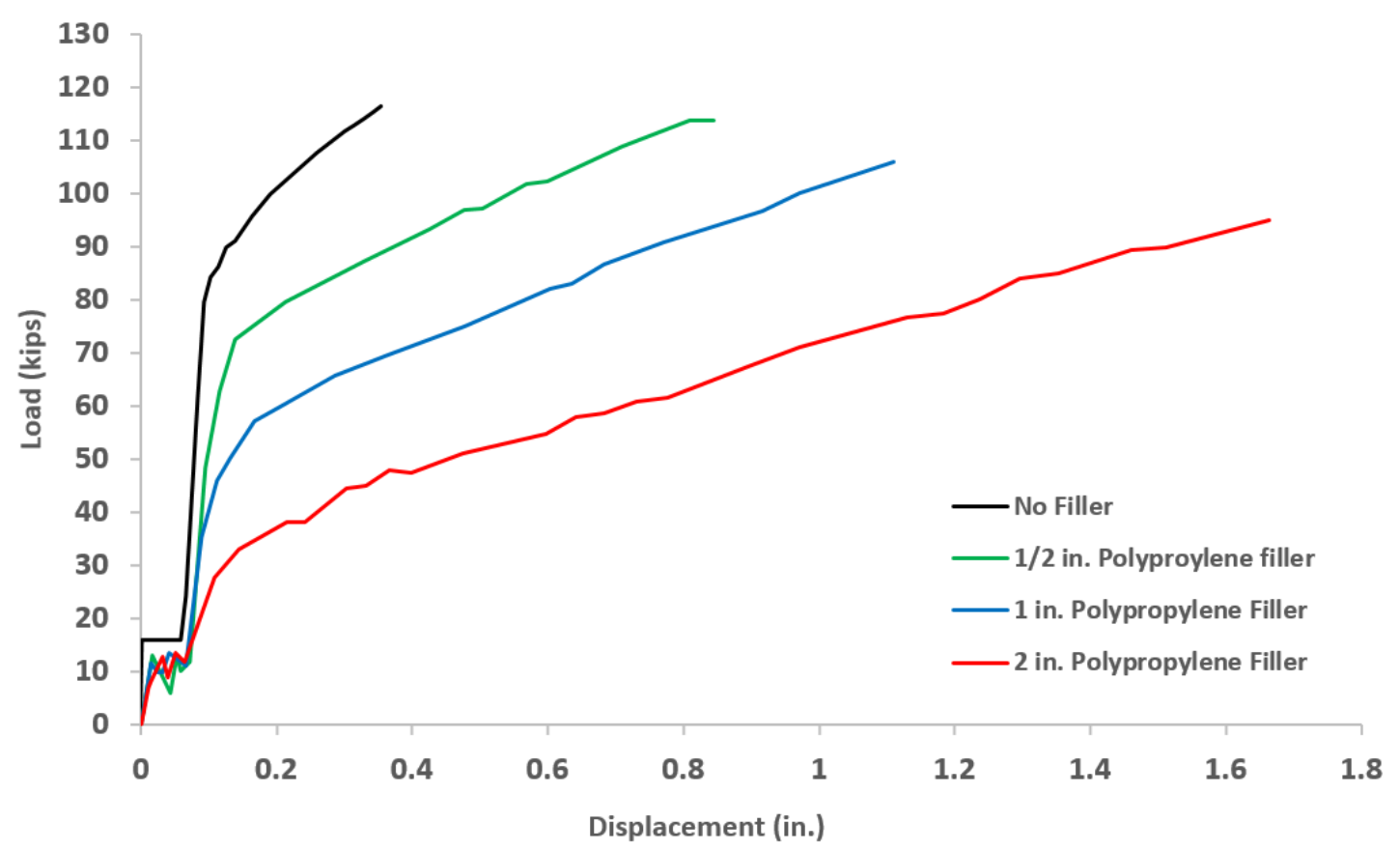

Fig. B-2: FEA results of load vs. deformation for connection with Polypropylene fillers. 


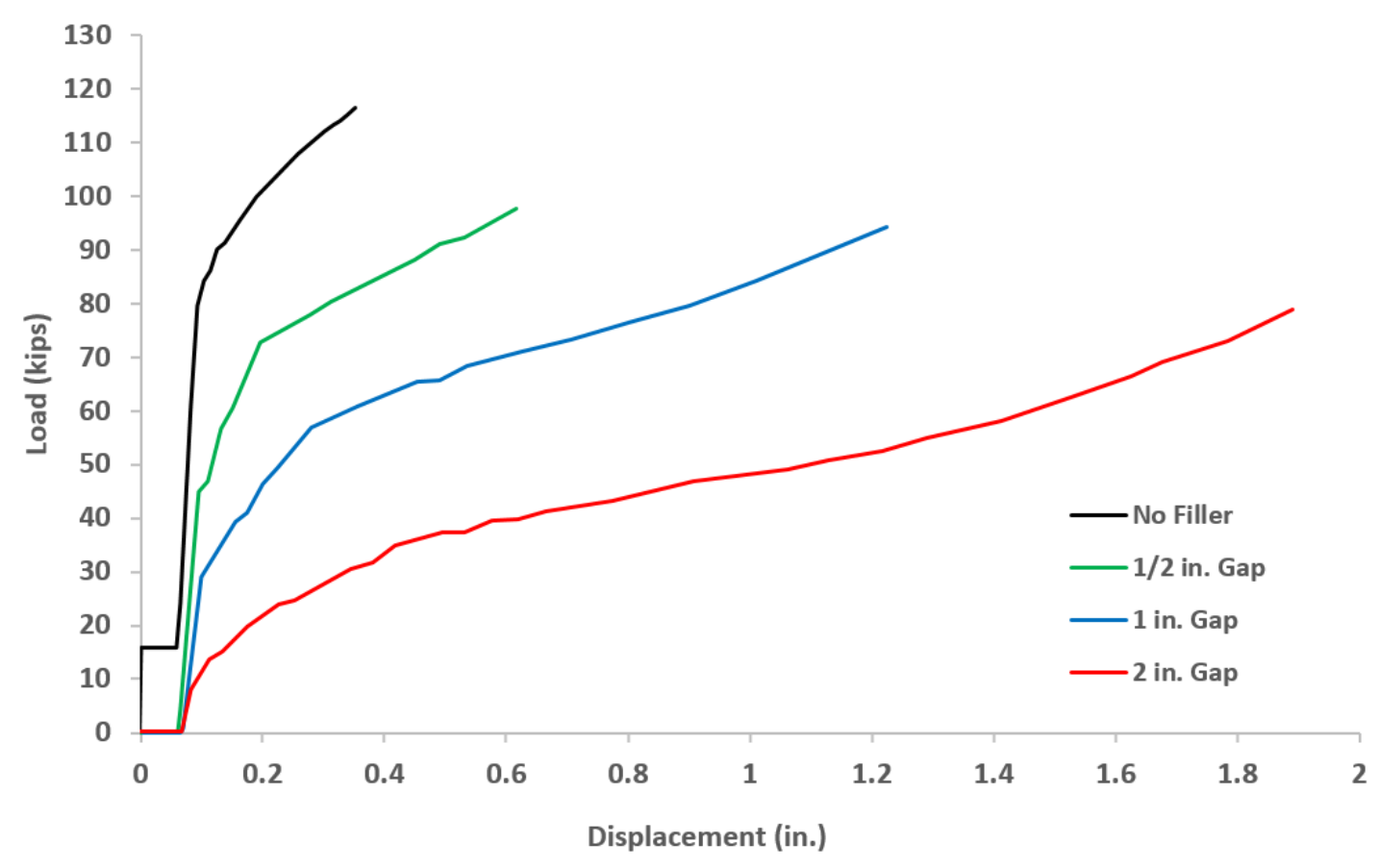

Fig. B-3: FEA results of load vs. deformation for connection with Air Gap.

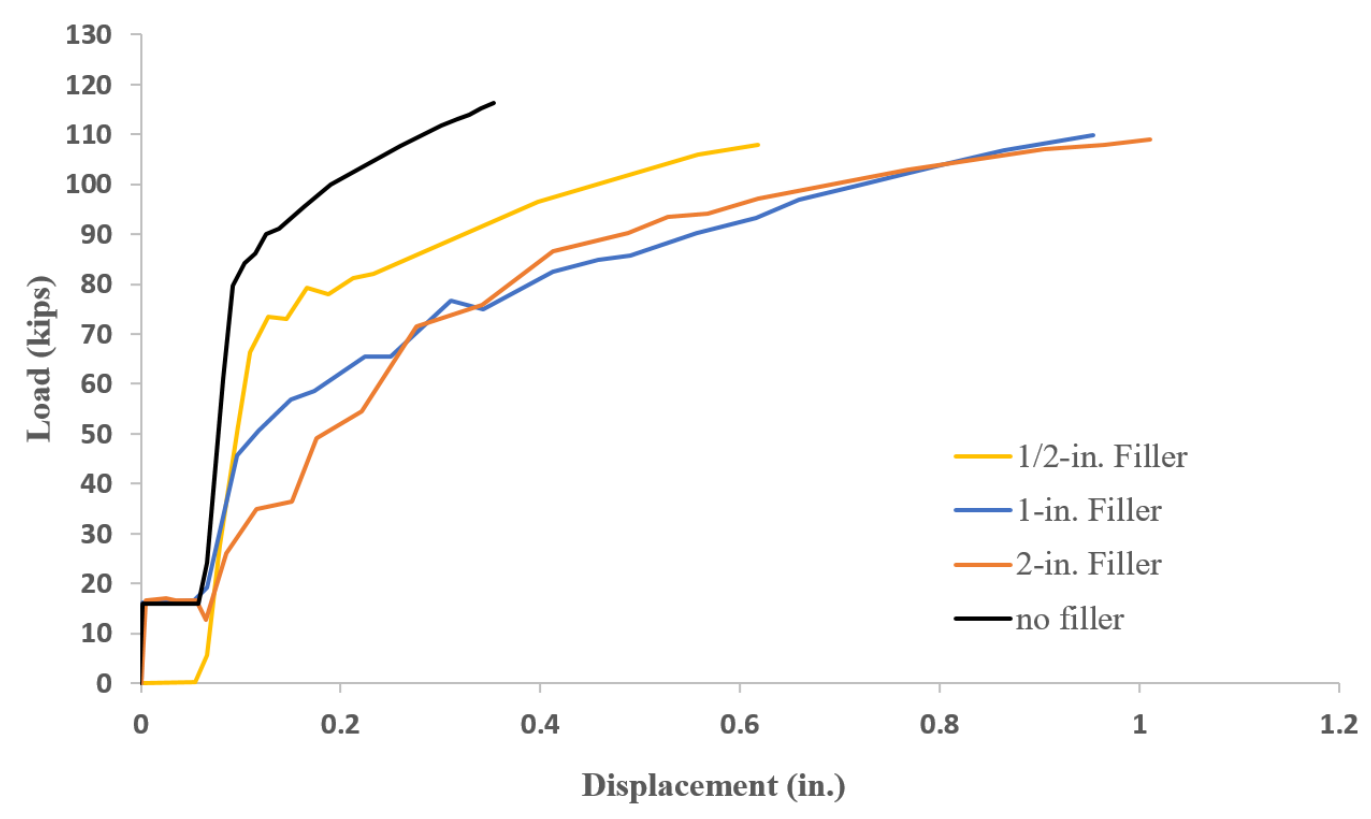

Fig. B-4: FEA results of load vs. deformation for connection with fillers that have 50\% of steel Strength. 


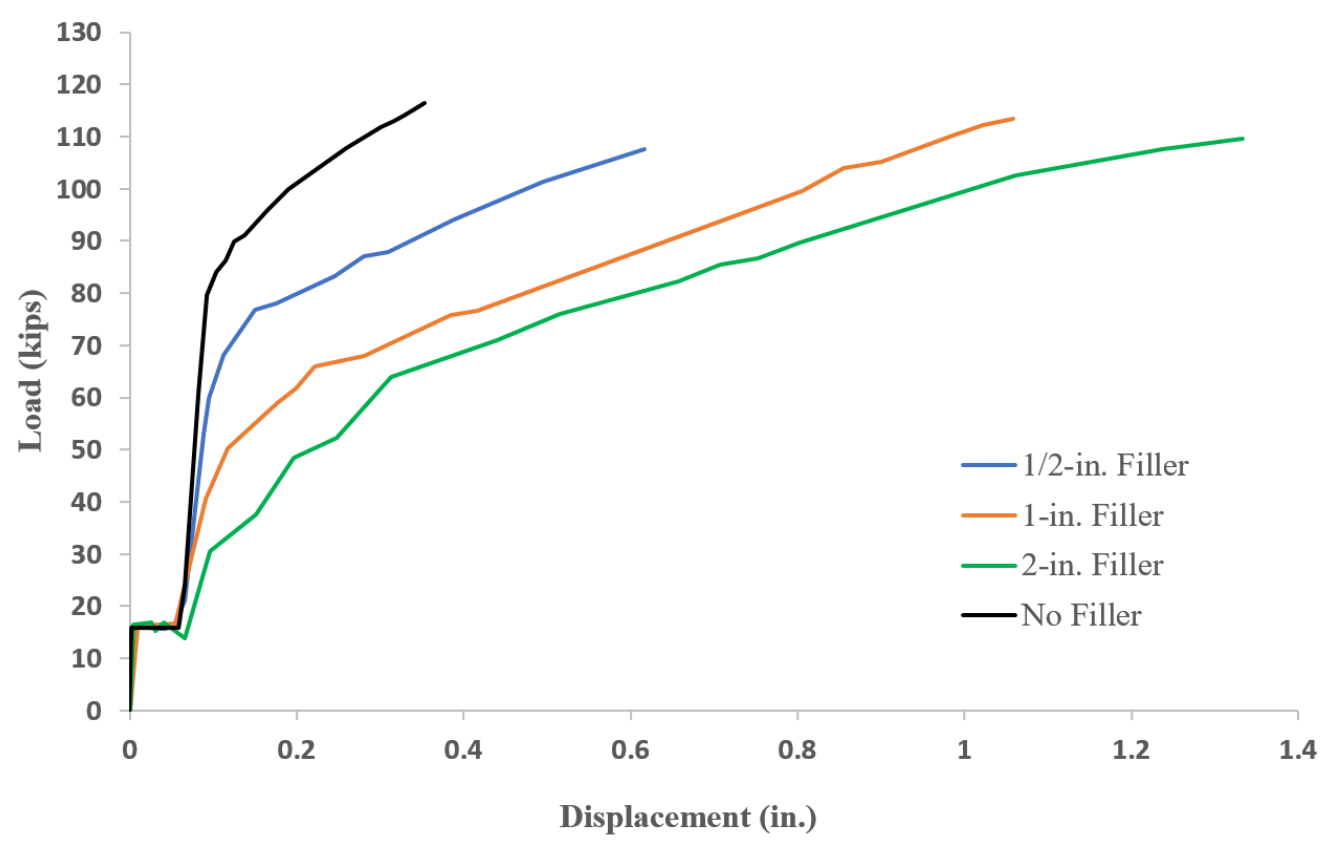

Fig. B-5: FEA results of load vs. deformation for connection with fillers that have $25 \%$ of steel Strength.

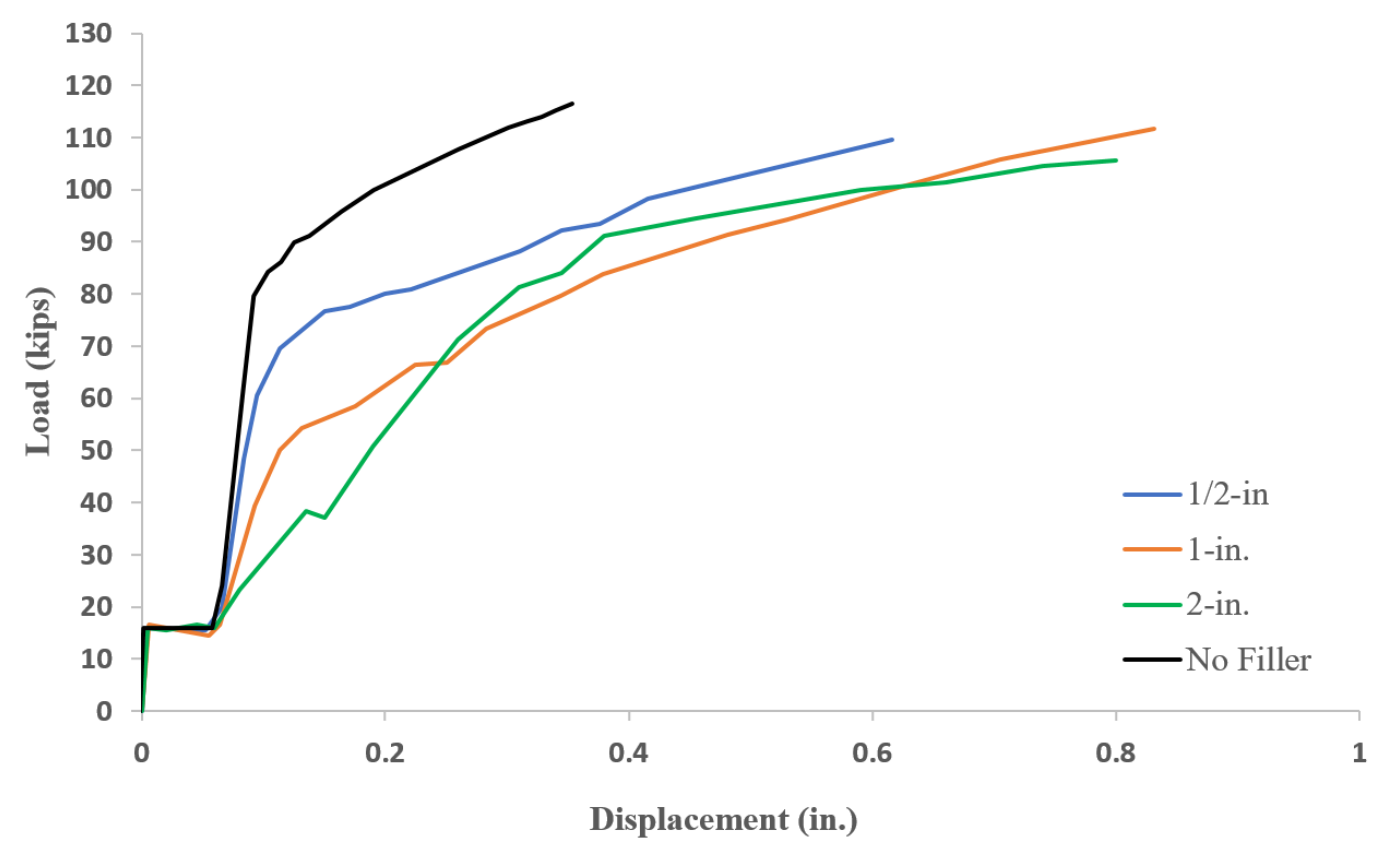

Fig. B-6: FEA results of load vs. deformation for connection with fillers that have $50 \%$ of steel modulus of elasticity. 


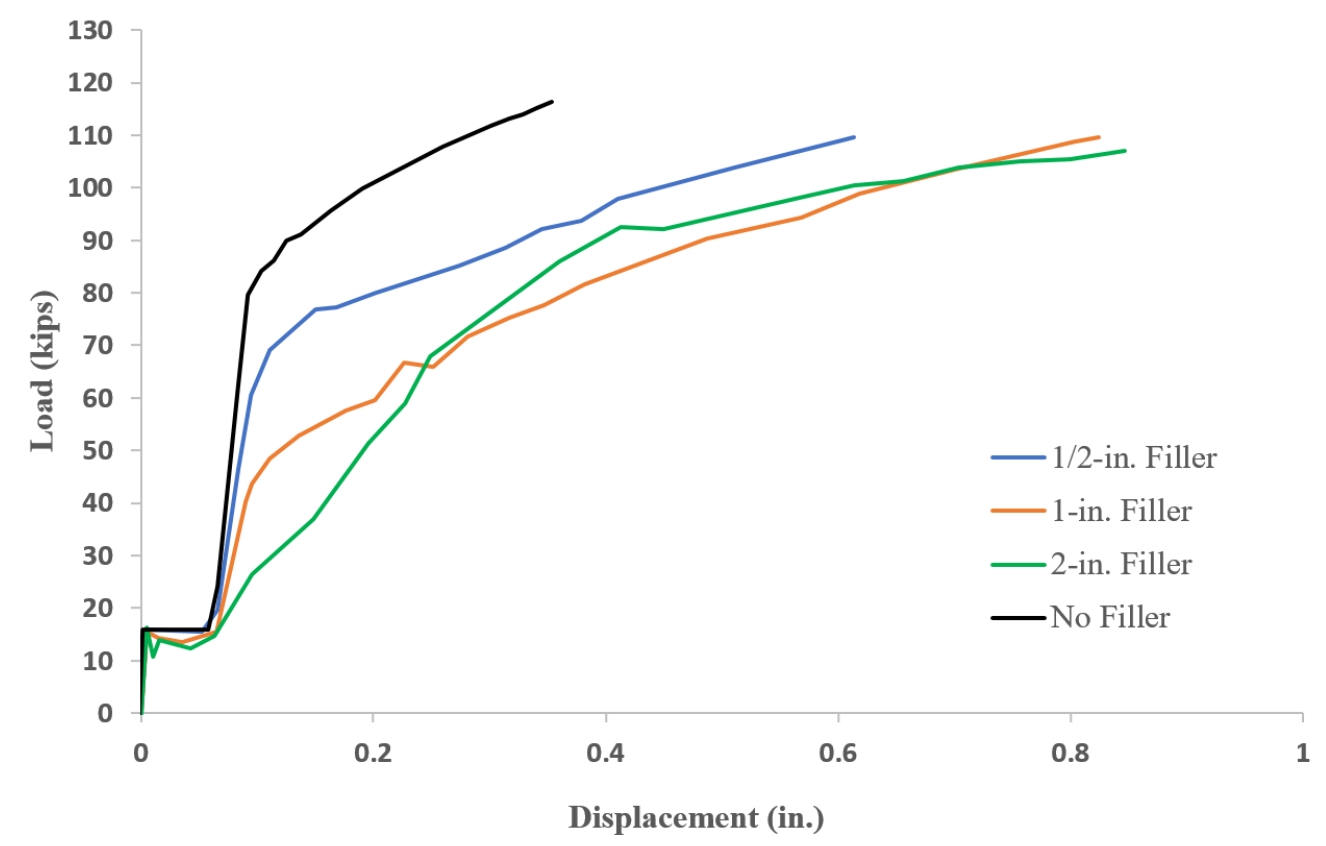

Fig. B-7: FEA results of load vs. deformation for connection with fillers that have $25 \%$ of steel modulus of elasticity.

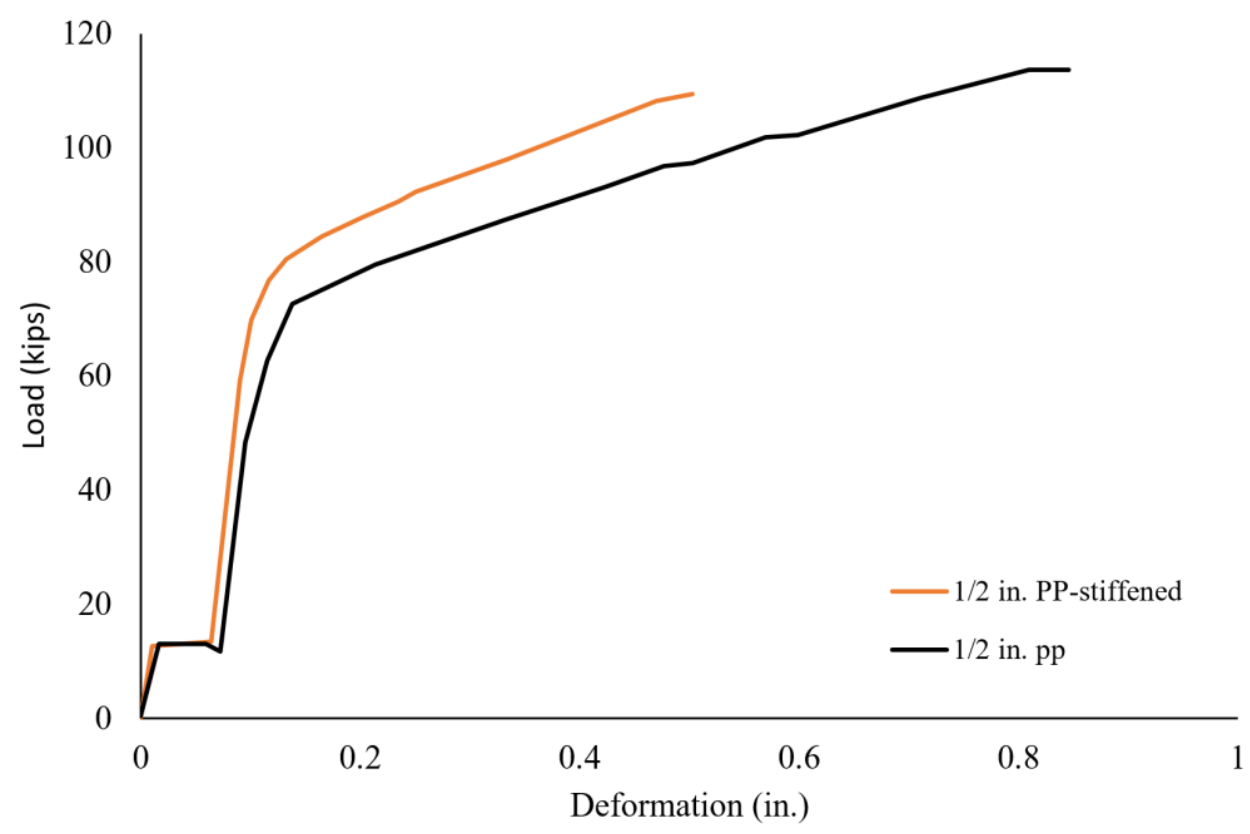

Fig. B-8: 1/2 inch PP fillers vs. connection with Stiffened splice plate. 


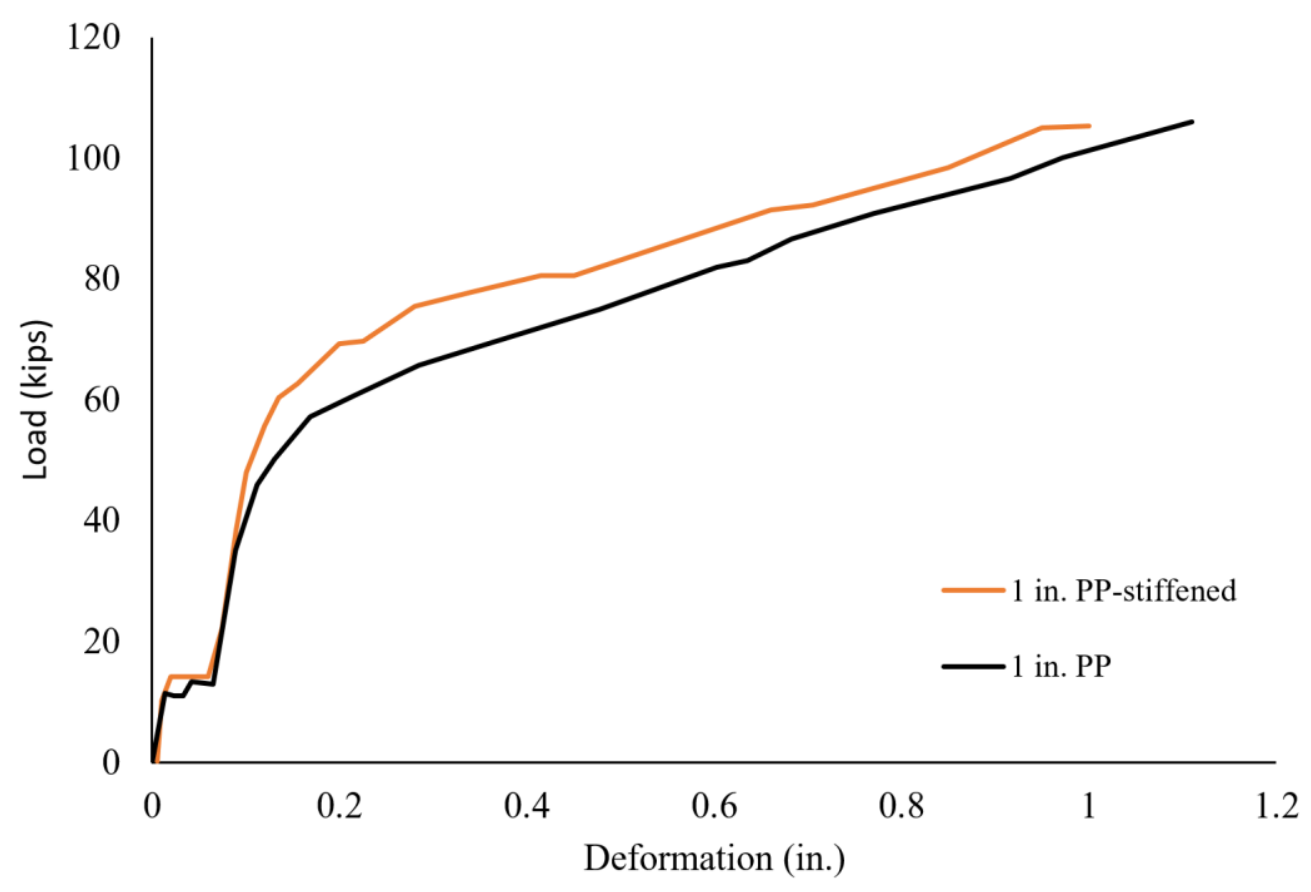

Fig. B-9: 1 inch PP filler vs. connection with Stiffened splice plate.

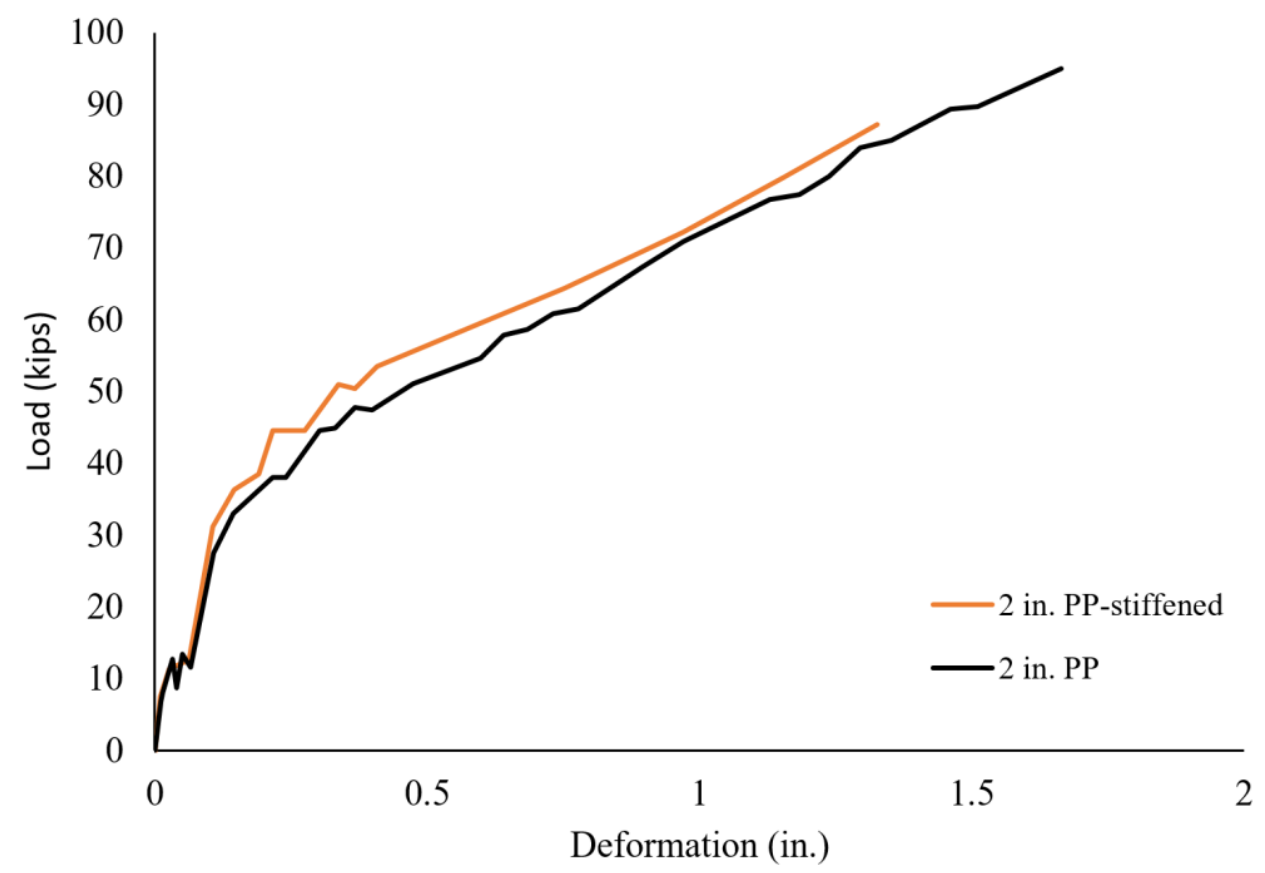

Fig. B-10: 2 inch PP vs. connection with Stiffened splice plate. 